Universidad de Lima

Facultad de Comunicación

Carrera de Psicología

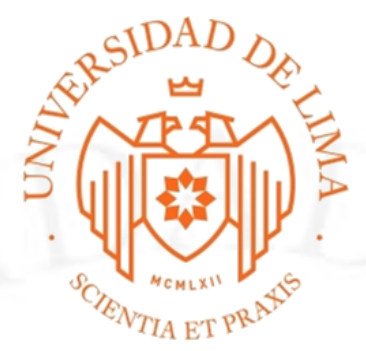

\title{
PROPIEDADES PSICOMÉTRICAS DEL CUESTIONARIO DE ESQUEMAS DE YOUNG (YSQ-S3) EN MUESTRA MIXTA PERUANA
}

Tesis para optar el título profesional de Licenciado en Psicología

\author{
Andrea Alessandra Matute Cruces \\ Código 20121937
}

Asesor

Andrés Alberto Burga León

Lima - Perú

Julio del 2019 


\section{PROPIEDADES PSICOMÉTRICAS DEL CUESTIONARIO DE ESQUEMAS DE YOUNG (YSQ-S3) EN MUESTRA MIXTA PERUANA}




\section{RESUMEN}

Este estudio tiene como objetivo estudiar las propiedades psicométricas de la traducción española del cuestionario de esquemas de Young en su tercera versión abreviada (YSQS3) en una muestra mixta peruana. Los participantes fueron 562 personas, $57.65 \%$ (muestra clínica) y $42.35 \%$ (muestra no clínica). Este estudio recolectó las evidencias de validez en relación a la estructura interna correspondiendo con una estructura factorial de 18 factores o esquemas de primer orden. Además, recolectó evidencias de validez vinculada a las relaciones con otras variables, ya que la muestra clínica presenta puntuaciones estadísticamente significativas más altas que la muestra no clínica en todos los esquemas y en la puntuación total del cuestionario. Finalmente, las estimaciones de confiabilidad de las puntuaciones del YSQ-S3 fueron aceptables. En conclusión, el presente estudio reveló un apoyo empírico para la solidez psicométrica de la versión peruana del YSQ-S3.

Palabras Clave: Esquemas Desadaptativos Tempranos, Cuestionario de Esquemas de Young, Propiedades Psicométricas.

\section{ABSTRACT}

The aim of this study is to study the psychometric properties of the translation of the questionnaire of schemes of young people in its third abbreviated version (YSQ-S3) in a mixed Peruvian sample. The participants were 562 people, $57.65 \%$ (clinical sample) and $42.35 \%$ (non-clinical sample). This study collected the evidence of validity in relation to the internal structure corresponding to a factorial structure of 18 factors or first order schemes. In addition, it collected evidences of validity linked to the relationships with other variables, since the clinical sample presents higher statistically significant scores than the non-clinical sample in all the schemes and in the total score of the questionnaire. Finally, the reliability estimates of the YSQ-S3 scores were acceptable. In conclusion, the present study revealed empirical support for the psychometric strength of the Peruvian version of the YSQ-S3.

Keywords: Early Maladaptive Schema, Young Schema Questionnaire, Psychometric Properties. 


\section{TABLA DE CONTENIDO}

INTRODUCCIÓN .................................................................................................9

CAPÍTULO I: PLANTEAMIENTO DEL PROBLEMA .................................... 10

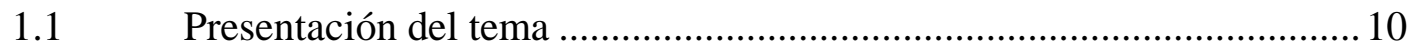

$1.2 \quad$ Justificación y relevancia ................................................................. 14

CAPÍTULO II: MARCO TEÓRICO ......................................................................... 16

2.1 Definición de los esquemas desadaptativos tempranos (EDT)............... 16

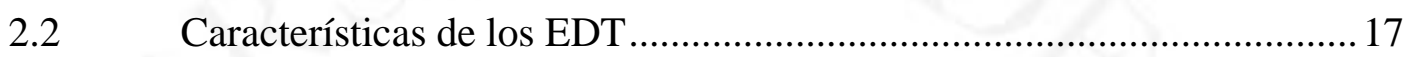

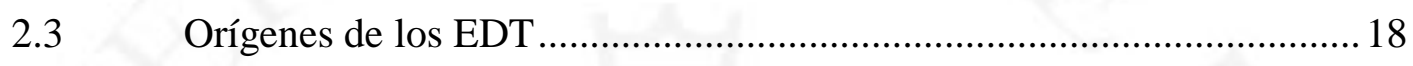

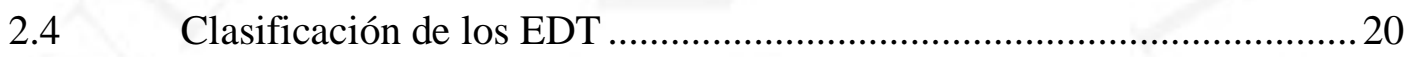

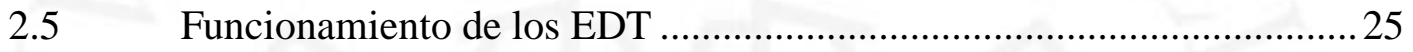

2.6 Relación entre esquemas y trastornos mentales .....................................28

2.7 Relación entre esquemas y trastornos de la personalidad.......................29

2.8 Características del cuestionario de esquemas ....................................... 31

2.9 Resumen de las propiedades psicométricas del YSQ-S3 ........................ 33

CAPÍTULO III: OBJETIVOS, HIPÓTESIS Y DEFINICIÓN DE VARIABLES

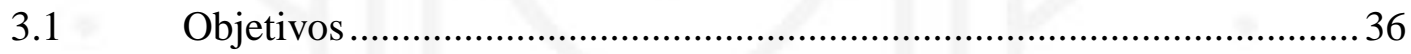

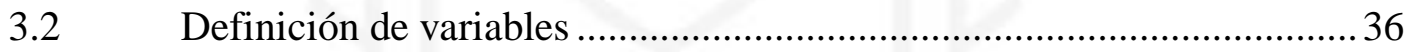

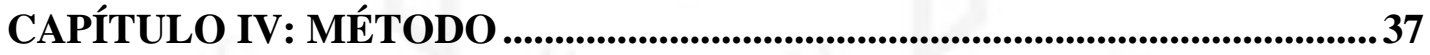

4.1 Tipo y diseño de investigación ........................................................... 37

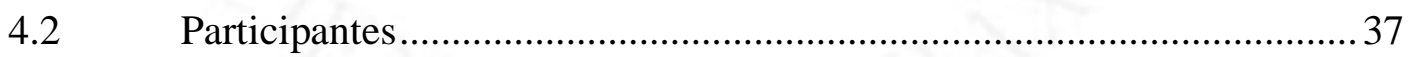

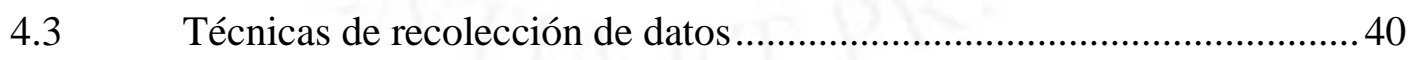

4.4 Procedimiento de recolección de datos.................................................... 43

CAPÍTULO V: RESULTADOS.................................................................................. 45

5.1 Evidencias de validez vinculadas al contenido .................................... 45

5.2 Evidencias de validez vinculadas a la estructura interna .......................50

5.3 Evidencias de validez vinculadas a las relaciones con otras variables ... 56

5.4 Estimación de la confiabilidad del cuestionario de esquemas de Young 60

CAPÍTULO VI: DISCUSIÓN.........................................................................62 


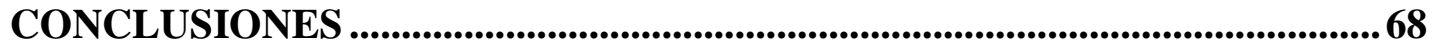

RECOMENDACIONES .................................................................................69

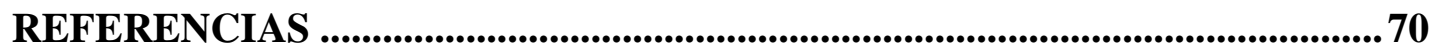

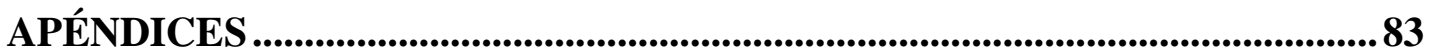




\section{ÍNDICE DE TABLAS}

Tabla 2.1. Organización de esquemas desadaptativos tempranos según dimensiones y esquemas

Tabla 2.2. Ejemplos de respuestas disfuncionales de afrontamiento.............................26

Tabla 2.3. Transición cronológica de los cuestionarios de esquemas .............................33

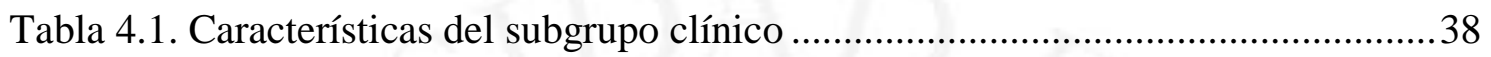

Tabla 4.2. Características del subgrupo no clínico ....................................................... 39

Tabla 4.3. Dimensiones de esquemas, necesidades asociadas, esquemas e ítems..........41

Tabla 5.1. Coeficiente V de Aiken para los ítems de la dimensión desconexión y rechazo.

Tabla 5.2. Coeficiente V de Aiken para los ítems de la dimensión deterioro en autonomía y desempeño.

Tabla 5.3. Coeficiente V de Aiken para los ítems de la dimensión límites deficitarios .47

Tabla 5.4. Coeficiente V de Aiken para los ítems de la dimensión dirigido por las necesidades de los demás 48

Tabla 5.5. Coeficiente V de Aiken para los ítems de la dimensión sobrevigilancia e inhibición

Tabla 5.6. Resumen de los factores de primer y segundo orden, según los modelos probados. .51

Tabla 5.7. Índices de ajuste para los modelos de la estructura factorial del YSQ-S3 ....52

Tabla 5.8. Factores y cargas factoriales de los respectivos ítems..... .52

Tabla 5.9. Estadísticos descriptivos para los 18 esquemas .55

Tabla 5.10. Comparación de las medias y medianas de los esquemas en función al tipo de muestra.....

Tabla 5.11. Coeficiente omega para los 18 esquemas de primer orden del YSQ-S3 .....61 


\section{ÍNDICE DE FIGURAS}

Figura 5.1. Puntuación media observada al comparar los esquemas entre el subgrupo clínico y no clínico..

Figura 5.2. Tamaño del efecto observado al comparar los esquemas entre el subgrupo clínico y no clínico. 


\section{ÍNDICE DE APÉNDICES}

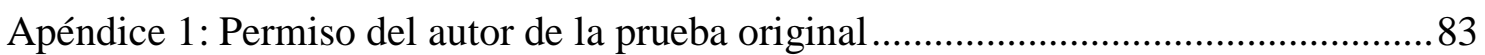

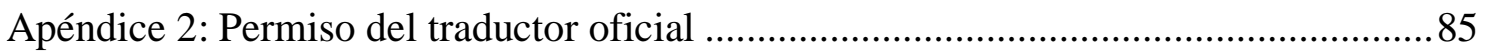

Apéndice 3: Permiso a directora de hospital "Víctor Larco Herrera" .............................. 86

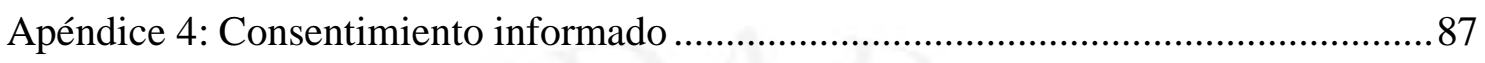

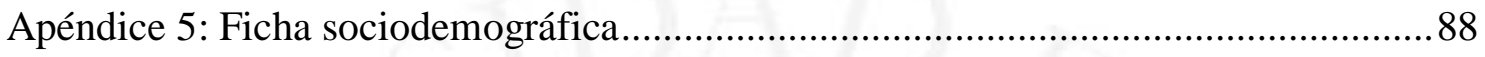

Apéndice 6: Cuestionario de esquemas (traducción española) .........................................89

Apéndice 7: Propuesta del cuestionario de esquemas....................................................99

Apéndice 8: Plantilla de Corrección ...............................................................................99

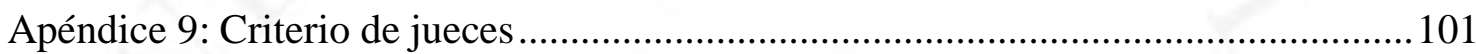

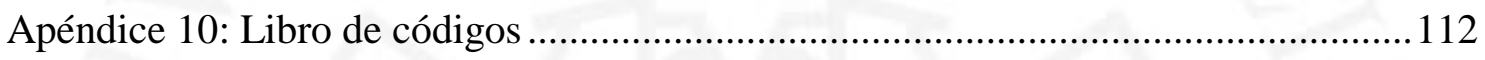




\section{INTRODUCCIÓN}

Los esquemas son patrones cognitivos estables que actúan en el sistema de creencias y se basan en las concepciones acerca de uno mismo y de formas de interacción con los demás. Contiene componentes cognitivos, afectivos, interpersonales y conductuales, y están fuera de la conciencia. Al originarse prematuramente en la vida, se observa que hay esquemas adaptativos y desadaptativos (Young, 1999). De esta manera, los esquemas desadaptativos tempranos son "patrones disfuncionales, autosaboteadores, de pensamiento y emoción que se iniciaron a temprana edad y se reiteran a lo largo de la vida" (Young y Klosko, 2007, p. 3).

Los esquemas desadaptativos se pueden entender y analizar mediante una propuesta holística, que es el enfoque transdiagnóstico. Dicho enfoque forma parte de la psicopatología y de la terapia cognitivo conductual, ayuda a la comprensión y tratamiento de los trastornos mentales mediante el análisis del funcionamiento de la persona en sus diferentes ámbitos de vida. En esa línea, los esquemas desadaptativos, al ser formas de interpretación estables e invariables, cuya repercusión es a nivel personal e interpersonal dentro de su propio contexto; serían indicadores transdiagnósticos (Sandín, Chorot y Valiente, 2012).

Schmidt, Joiner, Young y Telch (1995) crearon el cuestionario de esquemas, ante la necesidad de identificar las creencias centrales profundas o esquemas; con el fin de realizar una reestructuración cognitiva basado en el enfoque psicoterapéutico cognitivoconductual. A pesar de que la teoría se basa en evidencia empírica, en el Perú no existe el análisis de las propiedades psicométricas de la última versión abreviada del cuestionario de esquemas (YSQ-SF3), lo cual permitiría comprender dimensiones transdiagnósticas.

Por ello, se propone hallar las propiedades psicométricas de este instrumento, que sigue siendo objeto de investigación, el cual presenta dieciocho esquemas desadaptativos, y ha sido traducido, a la fecha, en varios idiomas y culturas (Young, Klosko y Weishaar 2015). 


\section{CAPÍTULO I: PLANTEAMIENTO DEL PROBLEMA}

\subsection{Presentación del tema}

La salud mental es un componente fundamental de la dimensión de la salud integral y es concebida, por la Organización Mundial de la Salud (OMS, 2013), como un "estado de bienestar en el que el individuo realiza sus capacidades, supera el estrés normal de la vida, trabaja de forma productiva y fructífera, y aporta algo a su comunidad" (p. 7).

Sin embargo, en la actualidad, aún existe una falta de recursos y respuestas por parte del sistema de salud en los diferentes países del mundo. Tales como, la distribución inequitativa, el uso ineficiente de los recursos y escasa calidad en el tratamiento de trastornos mentales (OMS, 2011).

La realidad peruana, no es la excepción, ya que, según una encuesta realizada del Instituto de Análisis y Comunicación “Integración” (2016), alrededor de 4 millones de personas en el país padecen de un trastorno mental; un $80 \%$ de las personas que padece problemas mentales no recibe tratamiento especializado; un 30\%, no tiene idea donde acudir para atender un trastorno mental; otro 30\%, no confía en los tratamientos que se brindan; y solo un 4\%, se atendió en un centro especializado.

El panorama revelado de la salud mental repercute en la salud física, ya que puede encontrarse comorbilidad entre los trastornos mentales y las enfermedades neurológicas, cardiovasculares, oncológicas, síndromes de inmunodeficiencia y no transmisibles (OMS, 2013).

Además, la deficiencia en salud mental se calculó que generaría un impacto mundial acumulado de $\$ 16,3$ billones en pérdidas económicas entre los años 2011 y 2030 (Bloom et al., 2011). De igual modo, el dinero que se destina en salud mental es inferior al 7\% del presupuesto en salud, a nivel mundial (Püras, 2015).

Un estudio realizado por el Banco Mundial en la capital del Perú muestra que los gastos directos relacionados con el tratamiento ambulatorio en tres hospitales psiquiátricos totalizaron $\$ 4,856,898$ en el año 2016, empleando la metodología de gasto institucional (Banco Mundial, 2018). De otro lado, se designa los recursos económicos a 
hospitales psiquiátricos, a pesar de tener antecedentes de mala atención sanitaria y abuso de los derechos humanos (OMS, 2013).

Por lo cual, la OMS elaboró el plan de acción integral sobre la salud mental cuyo fin es la promoción de los derechos humanos, acceso a una atención sanitaria y social, de gran calidad y culturalmente adaptada, sin estigmatizaciones ni discriminaciones. Dicho plan propone cuatro objetivos, cuyo cuarto objetivo es sobre el cual se hará principal hincapié: fortalecer los sistemas de información, los datos científicos y las investigaciones sobre salud mental (OMS, 2013).

De otro lado, en cuanto a los servicios de salud mental brindados para los trastornos mentales, son varios los tratamientos que se abordan desde las distintas corrientes psicoterapéuticas. Un avance en los tratamientos psicológicos, es el enfoque transdiagnóstico en la Terapia Cognitivo Conductual, es decir, observar lo que tienen en común los distintos síntomas y diagnósticos, desde una perspectiva dimensional. Este enfoque se basa en una clasificación funcional de los diferentes niveles de la conducta tanto cognitivos, emocionales, conductuales y fisiológicos, considerando el contexto de la persona. Esto permite comprender cómo ha sido causado y cómo se ha ido mantenido el trastorno mental en el tiempo (Sandín et al., 2012).

Ante ello, los profesionales de la salud, tales como psicólogos que poseen un enfoque integral, entre ellos Jeffrey Young, creador de la terapia de esquemas, comprende los trastornos mentales desde una perspectiva transdiagnóstica, funcional y contextual. Dicho de otro modo, estudia los eventos psicológicos considerando la interrelación entre la persona y su contexto, historia y acontecimientos actuales; aplicable para personas con trastornos de personalidad y trastornos psicológicos (Bamelis, Evers, Spinhoven y Arntz, 2014; López et. al., 2011).

Dicha terapia es integradora puesto que combina múltiples técnicas cognitivoconductuales, teoría del apego, Gestalt, constructivista y elementos psicodinámicos para profundizar la experiencia emocional, considerando la relación terapéutica y los estilos de afrontamiento disfuncionales (Young et al., 2015; Rodríguez, 2009). Toma en consideración como constructo principal los denominados esquemas desadaptativos tempranos, es decir, patrones profundos y disfuncionales de pensamientos, conductas, sentimientos y relaciones con los demás. 
Dentro de la terapia de esquemas, la fase inicial de la terapia consiste en la identificación de los esquemas desadaptativos del sujeto mediante un cuestionario. $\mathrm{Su}$ aplicación pretende hacer consciente el sistema de creencias profundas, comprender el funcionamiento del individuo y establecer directrices para una reestructuración cognitiva.

Dicho cuestionario es empleado por los psicoterapeutas formados en la terapia de esquemas y, en varios países, se está realizando la adaptación respectiva; con el fin de que pueda ser interpretable y empleado en el contexto socio-cultural al que va dirigido.

Se observa que, en el panorama internacional, se han realizado investigaciones examinando la confiabilidad y evidencias de validez de las puntuaciones derivadas de aplicar cuestionario de esquemas en poblaciones de adolescentes, estudiantes universitarios y muestras mixtas en adultos clínicos y no clínicos. Cabe resaltar que, tanto en los países occidentales como orientales donde se han explorado las propiedades psicométricas, se ha llegado a conclusiones similares en cuanto a una estructura de dieciocho esquemas desadaptativos tempranos comprobando la teoría original de Young (Sakulsriprasert, Phukao, Kanjanawong y Meemon, 2016).

Además, se ha investigado las evidencias de validez vinculadas a las relaciones con otras variables del cuestionario de esquemas en muestras clínicas. En los estudios con muestra clínica suele emplearse el criterio categorial para clasificar trastornos mentales según la cuarta versión del manual diagnóstico y estadístico de los trastornos mentales (DSM-IV) y, generalmente, se examina las relaciones entre ambos. Se ha encontrado que ciertos esquemas desadaptativos están sobre la base de ciertos diagnósticos (Rijkeboer y van den Bergh, 2006) e incluso su presencia pudiera predecir aspectos como el perfeccionismo, ansiedad y depresión, insatisfacción con la imagen corporal, afectividad positiva y negativa (Pullido, 2015; López, Rondón, Alfano y Cellerino, 2012; Caputto, Cordero, Keegan y Arana, 2015; Agudelo, Casadiegos y Sánchez, 2009).

Cabe mencionar que existen tres versiones distintas, las cuales, difieren de la cantidad de esquemas desadaptativos que evalúa el cuestionario de esquemas y la cantidad de ítems que posee; existiendo una versión corta y una versión larga para cada versión. Por ejemplo, en Sudamérica, se marca como antecedente, la adaptación del cuestionario de los esquemas en Colombia en su versión corta (YSQ-SF) y la segunda versión larga (YSQ-L2) en estudiantes universitarios (Londoño et al., 2012; Castrillón et 
al., 2005). Una investigación del cuestionario de esquemas de la última versión (YSQS3) ha sido realizada el año pasado en Chile, donde se confirmó la estructura factorial de dieciocho esquemas de primer orden como propone la teoría (Quiñones, Ramírez, Melipillán, Ugarte y Florenzano, 2018).

En el contexto nacional peruano, existen antecedentes en cuanto a la adaptación del cuestionario de Young en su versión abreviada en estudiantes universitarios del distrito de Villa el Salvador (Hilario, 2016). Además, en su segunda edición, versión larga, en escolares de dos distritos de Lima Sur (León y Sucari, 2012), en estudiantes de educación secundaria de Otuzco (Chávez, 2017) y estudiantes de psicología de una universidad privada de Lima (Álvarez, 2011). De igual manera, se han realizado investigaciones de los esquemas desadaptativos en estudios de caso y buscando la relación del constructo en relación con otras variables (Aguirre, 2017; Carranza, 2017; Castañeda y Fernández, 2017; Cipriano, 2017; De la Cruz, 2019; García y Pinto, 2018; Holguin, 2018; Huerta et al., 2016; Iturregui, 2017; Malacas, 2013; Saavedra, 2018; Salvatierra, 2018). Sin embargo, las investigaciones aún no ha empleado la última versión del cuestionario de esquemas adaptada en el Perú.

En ese sentido, el cuestionario de esquemas continúa siendo objeto de investigación en diversos estudios; en particular, la última versión (YSQ-SF3, siglas en inglés), que presenta 18 esquemas desadaptativos y 5 dimensiones, y ha sido traducida, a la fecha, en varios idiomas y culturas (Young et al., 2015).

Por lo tanto, teniendo en consideración que, la adaptación de la última versión del cuestionario de esquemas (YSQ-SF3) aún no se ha investigado en una muestra peruana; se pretende responder a la siguiente pregunta de investigación: ¿Cuáles son las propiedades psicométricas de la tercera edición del cuestionario de los esquemas, versión abreviada (YSQ-SF3), en una muestra mixta peruana? Específicamente: ¿Cuáles son las evidencias de validez vinculadas al contenido del YSQ-SF3? ¿Cuáles son las evidencias de validez vinculadas a la estructura interna del YSQ-SF3? ¿Cuáles son las evidencias de validez vinculadas a las relaciones con otras variables de la adaptación del YSQ-SF3? ¿Cuáles son las evidencias de estimación de confiabilidad de las puntuaciones derivadas del YSQ-SF3? 


\section{$1.2 \quad$ Justificación y relevancia}

La presente investigación demuestra su relevancia, por un lado, para el subgrupo clínico ya que fomentar investigaciones basadas en evidencia empírica, bajo criterios éticos beneficiando a una población que padece de trastornos que afectan su salud mental. Por consiguiente, contribuye al cuarto objetivo del plan de acción integral sobre salud mental de fortalecer los sistemas de información en el país.

Los resultados de esta investigación podrán sistematizarse en una propuesta para ser incorporado como un instrumento psicológico, ya que se podría identificar los esquemas desadaptativos relacionados a la patología mental que presentan.

De manera que, podría aportar una mejor comprensión y descripción del caso, explicación del desarrollo, adquisición y mantenimiento de sus diagnósticos psiquiátricos dentro de su contexto socio-familiar, desde una perspectiva transdiagnóstica.

Además, sería una herramienta de apoyo formativo en los profesionales de la salud mental que se formen en la terapia de esquemas y/o deseen explorar variables transdiagnósticas; con el fin de obtener una perspectiva más amplia en beneficio del tratamiento de las personas.

Desde una perspectiva psicopatológica, se encontró relación entre los esquemas desadaptativos con el modelo de rasgos que propone el DSM-5 (Bach, Lee, Lykke y Simonsen, 2015), teniendo una utilidad clínica en la interpretación y utilización de los esquemas como expresiones de los rasgos del DSM-5; de manera, que permite una mejor formulación y comprensión de los casos clínicos.

Esto permitiría que los psiquiatras y/o psicoterapeutas puedan ser capaces de interpretar y utilizar los rasgos del DSM-V como si fueran expresiones de esquemas, modos y conceptos similares (Bach, Lee, Lykke y Simonsen, 2015).

De otro lado, beneficia al subgrupo no clínico, puesto que permite identificar experiencias tempranas negativas, las cuales suponen factores de riesgo para desarrollar cuadros clínicos, pudiendo predecir los mismos, tal como la sintomatología positiva de la esquizofrenia (Bortolon, Boulenger, Capdevielle, Gély-Nargeot y Raffard, 2013), lo cual permite abrir nuevos horizontes de investigaciones en relación a evidencia de validez predictiva. 
En ese sentido, contar con el cuestionario de esquemas, que forma parte de las terapias del enfoque cognitivo-conductual, adaptado en el contexto de la realidad peruana tanto en personas con cuadros clínicos, así como aquellas que no lo presentan, facilita la labor del psicólogo en su intervención terapéutica.

Finalmente, contribuiría con un instrumento insumo o base adaptado a la realidad peruana para recoger información más precisa, tomar decisiones más adecuadas y realizarse posteriores investigaciones; considerando nuestro contexto socio-cultural; en vez de emplear cuestionarios de países extranjeros que no poseen evidencia empírica adaptada. 


\section{CAPÍTULO II: MARCO TEÓRICO}

Esta sección tiene el propósito de abordar teóricamente los esquemas desadaptativos tempranos. Para ello, la estrategia que se seguirá es presentar el origen del modelo psicoterapéutico que sostiene el constructo teórico. Luego, exponer acerca de los esquemas mentales, haciendo hincapié en los esquemas desadaptativos tempranos; conceptualizar sus orígenes, sustento biológico, características, clasificación, así como, las operaciones y modos que existen. Para concluir, se explicará el instrumento psicológico que mide los esquemas y se presentarán investigaciones previas que sustentan sus propiedades psicométricas.

\subsection{Definición de los esquemas desadaptativos tempranos (EDT)}

Las terapias cognitivas-conductuales argumentan que las perturbaciones que padecen las personas provienen de la interpretación que éstas realizan acerca de los sucesos y no por éstos mismos. Teniendo en consideración que la persona es capaz de modificar su evaluación subjetiva y la manera en interpretar hechos y situaciones que vive; el objetivo es el poder replantear los esquemas inadecuados para que se pueda percibirse a sí mismo y a su entorno de manera más adaptativa y realista (Beck y Freeman, 1995).

Beck postula que los esquemas son "patrones cognitivos estables que constituyen la base de la regularidad de las interpretaciones de la realidad" (Beck, Rush, Shaw y Emery, 1979, p.12). Además, dichos esquemas son adaptativos y surgen de experiencias de aprendizaje previas conjuntamente con los determinantes genéticos que posee el individuo. No obstante, la manera en cómo se emplean puede conllevar a padecer malestar psicológico puesto que, si son manejados de forma automática, rígida y desadaptativa en cualquier situación, pueden influir en la aparición de desórdenes psicológicos (Young et al., 2015).

En esa línea, Young partiendo de dicha concepción, postula que los esquemas comprenden creencias de sí mismo y de las relaciones con los demás, cogniciones, actitudes, recuerdos, emociones, sensaciones corporales y conductas que el individuo integra en su vida. 
Dichos esquemas son multifacéticos, contienen componentes cognitivos, afectivos, interpersonales y conductuales, y están fuera de la conciencia. Al originarse prematuramente en la vida, se observa que hay esquemas positivos (adaptativos) y negativos (desadaptativos); así como tempranos y tardíos (Young y Klosko, 2007).

\subsection{Características de los EDT}

Según la explicación de Young acerca de los esquemas desadaptativos tempranos (EDT) son "temas extremadamente estables y permanentes que se desarrollen durante la niñez y son elaborados a lo largo de la vida del sujeto, los cuales son fortalecidos por el procesamiento de experiencias posteriores" (Young, 1999, p.9); los cuales fueron funcionales en un inicio, es decir, brindaban respuestas adecuadas ante demandas externas; sin embargo, más adelante, ya no actúan como mecanismos de ajuste, ya que carecen de flexibilidad y conveniencia para responder a las nuevas demandas del individuo, lo cual resulta limitante.

Específicamente, los esquemas desadaptativos son crónicos, a menos que sean tratados; puesto que, son aceptados como verdades a priori, irrefutables, creencias profundamente arraigadas aprendidas a una edad muy temprana.

Aunque puedan interferir con el logro de sus necesidades básicas como autonomía, unión con los demás, autoexpresión, límites, gratificaciones y autoestima; forman parte de su sentido de identidad y proporciona al paciente sentimientos de seguridad. Esto es debido a que es la forma en que han conocido al mundo y a sí mismos, les es cómodo y familiar; por ende, son difíciles de modificarlos y se vuelven resistentes al cambio (López, et al., 2011).

Más aún, son creencias incondicionales sobre uno mismo en relación al ambiente, por lo cual se activan mediante acontecimientos relevantes o coherentes con un esquema concreto. Con ello, están asociados a niveles elevados de afecto y son consecuencia de experiencias disfuncionales con personas significativas; razón por la cual, también, se evidencia en la problemática de parejas.

En ese sentido, los esquemas pueden tener distintos grados de gravedad y de resistencia al cambio. 
En cuanto a lo primero, la gravedad, se encuentra relacionada con la cantidad de situaciones que los podrían activar. Respecto a lo segundo, la mayor o menor resistencia, dependerá de lo temprano o tardío de la edad en que se generaron los esquemas, de la cantidad de figuras significativas que lo generaron y de la cantidad o duración de las situaciones que lo generaron (Young et al., 2015).

\subsection{Orígenes de los EDT}

Los esquemas desadaptativos tempranos tienen una base biológica así como influencia del contexto familiar y social (Rodríguez, 2009).

En cuanto a la biología de los esquemas desadaptativos tempranos, Young et al. (2015) postula ciertas hipótesis acerca del desarrollo y cambio de los mismos. En principio, existen múltiples sistemas emocionales en el cerebro, donde las distintas emociones poseen su propia red cerebral. Particularmente, se abordará la red cerebral asociada con el miedo y trauma, las cuales, en su mayoría, guardan relación con las causas de esquemas desadaptativos, en especial, por las experiencias tempranas poco favorables que pudieron desarrollar ciertos esquemas.

Según estos postulados biológicos, dos sistemas actúan de forma paralela y son los encargados de almacenar y recuperar distintos tipos de información significativa de las experiencias, estos son: la amígdala y el hipocampo. De forma que, la amígdala se ocupa de almacenar la memoria emocional y lo recupera mediante la expresión de respuestas orgánicas que preparan al individuo ante el peligro; en cambio, el hipocampo se ocupa de almacenar la memoria cognitiva y recupera la información mediante la memoria consciente.

Ante ello, el hecho de que la experiencia traumática contenga aspectos emocionales y cognitivos y éstos se localicen en diferentes sistemas cerebrales podría explicar por qué los esquemas no pueden ser modificables, exclusivamente, por métodos cognitivos.

Además de que, los esquemas que se desarrollan en el estadio pre-verbal, es decir, antes de la adquisición del lenguaje, almacenan recuerdos, emociones y sensaciones corporales, siendo éstos los que conforman el núcleo central del esquema y se activan más rápidamente que las cogniciones. 
Por ello, se expone como principal relevancia en el tratamiento, el trabajo sobre la experiencia emocional del paciente donde se ayuda a atribuir palabras a la experiencia del esquema, conectar con las emociones y sensaciones corporales con los recuerdos infantiles.

Por otro lado, también provienen de la interacción del desarrollo de las necesidades emocionales insatisfechas, experiencias vitales tempranas que favorecen la aparición de los mismos y el temperamento emocional (Rodríguez, 2009).

De acuerdo con López et al. (2011), se considera que todas las personas tenemos cinco necesidades emocionales universales que satisfacer en la infancia, entre ellas se encuentran: el poder establecer vínculos seguros con figuras significativas, en donde se manifieste estabilidad, seguridad, cuidados y aceptación del menor; el desarrollo de autonomía, competencia y sentido de identidad; contar con la libertad para expresar necesidades y emociones válidas; desenvolverse con espontaneidad y juego; finalmente, tener límites realistas y auto-control.

El siguiente punto son los cuatro tipos de experiencias vitales tempranas que sostienen la aparición de los esquemas desadaptativos. El primer tipo es la frustración tóxica, donde el menor no recibe la suficiente estabilidad, comprensión o amor, debido a deficiencias de su entorno. El segundo tipo es la traumatización, donde el niño se siente que su autonomía se encuentra vulnerable o en peligro, puesto que es dañado, criticado, controlado o victimizado constantemente. El tercer tipo es el recibir demasiado de algo bueno, siendo las figuras significativas las que proveen algo bueno para el infante en demasía, dejando de ser saludable para el menor debido a que deja de ser mesurado. El cuarto tipo es la identificación con otros significativos, el cual sino se realiza de manera que se respeten los límites en el desarrollo de una adecuada autonomía es perjudicial puesto que el menor adquiere esquemas de sus padres, siendo vulnerable a interiorizar pensamientos, sensaciones y experiencias de otros significativos.

En resumen, un individuo psicológicamente sano es aquel que mantiene cubiertas sus necesidades emocionales básicas, ha recibido experiencias vitales tempranas que han facilitado su desenvolvimiento personal guardando sintonía con su temperamento emocional; de modo que, logra conseguir un funcionamiento adaptativo a lo largo de la vida. 


\subsection{Clasificación de los EDT}

Young et al. (2015) plantea que los esquemas desadaptativos pueden ser condicionados o incondicionados. Se define los esquemas incondicionados como aquellos que se presentan en creencias incondicionales sobre el yo, el mundo, los otros y el futuro, y son los primeros esquemas a desarrollar; para cambiar estos esquemas uno necesita cambiar el sistema conceptual del yo, ya que los esquemas se mantienen con el fin de proporcionar una continuidad del concepto de sí mismo. Éstos son los primeros trece esquemas que aparecen en la tabla 1 .

En cambio, los esquemas condicionados son secundarios, éstos se desarrollan con el fin de compensar los esquemas incondicionados. Por ejemplo el esquema condicionado de "autosacrificio" en respuesta al esquema incondicionado de "imperfección": “Cumpliré todas las necesidades de esta persona e ignoraré la mía, entonces él me amará a pesar de mis defectos" (Young et al., 2015, p.23). Estos esquemas son los cinco últimos que aparecen en la tabla 1.

En ese sentido, Young (2003) identificó dieciocho esquemas desadaptativos tempranos, los cuales se agrupan en cinco dominios o dimensiones. A continuación, se muestra en la tabla 2.1 para un mejor entendimiento de los mismos: 
Tabla 2.1

Organización de esquemas desadaptativos tempranos según dimensiones y esquemas

\begin{tabular}{|c|c|c|c|c|}
\hline Dimensiones & Descripción de dimensiones & $\mathbf{N}^{\circ}$ & Esquemas desadaptativos & Descripción de esquemas \\
\hline \multirow{5}{*}{$\begin{array}{l}\text { Dimensión I: } \\
\text { Desconexión y } \\
\text { rechazo }\end{array}$} & \multirow{5}{*}{$\begin{array}{l}\text { Describe a personas que son incapaces de } \\
\text { constituir vinculaciones afectivas estables y } \\
\text { sólidas con otras, puesto que tienen la } \\
\text { creencia de que sus necesidades básicas de } \\
\text { seguridad, protección, amor y pertenencia } \\
\text { no serán satisfechas. En su mayoría, los } \\
\text { esquemas desadaptativos emergentes de } \\
\text { esta dimensión se relacionan, } \\
\text { estrechamente, con familias de procedencia } \\
\text { que se caracterizan por ser inestables } \\
\text { (abandono/inestabilidad), abusadoras } \\
\text { (desconfianza/abuso), frías (privación } \\
\text { emocional), con tendencia al rechazo } \\
\text { (imperfección/vergüenza) o aisladas del } \\
\text { mundo externo (aislamiento } \\
\text { social/alineación); entendiendo que dentro } \\
\text { de los paréntesis son los esquemas } \\
\text { manifestados. }\end{array}$} & 1 & Abandono/inestabilidad & $\begin{array}{l}\text { La percepción de que las personas significativas no serán capaces } \\
\text { de seguir proporcionándole el apoyo emocional, conexión o } \\
\text { protección práctica porque son emocionalmente inestables e } \\
\text { imprevisibles. }\end{array}$ \\
\hline & & 2 & Desconfianza/abuso & $\begin{array}{l}\text { La expectativa de que los demás perjudicarán, abusarán, } \\
\text { humillarán, engañarán, manipularán o se beneficiarán de uno. } \\
\text { Percepción de que el daño es intencionado y que uno, en } \\
\text { comparación con otros, siempre acaba engañado. }\end{array}$ \\
\hline & & 3 & Privación emocional & $\begin{array}{l}\text { La expectativa de que el propio deseo de un grado normal de } \\
\text { apoyo emocional no será adecuadamente satisfecho por los } \\
\text { demás. Puede haber privación: de cuidados, empatía o de } \\
\text { protección. }\end{array}$ \\
\hline & & 4 & Imperfección/Vergüenza & $\begin{array}{l}\text { El sentimiento de que uno es imperfecto, defectuoso, malo, no } \\
\text { deseado, inferior o inválido en aspectos importantes o, si se } \\
\text { expone ante los demás, no será querido. }\end{array}$ \\
\hline & & 5 & Aislamiento social & $\begin{array}{l}\text { El sentimiento de estar aislado del resto del mundo, de ser } \\
\text { diferente de las demás personas y/o de no ser parte de ningún } \\
\text { grupo o comunidad. }\end{array}$ \\
\hline $\begin{array}{l}\text { Dimensión II: } \\
\text { Deterioro en } \\
\text { autonomía y } \\
\text { desempeño }\end{array}$ & $\begin{array}{l}\text { Describe a personas donde aparece } \\
\text { vulnerada la capacidad de autonomía de la } \\
\text { persona tanto en la separación de figuras } \\
\text { significativas como para funcionar de } \\
\text { manera independiente cotidianamente. }\end{array}$ & 6 & Dependencia/incompetencia & $\begin{array}{l}\text { La creencia de que uno es incapaz de manejar las propias } \\
\text { responsabilidades cotidianas de una manera competente, sin } \\
\text { ayuda considerable de los demás. Tendencia a minimizar éxitos y } \\
\text { magnificar las deficiencias. }\end{array}$ \\
\hline
\end{tabular}


Continuación de la Tabla 2.1:

\begin{tabular}{|c|c|c|c|c|}
\hline Dimensiones & Descripción de dimensiones & $\mathbf{N}^{\circ}$ & Esquemas desadaptativos & Descripción de esquemas \\
\hline \multirow{3}{*}{$\begin{array}{l}\text { Dimensión II: } \\
\text { Deterioro en } \\
\text { autonomía y } \\
\text { desempeño }\end{array}$} & \multirow{3}{*}{$\begin{array}{l}\text { Por consiguiente, algunos podrían creer que } \\
\text { no poseen la capacidad de manejar } \\
\text { responsabilidades propias sin ayuda de los } \\
\text { demás (dependencia/incompetencia); } \\
\text { sentirse fusionados con la otra persona y, } \\
\text { uno de los individuos vinculados, no } \\
\text { podrían funcionar sin el otro (apego } \\
\text { confuso/yo inmaduro); creer en que fallará } \\
\text { inevitablemente en áreas de logro para el } \\
\text { sujeto (fracaso); finalmente, sentir miedo } \\
\text { exagerado a que se produzca una catástrofe } \\
\text { tanto médica, emocional o de tipo externa } \\
\text { en cualquier momento y no poder hacerle } \\
\text { frente (vulnerabilidad al peligro). }\end{array}$} & 7 & $\begin{array}{l}\text { Vulnerabilidad al peligro o a } \\
\text { la enfermedad }\end{array}$ & $\begin{array}{l}\text { Miedo exagerado a que una catástrofe inminente le sorprenderá } \\
\text { en cualquier momento y a que uno sea incapaz de impedirla. } \\
\text { Miedo a catástrofes: médicas, emocionales, externas. Por tanto, se } \\
\text { dan tres miedos irracionales a estar expuesto a un peligro } \\
\text { (externo), lo cual provoca el estar en un estado hipervigilante. }\end{array}$ \\
\hline & & 8 & Apego confuso/yo inmaduro & $\begin{array}{l}\text { La excesiva implicación y proximidad emocional con una o más } \\
\text { personas significativas. Creencia de que, como mínimo, uno de } \\
\text { los individuos a los que se siente unido no podrá sobrevivir ni ser } \\
\text { feliz sin el constante apoyo del otro. Se experimenta un } \\
\text { sentimiento de vacío, llegando a cuestionar la propia existencia. }\end{array}$ \\
\hline & & 9 & Fracaso & $\begin{array}{l}\text { La creencia de haber fracaso, de fracasar en el futuro o de ser, } \\
\text { básicamente, un compañero inadecuado para los propios amigos } \\
\text { en áreas de logro (académico, profesional, deportivo, etc.). Poca } \\
\text { confianza en las propias capacidades, creencia de no poder } \\
\text { sobresalir. }\end{array}$ \\
\hline \multirow[t]{2}{*}{$\begin{array}{l}\text { Dimensión III: } \\
\text { Límites } \\
\text { deficitarios }\end{array}$} & \multirow{2}{*}{$\begin{array}{l}\text { Describe personas que se singularizan por } \\
\text { no desarrollar límites internos adecuados en } \\
\text { relación a la reciprocidad o auto-disciplina. } \\
\text { Usualmente, pertenecen a familias que } \\
\text { fueron excesivamente permisivas o } \\
\text { indulgentes. }\end{array}$} & 10 & Grandiosidad/autorización & $\begin{array}{l}\text { La creencia de que uno es superior a las demás personas, le } \\
\text { corresponden determinados derechos y está autorizado a recibir } \\
\text { privilegios especiales o no está ligado a las normas de } \\
\text { reciprocidad que pautan la interacción social normal. Se asocia a } \\
\text { una búsqueda de poder y control; así como, irresponsabilidad en } \\
\text { los actos. }\end{array}$ \\
\hline & & 11 & $\begin{array}{l}\text { Autocontrol insuficiente/ } \\
\text { autodisciplina }\end{array}$ & $\begin{array}{l}\text { Dificultades generalizadas, rechazo a ejercer autocontrol } \\
\text { suficiente y a la tolerancia a la frustración para alcanzar los } \\
\text { propios objetivos personales o para restringir el exceso de } \\
\text { expresión de las propias emociones e impulsos. }\end{array}$ \\
\hline
\end{tabular}


Continuación de la Tabla 2.1:

\begin{tabular}{|c|c|c|c|c|}
\hline Dimensiones & Descripción de dimensiones & $\mathbf{N}^{\circ}$ & Esquemas desadaptativos & Descripción de esquemas \\
\hline \multirow[b]{3}{*}{$\begin{array}{l}\text { Dimensión IV: } \\
\text { Dirigido por las } \\
\text { necesidades de } \\
\text { los demás }\end{array}$} & $\begin{array}{l}\text { Describe a personas donde atribuyen un } \\
\text { énfasis excesivo a satisfacer las } \\
\text { necesidades de los demás frente a las } \\
\text { propias. Las razones tienen lugar en } \\
\text { familias que no brindan la suficiente }\end{array}$ & 12 & Subyugación & $\begin{array}{l}\text { Ceder en exceso a la coerción o control ajeno, aceptar a fin } \\
\text { de evitar la ira, las represalias o el abandono. Puede ser: } \\
\text { subyugación de necesidades (supresión de propias } \\
\text { preferencias, decisiones) o subyugación de emociones (ira, } \\
\text { tristeza, alegría, etc.). }\end{array}$ \\
\hline & $\begin{array}{l}\text { libertad para dejar al niño seguir sus } \\
\text { propias preferencias. En concreto, pueden } \\
\text { rendirse al control de los demás porque se } \\
\text { sienten obligados, percibiendo que sus } \\
\text { propias necesidades o sentimientos no son } \\
\text { válidos ni importantes, y son } \\
\text { hipersensibles a la sensación de percibirse }\end{array}$ & 13 & Autosacrificio & $\begin{array}{l}\text { El exceso de atención por satisfacer voluntariamente las } \\
\text { necesidades de los demás en situaciones cotidianas a } \\
\text { expensas de la propia gratificación. Sensibilidad aguda hacia } \\
\text { el dolor de los demás. Sentimientos de que la persona no } \\
\text { puede determinar el curso de los acontecimientos de su vida. }\end{array}$ \\
\hline & $\begin{array}{l}\text { atrapados, lo cual genera síntomas } \\
\text { desadaptativos (subyugación). De otro } \\
\text { lado, pueden satisfacer voluntariamente } \\
\text { las necesidades de los demás, sin } \\
\text { considerar su propia retribución, puesto } \\
\text { que poseen una sensibilidad aguda hacia el } \\
\text { sufrimiento ajeno (autosacrificio). Por } \\
\text { último, pueden realzar la aceptación y/o } \\
\text { reconocimiento de los demás, ya que su } \\
\text { autoestima depende de cómo los demás } \\
\text { reaccionarán; por consiguiente, actúan de } \\
\text { forma inauténtica que ni los satisface } \\
\text { (búsqueda de aprobación/búsqueda de } \\
\text { reconocimiento). }\end{array}$ & 14 & $\begin{array}{c}\text { Búsqueda de } \\
\text { aprobación/búsqueda de } \\
\text { reconocimiento }\end{array}$ & $\begin{array}{l}\text { El exceso de énfasis en la obtención de aprobación, } \\
\text { reconocimiento o atención de las demás personas o en } \\
\text { adecuarse a expensas de desarrollar una sensación segura y } \\
\text { auténtica del self. La autoestima se construye a partir de lo } \\
\text { que otros piensen acerca de la persona, cree que tiene que } \\
\text { cuidar su imagen ante los demás. }\end{array}$ \\
\hline
\end{tabular}


Continuación de la Tabla 2.1:

\begin{tabular}{|c|c|c|c|c|}
\hline Dimensiones & Descripción de dimensiones & $\mathbf{N}^{\circ}$ & Esquemas desadaptativos & Descripción de esquemas \\
\hline \multirow{4}{*}{$\begin{array}{l}\text { Dimensión V: } \\
\text { Sobrevigilancia e } \\
\text { inhibición }\end{array}$} & $\begin{array}{l}\text { Describe a personas que realizan una } \\
\text { supresión de sentimientos y el accionar } \\
\text { espontáneo por la complacencia de reglas. }\end{array}$ & 15 & Negatividad/pesimismo & $\begin{array}{l}\text { Percepción generalizada y constante en los aspectos } \\
\text { negativos (dolor, muerte, pérdida, conflicto, etc.) y } \\
\text { simultáneamente minimizar o pasar por alto aspectos } \\
\text { positivos u optimistas. }\end{array}$ \\
\hline & $\begin{array}{l}\text { Podría centrarse su atención en aspectos } \\
\text { negativos de la vida, involucrando }\end{array}$ & 16 & Inhibición emocional & $\begin{array}{l}\text { Excesiva inhibición de la acción, sentimiento o } \\
\text { comunicación espontánea, normalmente, para evitar } \\
\text { sentimientos de vergüenza, pérdida de control de impulsos o } \\
\text { desaprobación. }\end{array}$ \\
\hline & $\begin{array}{l}\text { (negatividad/pesimismo). También, } \\
\text { limitaciones de sentimientos y actuar } \\
\text { espontáneo para evitar crítica de su } \\
\text { comportamiento o miedo a perder el }\end{array}$ & 17 & $\begin{array}{l}\text { Estándares inflexibles I } \\
\text { (Castigo) }\end{array}$ & $\begin{array}{l}\text { La creencia de que las personas deberían ser duramente } \\
\text { castigadas por cometer errores. Conlleva la tendencia a ser } \\
\text { punitivo, impaciente e intolerante. Actitud hipercrítica. } \\
\text { Deterioro del placer, salud, autoestima. }\end{array}$ \\
\hline & $\begin{array}{l}\text { control de impulsos, se destaca la } \\
\text { racionalización (privación emocional). } \\
\text { Por último, se presenta el esfuerzo } \\
\text { constante por contemplar estándares altos } \\
\text { hacia uno mismo y demás, para evitar la } \\
\text { desaprobación o vergüenza, manteniendo } \\
\text { los "deberías" en la vida (metas } \\
\text { inalcanzables/hipercriticismo). } \\
\text { Finalmente, siendo reticente a contemplar } \\
\text { la imperfección humana o las intenciones } \\
\text { de los demás, conlleva al esquema de } \\
\text { castigo. }\end{array}$ & 18 & $\begin{array}{c}\text { Estándares inflexibles I } \\
\text { (Metas } \\
\text { inalcanzables/hipercriticismo) }\end{array}$ & $\begin{array}{l}\text { Tendencia a la hipercrítica de uno mismo y los demás. } \\
\text { Deterioro en el placer, relajación, salud, autoestima, } \\
\text { sensación de logro o las relaciones satisfactorias. Se sienten } \\
\text { presionadas ante las expectativas que ellos creen que los } \\
\text { demás tienen sobre él mismo. Se le une a este factor, la } \\
\text { ansiedad y el control excesivo del tiempo para hacer las } \\
\text { cosas. }\end{array}$ \\
\hline
\end{tabular}

Nota. Los dieciocho esquemas desadaptativos planteados se muestran distribuidos por dimensiones. Fuente: Young, J., Klosko, J. y Weishaar, M. (2015). Terapia de esquemas.

Guía práctica. Serie Psicoterapias Cognitivas. Biblioteca de psicología. Bilbao: Desclée de Brouwer. 


\subsection{Funcionamiento de los EDT}

Los esquemas desadaptativos funcionan bajo dos tipos de acciones $\mathrm{u}$ operaciones principales: la perpetuación del esquema o la curación del esquema. Por un lado, puede conservar la función del esquema reforzando pensamientos, sentimientos y conductas disfuncionales; o podría ayudar a debilitar los esquemas disfuncionales, lo cual se observa en el tratamiento terapéutico (Rodríguez, 2009).

En primer lugar, de acuerdo a López et al. (2011), se consigue la perpetuación o mantenimiento del esquema mediante tres mecanismos principales: distorsiones cognitivas, patrones vitales autoderrotistas y estilos de afrontamiento.

En relación con las distorsiones cognitivas, las personas percibirán las situaciones de manera sesgada o buscarán información que confirme y refuerce el esquema desadaptativo, evitando tomar en cuenta información que pueda refutar o desmentir el mismo.

Acerca de los patrones vitales, el individuo selecciona, de manera inconsciente, situaciones que revalidan los esquemas disfuncionales; de manera que provocan conductualmente los patrones equivocados. Ello se puede ver reflejado en el tipo de amistades o relaciones que presenta en la interacción con los demás.

Otro punto son los estilos de afrontamiento y respuestas desadaptativas, las cuales, según Rodríguez (2009), se originan para evitar experimentar emociones que podrían ser de gran angustia. Éstos estilos guardan correspondencia con las respuestas básicas ante una amenaza: lucha, huía y el quedarse inmóvil; es decir, sobrecompensación, evitación y rendición, respectivamente (Young y Klosko, 2007). A continuación, se explica, de manera general, cada una:

La sobrecompensación consiste en manifestar conductas, pensamientos, sentimientos y relacionándose con otros contrariamente al esquema establecido; ello conduce a que no se experimente el afecto desagradable asociado al esquema. No obstante, puede parecer como un intento beneficioso de combatir contra el esquema, empero, éste estilo de afrontamiento solo lo perpetúa aún más.

Por otra parte, la evitación hace referencia a la evitación de cogniciones, emociones y conductas con fin de no activar el esquema disfuncional. 
Sin embargo, muchas veces, se logra eludir mediante la distracción con otro tipo de actividades o elementos para sentirse mejor, mostrándose renuentes a afrontar o que se active el esquema, entre ellas se encuentra el abuso de sustancias, volverse adictos al trabajo, comer de forma compulsiva, etc.

Por último, la rendición se trata de aceptar plenamente y confirmar el esquema, integrándolo como si fuera verdadero y evitando luchar contra él; por ende, se reviven las experiencias infantiles que crearon el esquema mediante la búsqueda, inconsciente, de situaciones que confirmen el mismo. Dicho de otro modo, la persona se mantiene en el mismo círculo debido a que se enfrenta a la emoción dolorosa que le genera el esquema disfuncional y actúa confirmando, nuevamente, el mismo.

Tabla 2.2

Ejemplos de respuestas disfuncionales de afrontamiento

\begin{tabular}{|c|c|c|c|}
\hline $\begin{array}{c}\text { Esquema } \\
\text { desadaptativo } \\
\text { temprano }\end{array}$ & $\begin{array}{c}\text { Conducta de esquema de } \\
\text { mantenimiento }\end{array}$ & $\begin{array}{l}\text { Conducta de esquema de } \\
\text { sobrecompensación }\end{array}$ & $\begin{array}{c}\text { Conducta de esquema } \\
\text { de evitación }\end{array}$ \\
\hline $\begin{array}{l}\text { Abandono/ } \\
\text { inestabilidad }\end{array}$ & $\begin{array}{l}\text { Selecciona parejas que no } \\
\text { pueden comprometerse y } \\
\text { permanecer en las } \\
\text { relaciones. }\end{array}$ & $\begin{array}{l}\text { Se aferra y "agobia" a la } \\
\text { pareja hasta el punto de } \\
\text { alejarla; ataca vehemente a } \\
\text { la pareja incluso ante las } \\
\text { separaciones más leves. }\end{array}$ & $\begin{array}{l}\text { Evita las relaciones } \\
\text { íntimas; bebe mucho a } \\
\text { solas. }\end{array}$ \\
\hline $\begin{array}{l}\text { Desconfianza/ } \\
\text { abuso }\end{array}$ & $\begin{array}{l}\text { Selecciona } \\
\text { abusadoras y permite el } \\
\text { maltrato. }\end{array}$ & Usa & $\begin{array}{l}\text { Evita ser vulnerable y } \\
\text { confiar en alguien; } \\
\text { guarda los secretos. }\end{array}$ \\
\hline $\begin{array}{l}\text { Privación } \\
\text { emocional }\end{array}$ & $\begin{array}{l}\text { Selecciona parejas } \\
\text { emocionalmente distante y } \\
\text { no les pide que satisfagan } \\
\text { sus necesidades. }\end{array}$ & $\begin{array}{l}\text { Actúa de un modo } \\
\text { emocionalmente } \\
\text { demandante con las parejas } \\
\text { y amigos próximos. }\end{array}$ & $\begin{array}{l}\text { Evita completamente las } \\
\text { relaciones íntimas. }\end{array}$ \\
\hline $\begin{array}{l}\text { Imperfección/ } \\
\text { vergüenza }\end{array}$ & $\begin{array}{l}\text { Selecciona amigos críticos } \\
\text { y con tendencia al rechazo, } \\
\text { se menosprecia. }\end{array}$ & $\begin{array}{l}\text { Critica y rechaza a los } \\
\text { demás con apariencia de ser } \\
\text { perfecto. }\end{array}$ & $\begin{array}{l}\text { Evita expresar los } \\
\text { pensamientos } \\
\text { sentimientos auténticos y } \\
\text { no permite que los demás } \\
\text { se aproximen. }\end{array}$ \\
\hline $\begin{array}{l}\text { Aislamiento } \\
\text { social }\end{array}$ & $\begin{array}{l}\text { En los encuentros sociales } \\
\text { se centra exclusivamente } \\
\text { en las diferencias de los } \\
\text { demás y no en las } \\
\text { similitudes. }\end{array}$ & $\begin{array}{l}\text { Se convierte en camaleón } \\
\text { para adaptarse a los grupos. }\end{array}$ & $\begin{array}{l}\text { Evita las situaciones } \\
\text { sociales y los grupos. }\end{array}$ \\
\hline Dependencia & $\begin{array}{l}\text { Pide a otras } \\
\text { significativas } \\
\text { cónyuge) que } \\
\text { (padres, } \\
\text { adopten } \\
\text { todas sus decisiones } \\
\text { financieras. }\end{array}$ & $\begin{array}{l}\text { Acaba con tanta } \\
\text { autoconfianza que no pide } \\
\text { nada a nadie } \\
\text { ("contraindependiente"). }\end{array}$ & $\begin{array}{l}\text { Evita acometer nuevos } \\
\text { retos, como aprender a } \\
\text { conducir. }\end{array}$ \\
\hline
\end{tabular}


Continuación de la Tabla 2.2:

\begin{tabular}{|c|c|c|c|}
\hline $\begin{array}{c}\text { Esquema } \\
\text { desadaptativo } \\
\text { temprano } \\
\end{array}$ & $\begin{array}{c}\text { Conducta de esquema de } \\
\text { mantenimiento }\end{array}$ & $\begin{array}{l}\text { Conducta de esquema de } \\
\text { sobrecompensación }\end{array}$ & $\begin{array}{c}\text { Conducta de esquema de } \\
\text { evitación }\end{array}$ \\
\hline $\begin{array}{l}\text { Vulnerabilidad } \\
\text { al Peligro o } \\
\text { Enfermedad }\end{array}$ & $\begin{array}{l}\text { Lee obsesivamente sobre } \\
\text { catástrofes en los } \\
\text { periódicos y los anticipa en } \\
\text { situaciones cotidianas. }\end{array}$ & $\begin{array}{l}\text { Actúa de forma arriesgada } \\
\text { sin preocuparse del peligro } \\
\text { ("contrafóbico"). }\end{array}$ & $\begin{array}{l}\text { Evita acudir a lugares que } \\
\text { no parezcan ser totalmente } \\
\text { "seguros". }\end{array}$ \\
\hline $\begin{array}{c}\text { Apego } \\
\text { Confuso/Yo } \\
\text { Inmaduro }\end{array}$ & $\begin{array}{l}\text { Cuenta todo a su madre, } \\
\text { incluso de adulto; vive a } \\
\text { través de la pareja. }\end{array}$ & $\begin{array}{l}\text { Trata de convertirse en lo } \\
\text { opuesto a otras personas } \\
\text { significativas en todos sus } \\
\text { modos de actuación. }\end{array}$ & $\begin{array}{l}\text { Evita la intimidad; } \\
\text { permanece independiente. }\end{array}$ \\
\hline Fracaso & $\begin{array}{l}\text { Efectúa las tareas de un } \\
\text { modo desganado o } \\
\text { caprichoso. }\end{array}$ & $\begin{array}{l}\text { Se convierte en alguien } \\
\text { hipercompetente } \\
\text { moviéndose } \\
\text { incesantemente. }\end{array}$ & $\begin{array}{l}\text { Evita completamente los } \\
\text { trabajos que impliquen } \\
\text { algún desafío; pospone las } \\
\text { tareas. }\end{array}$ \\
\hline Grandiosidad & $\begin{array}{l}\text { Obliga a los demás a } \\
\text { aceptar sus formas, } \\
\text { fanfarronea sobre sus } \\
\text { logros. }\end{array}$ & $\begin{array}{l}\text { Atiende excesivamente las } \\
\text { necesidades ajenas. }\end{array}$ & $\begin{array}{l}\text { Evita situaciones en las que } \\
\text { coincida con la norma, en } \\
\text { las que no sea superior. }\end{array}$ \\
\hline $\begin{array}{l}\text { Insuficiente } \\
\text { Autocontrol }\end{array}$ & $\begin{array}{l}\text { Abandona fácilmente las } \\
\text { rutinas cotidianas. }\end{array}$ & $\begin{array}{l}\text { Se convierte en una persona } \\
\text { excesivamente } \\
\text { autocontrolada } \\
\text { autodisciplinada. }\end{array}$ & $\begin{array}{lll}\text { Evita el empleo o la } & \text { lán } \\
\text { aceptación } & & \text { de } \\
\text { responsabilidad. } & & \end{array}$ \\
\hline Subyugación & $\begin{array}{l}\text { Deja que las demás } \\
\text { personas controlen las } \\
\text { situaciones y tomen las } \\
\text { decisiones pertinentes. }\end{array}$ & $\begin{array}{l}\text { Se revela contra la } \\
\text { autoridad. }\end{array}$ & $\begin{array}{l}\text { Evita situaciones que } \\
\text { podrían conllevar conflicto } \\
\text { con otro individuo. }\end{array}$ \\
\hline Autosacrificio & $\begin{array}{l}\text { Da mucho a los demás y no } \\
\text { pide nada a cambio. }\end{array}$ & $\begin{array}{l}\text { Da lo menos posible a los } \\
\text { demás. }\end{array}$ & $\begin{array}{l}\text { Evita las situaciones que } \\
\text { conllevan dar o recibir. }\end{array}$ \\
\hline $\begin{array}{l}\text { Búsqueda de } \\
\text { Aprobación }\end{array}$ & $\begin{array}{l}\text { Actúa para impresionar a } \\
\text { los demás. }\end{array}$ & $\begin{array}{l}\text { Destaca para provocar la } \\
\text { desaprobación de los } \\
\text { demás; permanece oculto. }\end{array}$ & $\begin{array}{l}\text { Evita interactuar con esos } \\
\text { cuya aprobación anhela. }\end{array}$ \\
\hline $\begin{array}{l}\text { Negativismo/ } \\
\text { Pesimismo }\end{array}$ & $\begin{array}{l}\text { Se centra en lo negativo; } \\
\text { ignora lo positivo; se } \\
\text { preocupa constantemente. }\end{array}$ & $\begin{array}{l}\text { Es } \quad \text { excesivamente } \\
\text { optimista; niega las } \\
\text { realidades desagradables. }\end{array}$ & $\begin{array}{l}\text { Bebe para ahogar sus } \\
\text { sentimientos pesimistas y } \\
\text { su infelicidad. }\end{array}$ \\
\hline $\begin{array}{l}\text { Inhibición } \\
\text { emocional }\end{array}$ & $\begin{array}{l}\text { Mantiene una compostura } \\
\text { calmada y emocionalmente } \\
\text { plana. }\end{array}$ & $\begin{array}{l}\text { Con torpeza trata de ser el } \\
\text { "centro de la fiesta" incluso } \\
\text { aunque sea de manera } \\
\text { forzada y antinatural. }\end{array}$ & $\begin{array}{l}\text { Evita las situaciones en las } \\
\text { que se discuta o se } \\
\text { expresan sentimientos. }\end{array}$ \\
\hline $\begin{array}{c}\text { Metal } \\
\text { inalcanzables }\end{array}$ & $\begin{array}{l}\text { Destina cantidades } \\
\text { extraordinarias de tiempo a } \\
\text { tratar de ser perfecto. }\end{array}$ & $\begin{array}{l}\text { Se despreocupa de las } \\
\text { normas, ejecuta las tareas } \\
\text { sin ningún cuidado o } \\
\text { atención. }\end{array}$ & $\begin{array}{l}\text { Evita o pospone las } \\
\text { situaciones y tareas cuya } \\
\text { ejecución se juzgará. }\end{array}$ \\
\hline Castigo & $\begin{array}{l}\text { Se trata así mismo y a los } \\
\text { demás de forma punitiva }\end{array}$ & $\begin{array}{l}\text { Se comporta de un modo } \\
\text { abiertamente indulgente. }\end{array}$ & $\begin{array}{l}\text { Evita a los demás por } \\
\text { miedo a ser castigado. }\end{array}$ \\
\hline
\end{tabular}

Nota. Las respuestas disfuncionales de afrontamiento son flexibles según el contexto y dependen de cómo se ha formado los esquemas desadaptativo temprano, según la historia de vida de la persona. Fuente: Young, J., Klosko, J. y Weishaar, M. (2015). Terapia de esquemas. Guía práctica. Serie Psicoterapias Cognitivas. Biblioteca de psicología. Bilbao: Desclée de Brouwer. 
De otro lado, se consigue la curación del esquema mediante la disminución de la intensidad de los recuerdos conectados con el esquema tanto emocionales, sensaciones corporales y cogniciones desadaptativas; conllevando así a un cambio conductual sustituyendo estilos de afrontamiento desadaptativos por patrones conductuales adaptativos, mediante técnicas activadoras de experiencias en diversas áreas (Young y Klosko, 2007).

\subsection{Relación entre esquemas y trastornos mentales}

El trastorno mental es conceptualizado, por la asociación americana de psiquiatría (APA, 2002) como un patrón comportamental o psicológico asociado a un malestar, discapacidad o a un riesgo significativamente aumentado de morir o de sufrir dolor, discapacidad o pérdida de libertad; dicho patrón no deber ser parte de una respuesta culturalmente aceptada a un acontecimiento particular.

Desde la perspectiva psicopatológica, se abordará los siguientes trastornos mentales, de acuerdo a la clasificación del DSM-IV (2002): trastornos relacionados con sustancias; esquizofrenia y otros trastornos psicóticos; trastornos del estado de ánimo; trastornos de ansiedad; trastornos de la conducta alimentaria y trastornos de bipolaridad.

Se abordarán los trastornos mentales mencionados, los cuales han sido objeto de estudio a través de perfiles de los esquemas desadaptativos tempranos en muestras clínicas; es decir, se ha encontrado relación entre los trastornos mentales y esquemas desadaptativos.

De esta manera, en pacientes depresivos se asocia con los esquemas de imperfección, autocontrol insuficiente, autosacrificio, aislamiento social y negatividad (Shah y Waller, 2000; Alfasfos, 2009).

En los trastornos de ansiedad, se observa que el esquema de vulnerabilidad al peligro y a la enfermedad, es uno de los principales involucrados (Hawke y Provencher, 2012). En personas con trastorno obsesivo compulsivo, se hallan los esquemas de imperfección, vulnerabilidad al peligro, inhibición emocional y aislamiento social (Lochner et al., 2005; Voderholzer et al., 2014).

Estudios en esquizofrenia y trastornos psicóticos, los esquemas desadaptativos son relevantes y se asociaron con los síntomas positivos pero no con los negativos, siendo 
los esquemas asociados de privación emocional, aislamiento social, imperfección, apego confuso, fracaso y subyugación (Bortolon et al., 2013).

Los trastornos por uso de sustancias, específicamente en muestra de jóvenes, la adicción al cannabis se relaciona con los esquemas de dependencia y autocontrol insuficiente (Grebot y Dardar, 2010). La adicción al juego patológico muestra asociación con los esquemas de privación emocional, autosacrificio, inhibición emocional, metas inalcanzables, autocontrol insuficiente (Kantona y Körmendi, 2012).

En cuanto a los trastornos de conducta alimentaria, se hallan asociaciones con los esquemas de abandono, imperfección, aislamiento social, autosacrificio e inhibición emocional (Jones, Leung y Harris, 2007), privación emocional y subyugación (Unoka, Tölgyes, Czobor y Simon, 2010).

Finalmente, en pacientes con bipolaridad demostraron poseer en común los esquemas de abandono, apego confuso, subyugación y grandiosidad (Khosravi, Ebrahimi, Shayan, Havasian y Jamshidi, 2017; Nilsson, Nielsen y Halvorsen, 2015).

\subsection{Relación entre esquemas y trastornos de la personalidad}

Los trastornos de la personalidad se concibe, por la (APA, 2014), como patrones inflexibles y desadaptativos de percibir, relacionarse y pensar sobre el entorno y uno mismo, que se manifiesta en diferentes contextos sociales y personales, causan malestar subjetivo y un deterioro funcional significativo.

De acuerdo a la investigación de Bach et al. (2015), se presentarán los trastornos de personalidad antisocial, narcisista, obsesivo compulsivo, evitativo, esquizotípico y límite, considerando el sistema multiaxial del DSM-V (APA, 2014); el cual propone veinticinco facetas de rasgos de personalidad y que describen cada trastorno.

- El trastorno de personalidad antisocial se encuentra relacionado con las facetas de personalidad de manipulación, deshonestidad, impulsividad, temeridad, hostilidad, irresponsabilidad e insensibilidad.

- El trastorno de personalidad narcisista se encuentra relacionado con las facetas de personalidad de grandiosidad y búsqueda de atención. 
- El trastorno de personalidad obsesivo compulsivo se encuentra relacionado con las facetas de personalidad de perfeccionismo rígido y perseveración.

- El trastorno de personalidad evitativo se encuentra relacionado con las facetas de personalidad de ansiedad, evitación de intimidad, anhedonia y retraimiento.

- El trastorno de personalidad esquizotípico se encuentra relacionado con las facetas de personalidad de retraimiento, susceptibilidad, afectividad restringida, experiencias y creencias inusuales, excentricidad y desregulación perceptual y cognitiva.

- El trastorno de personalidad límite se encuentra relacionado con las facetas de personalidad de hostilidad, impulsividad, temeridad, ansiedad, inseguridad de separación y labilidad emocional.

Además, Bach et al. (2015) investigaron la alineación entre las facetas de rasgos de personalidad, dominios de personalidad y los dieciocho esquemas desadaptativos de la terapia de esquemas. A modo de resumen, se mencionará la relación de los cinco dominios con los esquemas.

El primer dominio de afectividad negativa se relacionó con los esquemas de privación emocional, abandono, desconfianza, aislamiento social, imperfección, fracaso, dependencia, vulnerabilidad al peligro, apego confuso, subyugación, inhibición emocional, autocontrol insuficiente, pesimismo y castigo. El segundo dominio de desapego se relacionó con los esquemas de privación emocional, desconfianza, aislamiento social, imperfección, fracaso, dependencia, vulnerabilidad al peligro, subyugación, inhibición emocional, autocontrol insuficiente, pesimismo y castigo. El tercer dominio de antagonismo se relacionó con el esquema de grandiosidad. El cuarto dominio de desinhibición se relacionó con los esquemas de abandono, desconfianza, aislamiento social, imperfección, fracaso, dependencia, vulnerabilidad al peligro, subyugación y autocontrol insuficiente. El quinto dominio de psicoticismo se relacionó con los esquemas de privación emocional, abandono, desconfianza, aislamiento social, imperfección, fracaso, dependencia, vulnerabilidad al peligro, subyugación, inhibición emocional, autocontrol insuficiente y pesimismo.

Además, los resultados apoyan la capacidad de las facetas de rasgos de personalidad para explicar esquemas. Particularmente, las correlaciones entre la faceta de 
grandiosidad y el esquema grandiosidad; la faceta sumisión y el esquema subyugación; la faceta perfeccionismo rígido y el esquema metas inalcanzables; la faceta búsqueda de atención y el esquema búsqueda de aprobación; la faceta distractibilidad y el esquema autocontrol insuficiente; la faceta afectividad restringida y el esquema inhibición emocional; la faceta depresión y el esquema pesimismo; la faceta retraimiento y el esquema aislamiento social; la faceta susceptibilidad y el esquema desconfianza; la faceta inseguridad de separación y el esquema de abandono.

\subsection{Características del cuestionario de esquemas}

El cuestionario de esquemas de Young es una medida de autoinforme para evaluar los esquemas desadaptativos de las personas que van a consulta. Se valora, en base a una escala Likert de seis puntos, que comienza desde 1 punto (totalmente falso) hasta 6 puntos (me describe perfectamente) (Young y Klosko, 2007).

Young et al. (2015) expone que el objetivo de la administración de la prueba es que permite un diagnóstico global de los problemas y síntomas presentes; así como, los patrones centrados en la historia de vida del paciente. Ello se recibe como insumo para la formulación de hipótesis sobre los patrones de vida, esquemas y estilos de afrontamiento.

Generalmente, se le brinda la opción a la persona para que lo complete en casa; no obstante, puede haber situaciones que requieren trabajar conjuntamente sobre el cuestionario durante las sesiones que, generalmente, toma entre una o dos sesiones la revisión completa del mismo.

Del mismo modo, el análisis del cuestionario, acorde con Young y Klosko (2001) y Young et al. (2015), se realiza centrándose en los ítems de cada esquema que poseen las puntuaciones más altas, entre 5 y 6 en la escala de Likert, evaluando los patrones que aparecen; no solo ello, sino que se explora más en los mismos, animando al paciente a ahondar más en el mismo. Por otro lado, el terapeuta le enseña al paciente el nombre de cada uno de los esquemas con puntuaciones elevadas el significado de los mismos.

En ese sentido, es un intercambio mutuo entre paciente y terapeuta en donde revisan el cuestionario de esquemas; siendo el profesional el que formula y revisa las hipótesis que se genera acerca de los mismos y logra vincular los esquemas con los problemas que presenta e historia de vida. 
Por otro lado, el paciente toma consciencia de los esquemas que presenta y comprende el significado de los mismos y su funcionamiento.

De igual modo, considerando las ventajas de aplicación, se ha demostrado que el cuestionario es útil para detectar cambios en los esquemas desadaptativos debido a las intervenciones terapéuticas, como en el caso de la depresión (Wegener, Alfter, Geiser, Liedtke y Conrad, 2013). Además, es sensible para predecir la presencia de psicopatología y sus subescalas están relacionadas con las subescalas del Inventario de Sympton Breve (Schmidt et al., 1995), específicamente, el riesgo de trastorno bipolar (Hawke, Provencher y Arntz, 2011), la predicción de la respuesta a la exposición y la prevención de la respuesta del tratamiento del trastorno obsesivo-compulsivo (Haaland et al., 2011). No obstante, no cabe duda que se requiere mayor trabajo para evaluar aún más la evidencia de validez de constructo del cuestionario de esquema y sus variantes; sobre todo, en su correlación con otras psicopatologías.

En cuanto a la cronología del cuestionario de esquemas, desde la creación del cuestionario de esquemas, hubo variaciones en el tiempo con respecto a la cantidad de esquemas desadaptativos que evaluaba, así como, la cantidad de ítems que posee. De esta manera, existen 3 versiones y 2 formas del cuestionario, una forma corta y una forma larga, para cada versión.

El primer cuestionario de esquemas se creó en 1990, poseía 123 ítems, evaluaba 16 esquemas y éstos se agrupaban en 3 dimensiones. Al poco tiempo, en 1991, se creó la segunda versión del cuestionario de esquemas en su forma larga que poseía 205 ítems, continuaba evaluando 16 esquemas y éstos se agrupaban en 6 dimensiones.

Después, en 1995, se creó la forma corta de la segunda versión del cuestionario, poseía 75 ítems, evaluaba 15 esquemas y éstos se agrupaban en 5 dimensiones.

Más adelante, en el 2003, se creó la tercera versión del cuestionario de esquemas en su forma larga que poseía 232 ítems, evalúo 18 esquemas y éstos se agrupaban en 5 dimensiones.

Luego, en el 2005, se creó la forma corta de la tercera versión del cuestionario, poseía 90 ítems, evalúa 18 esquemas y éstos se agrupaban en 5 dimensiones. 
Tabla 2.3

Transición cronológica de los cuestionarios de esquemas

\begin{tabular}{lcccc}
\hline \multicolumn{1}{c}{ Nombre del Cuestionario } & $\begin{array}{c}\text { Año de } \\
\text { publicación }\end{array}$ & $\begin{array}{c}\text { Cantidad de } \\
\text { dimensiones }\end{array}$ & $\begin{array}{c}\text { Cantidad } \\
\text { de } \\
\text { esquemas }\end{array}$ & $\begin{array}{c}\text { Cantidad } \\
\text { de } \\
\text { reactivos }\end{array}$ \\
\hline $\begin{array}{l}\text { Young Schema Questionnaire (YSQ) } \\
\begin{array}{l}\text { Young Schema Questionnaire Long Form } \\
\text { Second Edition (YSQ-L2) }\end{array}\end{array}$ & 1990 & 3 & 16 & 123 \\
$\begin{array}{l}\text { Young Schema Questionnaire Short Form } \\
\text { Second Edition (YSQ-S2) }\end{array}$ & 1991 & 6 & 16 & 205 \\
$\begin{array}{l}\text { Young Schema Questionnaire Long Form } \\
\text { Third Edition (YSQ-L3) }\end{array}$ & 2003 & 5 & 15 & 75 \\
$\begin{array}{l}\text { Young Schema Questionnaire Short Form } \\
\text { Third Edition (YSQ-S3) }\end{array}$ & 2005 & 5 & 18 & 232 \\
\hline
\end{tabular}

Nota. Los cuestionarios de esquemas fueron modificados, conforme se fueron ampliando la cantidad de esquemas desadaptativos y perfeccionando la teoría.

Por último, Young señala tres ventajas de usar la forma corta, en vez de la forma larga. Primero, porque es más fácil la administración. Segundo, porque es factorialmente pura, ya que contiene los cinco elementos de carga más altos para cada esquema. Tercero, se usa más frecuentemente en las investigaciones, donde los estudios indican que confiabilidad y estructura factorial para ambas formas abreviadas y extendidas son iguales. En este caso, se empleará la última versión, forma abreviada del cuestionario, el cual contiene 90 reactivos, los cuales miden los 18 esquemas desadaptativos tempranos y éstos esquemas se agrupan en 5 dimensiones.

\subsection{Resumen de las propiedades psicométricas del YSQ-S3}

Las investigaciones, que han examinado la fiabilidad y las evidencias de validez de las puntuaciones derivadas de aplicar el YSQ-S3, presentan adecuadas propiedades psicométricas cuando se realiza en muestras de más de 1000 sujetos y en muestras no clínica (Cid, 2015).

Algunos estudios han utilizado el análisis factorial exploratorio (Saritas y Gençoz, 2011; Soygüt, Karaosmonglu y Çakir, 2009) y, otros, emplearon el análisis factorial confirmatorio (Bach, et al., 2015; Calvete, Orue y González-Diez, 2013; Hawke y 
Provencher, 2012; Kriston, Schäfer, Jacob, Härter y Hölzel, 2013; Lee, Choi, Rim, Won y Lee, 2015; Lyrakos, 2014; Oettingen, Chodkiewicz, Mącik y Gruszczyńska, 2017; Rijo, 2009; Sakulsriprasert et al., 2016; Sardarzadeh, 2018; Quiñones et al., 2018).

Nos centraremos en los estudios revisados que utilizaron el análisis factorial confirmatorio ya que guarda afinidad con nuestra presente investigación. Estos estudios se han realizado en muestras de estudiantes universitarios, personas que atendían a las unidades psiquiátricas, personas que recibían consejería psicológica, presos de prisión por enfermedad mental y/o personas de la comunidad, en general.

En la gran mayoría de los estudios, se confirma la estructura de los 18 esquemas del cuestionario tanto en los países occidentales como orientales (Sakulsriprasert et al., 2016). Sin embargo, presentan ciertos inconvenientes.

Por ejemplo, ciertas investigaciones (Hawke y Provencher, 2012; Kriston et al. 2013; Lee et al., 2015; Oettingen et al., 2017; Rijo, 2009; Sakulsriprasert et al., 2016) tuvieron problemas para encontrar índices de ajuste aceptable para el modelo de los 18 esquemas de primer orden. Así, en el caso del estudio de Kriston et al. (2013) que se realizó con una muestra mixta alemana, tuvo problema en la prueba de discrepancia chi cuadrada $\left(\mathrm{x}^{2}=7.914\right)$ excediendo al umbral de ajuste aceptable (por debajo de 3.00), los índices de ajuste de CFI (.842) y TLI (.832) no alcanzaron el umbral requerido (por encima de .90) y la aproximación a la raíz cuadrada media residual no alcanzó el umbral recomendado por debajo de $1.000(\mathrm{WRMR}=1.615)$.

De otro lado, las investigaciones llevadas a cabo en Dinamarca (Bach, et al., 2015), Chile (Quiñones et al., 2018) y Grecia (Lyrakos, 2014) hallaron índices de ajuste aceptables al modelo de 18 esquemas de primer orden, confirmando la teoría. Sin embargo, hubo problemas en los índices de ajuste para confirmar las 5 dimensiones de segundo orden. Surgiendo en discusión el número de dimensiones de segundo orden que agruparían a los esquemas; excepto, la investigación llevada en Ucrania (Sardarzadeh, 2018) que confirma la estructura teórica original, tanto de primer como de segundo orden, en muestra no clínica.

Debido a los inconvenientes al demostrar la organización de los esquemas en 5 dimensiones de segundo orden, algunos autores (Sakulsriprasert et al., 2016) proponen un modelo de 4 factores de segundo orden con ciertas modificaciones en los ítems. 
Calvete et al. (2013) hallaron, mediante un análisis factorial exploratorio, adecuados índices de ajuste para un modelo de 3 factores de segundo orden y, según acotan, un menor número de dominios proporciona una mejor explicación de las correlaciones entre los esquemas. Sin embargo, Hawke y Provencher (2012) intentaron replicar un modelo de 3 factores de segundo orden mas no hallaron índices de ajuste adecuados al modelo. Finalmente, los estudios de Alemania (Kriston, et al., 2013), Polonia (Oettingen et al., 2017), España (Calvete et al., 2013) y Dinamarca (Bach, et al., 2015) sugieren un modelo bifactor, es decir, un modelo con un factor común o genérico y factores específicos relacionados.

De igual modo, se ha investigado las evidencias de validez vinculadas a las relaciones con otras variables del cuestionario de esquemas en muestras mixtas (Bach, et al., 2015; Hawke y Provencher, 2012; Kriston, et al., 2013; Lyrakos, 2014;Rijo, 2009; Saariaho, Saariaho, Karila y Joukamaa, 2009; Quiñones et al., 2018).

Todas las investigaciones señaladas encontraron diferencias de grupos estadísticamente significativas $(\mathrm{p}<.001)$ a nivel de puntuación total del cuestionario. Con ello, nos referimos que la muestra clínico obtuvo puntuaciones más altas que la muestra no clínica. Además, pudo distinguir entre subgrupos de la muestra (Bach, et al., 2015; Kriston, et al., 2013; Rijo, 2009). Por ejemplo, Rijo (2009) demostró que las personas de la comunidad obtuvieron puntuaciones inferiores en comparación con las personas que tenían un diagnóstico de trastorno mental; a su vez, estos últimos obtuvieron puntuaciones inferiores en comparación con las personas que tenían un diagnóstico de trastorno de la personalidad. Estas puntuaciones se evidenciaron para el total del cuestionario, así como, en cada uno de los esquemas.

En cuanto a las evidencias de confiabilidad de las puntuaciones derivadas del YSQ-S3, las investigaciones revisadas utilizan el coeficiente de alfa de Cronbach. Se obtiene una consistencia interna aceptable $(\alpha>.70)$ para el cuestionario total y los 18 esquemas (Bach, et al., 2015; Calvete et al., 2013; Hawke y Provencher, 202; Lyrakos, 2014). En el resto de investigaciones, no se obtuvo una consistencia interna aceptable para todos los esquemas; se observa que, tienen en común, el esquema de grandiosidad brinda un alfa de cronbach inferior a lo aceptado (Kriston, et al., 2013; Lee et al., 2015; Oettingen et al., 2017; Quiñones et al., 2018); así como, el esquema de metas inalcanzables (Oettingen et al., 2017; Rijo, 2009; Sakulsriprasert et al., 2016). 


\section{CAPÍTULO III: OBJETIVOS, HIPÓTESIS Y DEFINICIÓN DE VARIABLES}

\subsection{Objetivos}

- Obtener evidencias de validez relacionadas al contenido de la adaptación española del Cuestionario de esquemas de Young, tercera versión reducida (YSQ-S3) mediante el criterio de jueces utilizando el estadístico V de Aiken.

- Obtener evidencias de validez relacionadas a la estructura interna de la adaptación española del Cuestionario de esquemas de Young, tercera versión reducida (YSQS3). Ello se realizará mediante el análisis factorial confirmatorio.

- Obtener evidencias de validez vinculadas a las relaciones con otras variables de la adaptación española del Cuestionario de esquemas de Young, tercera versión reducida (YSQ-S3) mediante la comparación de la muestra clínica y la muestra no clínica.

- Obtener evidencias de confiabilidad de las puntuaciones derivadas del Cuestionario de los Esquemas de Young (YSQ-S3) mediante el coeficiente Omega.

\subsection{Definición de variables}

Esquemas Desadaptativos Tempranos: Son patrones que comprometen a los recuerdos, sensaciones corporales, emociones y cogniciones que el sujeto posee acerca de sí mismo y acerca de sus relaciones con otros (Young, 1999).

Los esquemas desadaptativos tempranos son medidos a través del cuestionario de esquemas propuesto por Jeffrey Young. En la presente investigación, se utilizará la traducción española oficial de la última versión del cuestionario de esquemas (YSQ-S3) realizada por Cid y Torrubia (como se citó en Calvete et al., 2013). 


\section{CAPÍTULO IV: MÉTODO}

\subsection{Tipo y diseño de investigación}

El tipo de investigación es psicométrica, ya que se busca describir las propiedades psicométricas del cuestionario de los esquemas de Young (YSQ-SF3), específicamente, demostrar que se cumplan los requisitos de las evidencias de validez y estimación de confiabilidad de la prueba. En ese sentido, se considera la sub área relativa a la adaptación de instrumentos psicológicos, que pueda ser útil para investigaciones futuras y de uso aplicativo en el abordaje psicoterapéutico según su contexto sociocultural (Alarcón, 2008).

El diseño metodológico es no experimental y transeccional descriptivo. Es no experimental puesto que no existe una manipulación intencional de variables. De otro lado, es transeccional descriptivo puesto que la medición se llevará a cabo en un momento dado, con el fin de describir la información recolectada de las respuestas de los ítems acerca de los esquemas desadaptativos en un subgrupo clínico y no clínico (Hernández, Fernández y Baptista, 2014).

\subsection{Participantes}

Se trabajó con una muestra de 562 participantes, que incluía un subgrupo clínico de 324 personas y un subgrupo no clínico de 238 personas.

El subgrupo clínico estuvo compuesto por personas que atendían a los consultorios externos de adultos del hospital Víctor Larco Herrera. De otro lado, el subgrupo no clínico estuvo compuesto por personas de la comunidad y se buscó que tuvieran edades similares a la recogida en el subgrupo clínica.

Los participantes de ambos subgrupos tenían edades que fluctuaba entre los 18 a 60 años de edad, grado de instrucción de secundaria completa y vivían en Lima Metropolitana.

A continuación, en la tabla 4.1, se presentan las características sociodemográficas de los participantes del subgrupo clínico. 
Tabla 4.1

Características del subgrupo clínico

\begin{tabular}{|c|c|c|}
\hline Datos Sociodemográficos & $\mathbf{n}$ & $\%$ \\
\hline \multicolumn{3}{|l|}{ Sexo } \\
\hline Femenino & 163 & $50.3 \%$ \\
\hline Masculino & 161 & $49.7 \%$ \\
\hline
\end{tabular}

Edad
$18-28$ años
$29-39$ años
$40-50$ años
$51-60$ años

\section{Grado de instrucción}

Secundaria Completa

Técnica Completa

Universitaria Completa

Posgrado

\section{Tratamientos}

Sin tratamiento

Solo tratamiento psicológico

Solo tratamiento psiquiátrico

Tratamiento psiquiátrico y psicológico

Tiempo de tratamiento psiquiátrico

0- 4 años

5 - 10 años

$11-19$ años

20 - 30 años
$2,5 \%$

Nota. El indicador " $n$ ” es la cantidad de personas que cumplían las subcategorías sociodemográficas señaladas, dando el total del subgrupo clínico de 324 personas.

En el subgrupo clínico se excluyó aquellas personas que presentaron retardo mental, trastornos debido a lesión y disfunción cerebral. Esto debido a que se requiere un grado de abstracción que favorezcan la comprensión de los ítems y el propósito de la investigación. Por ejemplo, personas que poseen trastornos debido a lesión y disfunción cerebral está comprometido el grado de consciencia de las mismas. 
De otro lado, en las personas con retardo mental, se les puede dificultar el discernimiento y comprensión del cuestionario. Para ello, se tuvo en cuentas las consideraciones de investigaciones anteriores (Bach et al., 2015; Lyrakos, 2013).

En cuanto a los participantes del subgrupo no clínico, en la tabla 4.2, se presentan las características sociodemográficas presentadas.

Tabla 4.2

Características del subgrupo no clínico

\begin{tabular}{lcc}
\hline \multicolumn{1}{c}{ Datos Sociodemográficos } & $\mathbf{n}$ & $\mathbf{( \% )}$ \\
\hline Sexo & 119 & $50,0 \%$ \\
Femenino & 119 & $50,0 \%$ \\
Masculino & & \\
Edad & 99 & $41,6 \%$ \\
$18-28$ años & 53 & $22,3 \%$ \\
$29-39$ años & 49 & $20,6 \%$ \\
$40-50$ años & 37 & $15,5 \%$ \\
$51-60$ años & & \\
Grado de instrucción & 59 & $24,8 \%$ \\
Secundaria Completa & 49 & $20,6 \%$ \\
Técnica Completa & 109 & $45,8 \%$ \\
Universitaria Completa & 21 & $8,8 \%$ \\
Posgrado & &
\end{tabular}

Nota: Los participantes de este subgrupo no se encontraban recibiendo tratamiento psicológico ni tratamiento psiquiátrico.

El tipo de muestreo que se utilizó para seleccionar a los participantes es no probabilístico por conveniencia (Ochoa, 2015). No probabilístico ya que la selección de las unidades de la muestra no es aleatorio, los individuos de la muestra poseen una probabilidad nula de ser seleccionados y no se conoce la probabilidad de inclusión exacta de cada unidad muestral. Es por conveniencia puesto que se selecciona a una muestra de la población accesible, que cumpla con ciertos criterios de inclusión para formar parte de la investigación. Por ejemplo, en el subgrupo clínico los criterios fueron asistir al consultorio externo del hospital psiquiátrico y tener un diagnóstico psiquiátrico correspondiente a trastornos mentales y/o trastornos de personalidad, según el DSM-IV. 
De igual manera, se buscó participantes de la comunidad, subgrupo no clínico, que tuvieran característica similar en cuanto a la edad y género a la recolectada en el subgrupo clínico.

El tamaño de la muestra es viable para realizar análisis factoriales, utilizando el criterio de emplear una muestra mayor a 250 participantes (Hu y Bentler, 1999) ya que, en muestras menores, existe un rechazo a los modelos planteados al considerar la sensibilidad de los índices de ajuste relativos (p.e., chi cuadrado, RMSEA) y absolutos (p.e., CFI) en cuanto a una especificación errónea. De igual forma, Kass y Tinsley (1979) recomiendan tener entre 5 a 10 participantes por variable hasta un total de 300 personas, ya que superior a ese número de casos los parámetros de prueba tienden a ser estables independientemente de la proporción de participante a variable.

\subsection{Técnicas de recolección de datos}

La recolección de la información se llevará a cabo mediante la aplicación de la adaptación española del Cuestionario de esquemas de Young, tercera versión (YSQ-S3) llevada a cabo por Cid y Torrubia (como se citó en Calvete et al., 2013), cuya versión original y nombre en inglés es Young Schema Questionnaire - Short Form, 3rd Edition (Young, 2005).

Este cuestionario es un instrumento de indagación aplicable a sujetos a partir de los 16 años. El YSQ-S3 consta de 90 elementos que se califican en una escala de Likert de 6 puntos: 1 (totalmente falso), 2 (la mayoría de veces falso), 3 (más verdadero que falso), 4 (en ocasiones verdadero), 5 (la mayoría de veces verdadero) y 6 (me describe perfectamente). El inventario mide 18 factores propuestos por Young (1999), organizados en 5 dominios. Cada esquema está representado por 5 elementos o ítems.

El primer dominio de desconexión y rechazo está compuesto por el esquema abandono, desconfianza, privación emocional, imperfección/vergüenza y aislamiento social. Los esquemas de dependencia/incompetencia, vulnerabilidad al peligro o a la enfermedad, apego confuso/yo inmaduro, y fracaso están subsumidos bajo el segundo dominio de deterioro en autonomía y desempeño. El tercer dominio de límites deficitarios incluye los esquemas de grandiosidad/autorización y un autocontrol insuficiente/autodisciplina. La subyugación, autosacrificio, búsqueda de 
aprobación/búsqueda de reconocimiento se organizan bajo el cuarto dominio dirigido por las necesidades de los demás. Finalmente, el quinto dominio de sobrevigilancia e inhibición se compone de los esquemas de negatividad/pesimismo, inhibición emocional, castigo, metas inalcanzables/hipercriticismo.

Tabla 4.3.

Dimensiones de esquemas, necesidades asociadas, esquemas e ítems

\begin{tabular}{|c|c|c|c|c|}
\hline $\begin{array}{l}\text { Dimensiones de } \\
\text { esquemas }\end{array}$ & $\begin{array}{l}\text { Necesidades } \\
\text { asociadas }\end{array}$ & Esquemas & Ítems & $\begin{array}{c}\text { Total } \\
\text { de } \\
\text { ítems }\end{array}$ \\
\hline \multirow{4}{*}{$\begin{array}{l}\text { Desconexión y } \\
\text { rechazo }\end{array}$} & \multirow{4}{*}{$\begin{array}{l}\text { Apego seguro, } \\
\text { aceptación, } \\
\text { nutrición, } \\
\text { protección }\end{array}$} & Abandono/inestabilidad & $2,20,38,56,74$ & 5 \\
\hline & & Desconfianza/abuso & $3,21,39,57,75$ & 5 \\
\hline & & Privación emocional & $1,19,37,55,73$ & 5 \\
\hline & & Imperfección/vergüenza & $5,23,41,59,77$ & 5 \\
\hline \multirow{3}{*}{$\begin{array}{c}\text { Deterioro en } \\
\text { autonomía y } \\
\text { desempeño }\end{array}$} & \multirow{3}{*}{$\begin{array}{l}\text { Autonomía, } \\
\text { competencia, } \\
\text { identidad }\end{array}$} & Aislamiento social & $4,22,40,58,76$ & 5 \\
\hline & & Dependencia/incompetencia & $7,25,43,61,79$ & 5 \\
\hline & & $\begin{array}{l}\text { Vulnerabilidad al peligro o a la } \\
\text { enfermedad }\end{array}$ & $8,26,44,62,80$ & 5 \\
\hline \multirow{4}{*}{$\begin{array}{c}\text { Límites } \\
\text { deficitarios }\end{array}$} & \multirow{4}{*}{$\begin{array}{l}\text { Límites realistas } \\
\text { y autocontrol }\end{array}$} & Apego confuso/Yo inmaduro & $9,27,45,63,81$ & 5 \\
\hline & & Fracaso & $6,24,42,60,78$ & 5 \\
\hline & & Grandiosidad/autorización & $14,32,50,68,86$ & 5 \\
\hline & & $\begin{array}{l}\text { Autocontrol } \\
\text { insuficiente/autodisciplina }\end{array}$ & $15,33,51,69,87$ & 5 \\
\hline \multirow{3}{*}{$\begin{array}{l}\text { Dirigido por las } \\
\text { necesidades de } \\
\text { los demás }\end{array}$} & \multirow{3}{*}{$\begin{array}{c}\text { Libre expresión } \\
\text { de necesidades } \\
\text { y emociones }\end{array}$} & Subyugación & $10,28,46,64,82$ & 5 \\
\hline & & Autosacrificio & $11,29,47,65,83$ & 5 \\
\hline & & $\begin{array}{l}\text { Búsqueda de aprobación/búsqueda } \\
\text { de reconocimiento }\end{array}$ & $16,34,52,70,88$ & 5 \\
\hline \multirow{4}{*}{$\begin{array}{l}\text { Sobrevigilancia } \\
\text { e inhibición }\end{array}$} & \multirow{4}{*}{$\begin{array}{l}\text { Espontaneidad y } \\
\text { juego }\end{array}$} & Negatividad/pesimismo & $17,35,53,71,89$ & 5 \\
\hline & & Inhibición emocional & $12,30,48,66,84$ & 5 \\
\hline & & Castigo & $18,36,54,72,90$ & 5 \\
\hline & & $\begin{array}{l}\text { Metas inalcanzables/ } \\
\text { hipercriticismo }\end{array}$ & $13,31,49,67,85$ & 5 \\
\hline
\end{tabular}

Nota. El cuestionario de esquemas muestra cómo se agrupa desde los ítems que lo componen hasta las dimensiones o dominios de los esquemas.

La investigación llevada a cabo, en España, por Calvete et al. (2013) estudió las propiedades psicométricas de la traducción española del cuestionario de esquemas de Young llevada a cabo por Cid y Torrubia (como se citó en Calvete et al., 2013) en colaboración con Jeffrey Young. 
Realizó un análisis factorial confirmatorio para evaluar las evidencias de validez vinculadas a la estructura interna, evidencias de validez vinculadas a las relaciones con otras variables y evidencias de validez vinculadas con la estabilidad temporal de la medida. De igual forma, compararon el modelo teórico con una solución empírica obtenida de un análisis factorial exploratorio correspondiente a sus datos.

En cuanto a los resultados del análisis factorial confirmatorio, encontraron adecuados índice de ajuste para el modelo de 18 factores de primer orden $\left(\mathrm{x}^{2}[3762]=\right.$ $10977, \mathrm{p}<.001 ; \mathrm{CFI}=.96 ; \mathrm{NNFI}=.96 ; \mathrm{RMSEA}=.05 ; \mathrm{SRMR}=.06)$. En ese sentido, los índices de ajuste de CFI (.96) estuvo por encima del .95, el RMSEA (.05) estuvo por debajo del .06 y el SRMR (.06) estuvo por debajo del .08; en concordancia con las recomendaciones de $\mathrm{Hu}$ y Bentler (1999). Sin embargo, no consiguieron adecuados índices de ajuste que avalaran el modelo original de 18 factores de primer orden y 5 factores de segundo orden $\left(\mathrm{x}^{2}[3905]=19654, \mathrm{p}<.001 ; \mathrm{CFI}=.92 ; \mathrm{NNFI}=.92 ; \mathrm{RMSEA}\right.$ $=.08 ; \mathrm{SRMR}=.08)$.

Además, examinaron la estructura de segundo orden del YSQ-S3, mediante el análisis factorial exploratorio empleando el programa Lisrel 8.8 (Du Toit, Du Toit, Mels y Cheng, 2005). Se analizó los componentes de principales con la rotación Varimax y los modelos de medición se probaron mediante la estimación de máxima verosimilitud. La prueba Scree empleada indicó una solución de 3 factores, que representó el 57.18\% de la varianza de los 18 esquemas. El primer factor de segundo orden explicó el 20\% de la varianza y hubo una carga factorial de los esquemas de autosacrificio, búsqueda de aprobación, metas inalcanzables, negatividad, castigo y grandiosidad. El segundo factor de segundo orden explicó el 19\% de la varianza y hubo una carga factorial de los esquemas de fracaso, dependencia, apego confuso, vulnerabilidad al peligro, autocontrol insuficiente, abandono y subyugación. El tercer factor de segundo orden explicó el 18\% de la varianza y hubo una carga factorial de los esquemas de privación emocional, inhibición emocional, aislamiento social, imperfección y desconfianza.

Cabe mencionar que utilizaron análisis de regresión múltiples para estudiar las puntuaciones media obtenida de los esquemas y, como predictores, se utilizó las puntuaciones obtenidas de los inventarios de depresión, ansiedad social y hostilidad. Los resultados mostraron que cada síntoma psicológico de depresión, ansiedad social y hostilidad está vinculado con ciertos esquemas desadaptativos. En ese sentido, los 
esquemas explicaron un $26 \%$ de la varianza en las puntuaciones del inventario de depresión; un $22 \%$ de la varianza en las puntuaciones del inventario de ansiedad social; y, un $21 \%$ de la varianza en las puntuaciones del inventario de hostilidad.

Finalmente, examinaron la estabilidad de las puntuaciones de los esquemas mediante las correlaciones de la prueba test-retest; dichas correlaciones fueron altas, variando de .50 a $.73($ mediana $=.62)$. Las pruebas $t$ pareadas para las puntuaciones media de cada esquema al inicio y, después de 6 meses, indicaron diferencias significativas en todos los esquemas $(\mathrm{p}<.001)$. Así como, un tamaño del efecto pequeño, entre .18 y .70, excepto para cuatro esquemas: privación emocional, imperfección, fracaso y subyugación; los cuales no se vio diferencia estadísticamente significativa.

\subsection{Procedimiento de recolección de datos}

En primer lugar, se contactó directamente con el autor del cuestionario de esquemas, Jeffrey Young, mediante un correo electrónico y número de fax disponible en la página web del Instituto de terapia de esquemas; con la finalidad de informar acerca de la investigación que se pretende llevar a cabo y solicitar la autorización del uso del cuestionario versión original (YSQ-S3); ante lo cual, nos refirió el empleo de la traducción oficial en español del cuestionario de esquemas realizada por Cid y Torrubia (como se citó en Calvete et al., 2013), la cual fue empleada.

En segundo lugar, una vez otorgado el permiso, se contactó con uno de los autores de la traducción española, Jordi Cid, el cual procedió vía correo electrónico enviar la prueba así como la plantilla de respuesta y se hizo tangible mediante la impresión de la misma.

Para el acceso al subgrupo clínico, en el hospital Víctor Larco Herrera; se hizo presente una carta formal de solicitud a la directora de la institución, a nombre de la universidad, para la aplicación del cuestionario en pacientes de consultorio externo tanto hombres como mujeres, que posean diagnósticos clínicos, según el DSM-IV (APA, 2002). De otro lado, fue más sencillo acceder al subgrupo no clínico, compuesta por personas de la comunidad. 
En ambas muestras se priorizó ciertos criterios de inclusión tales como tener un rango de edad entre 18 a 60 años, haber concluido como mínimo la secundaria completa y residir en Lima Metropolitana.

Para la aplicación del cuestionario, se elaboró un consentimiento informado en el cual se incluyó el objetivo de la investigación, por qué era importante la participación de cada persona, quién estaba a cargo del estudio y cómo contactarla vía email, la ausencia de riesgos, la naturaleza voluntaria y confidencialidad del estudio; además, que los datos recogidos serían empleados con fines académicos. Este consentimiento no varió y fue el mismo en ambos casos.

Así mismo, se empleó una ficha de datos socio-demográficos con el objetivo de establecer sus características y el cumplimiento con los criterios de inclusión y exclusión, para el subgrupo clínico. Los datos recolectados fueron: género, edad, grado de nivel de instrucción. Además, se consultó si estaban recibiendo un tratamiento psiquiátrico y/o si estaban recibiendo tratamiento psicológico, actualmente. En ambos casos, si la respuesta era afirmativa se tenía que indicar la cantidad de meses que recibe dicho(s) tratamiento(s).

En el caso del subgrupo no clínico, no atendían a un tratamiento psiquiátrico ni psicológico y, de igual forma, evidenciaron su respuesta en la ficha sociodemográfica. 


\section{CAPÍTULO V: RESULTADOS}

Los resultados que se presentan, a continuación, han seguido el enfoque moderno sobre validez (Kane, 2006) estipuladas en los estándares para pruebas educativas y psicológicas desarrollados por la Asociación Americana de Investigación en Educación (AERA), la Asociación Americana de Psicología (APA) y el Consejo Nacional sobre la medición en la educación (NCME) (2014).

\subsection{Evidencias de validez vinculadas al contenido}

Se utilizó el estadístico de la V de Aiken (Aiken, 1985), el cual permite medir el ajuste de los ítems al contenido a partir de las valoraciones de jueces expertos. En este caso, medir el grado de acuerdo entre jueces para determinar en qué medida los ítems representan los esquemas propuestos.

Navarro (2009) sugiere un grupo mínimo de cinco jueces y que, por lo menos, cuatro estén en concordancia para que el ítem sea válido, alcanzando coeficientes $\mathrm{V}$ de Aiken iguales o superiores a .80 , a un nivel de significación estadística de $\mathrm{p}<.05$. Este coeficiente puede obtener valores entre 0 y 1 , y a medida que sea más elevado el valor computado, el ítem tendrá mayor evidencia de validez de contenido (Escurra, 1988).

De acuerdo con Sireci y Faulkner-Bond (2014), se recomienda un número mínimo de diez jueces expertos que evalúen criterios de las evidencias de validez del contenido como la representación del dominio, la relevancia en el dominio y claridad en la redacción. En ese sentido, la traducción española del cuestionario de esquemas (YSQS3) fue presentada a doce jueces que correspondían a diferentes especialidades: psicólogos clínicos, psicólogos expertos en psicometría y psicólogos expertos en la terapia de esquemas.

A partir de las respuestas de los jueces, dichos resultados fueron procesados estadísticamente, utilizando el coeficiente $\mathrm{V}$ de Aiken .80, con un nivel de significancia de $\mathrm{p}<.05$ para ser considerados significativos. 
A continuación se presentan los resultados obtenidos del promedio de los tres criterios empleados al ítem.

Tabla 5.1

Coeficiente $V$ de Aiken para los ítems de la dimensión desconexión y rechazo

\begin{tabular}{|c|c|c|c|}
\hline Esquema & V de Aiken & Esquema & V de Aiken \\
\hline Privación Emocional & & Abandono/ & \\
\hline & & Inestabilidad & \\
\hline Ítem 1 & .97 & Ítem 2 & 1.00 \\
\hline Ítem 19 & 1.00 & Ítem 20 & 1.00 \\
\hline Ítem 37 & 1.00 & Ítem 38 & 1.00 \\
\hline Ítem 55 & .90 & Ítem 56 & 1.00 \\
\hline Ítem 73 & .93 & Ítem 74 & .97 \\
\hline Desconfianza/ Abuso & & Aislamiento Social & \\
\hline Ítem 3 & .97 & Ítem 4 & 1.00 \\
\hline Ítem 21 & .93 & Ítem 22 & .97 \\
\hline Ítem 39 & .93 & Ítem 40 & 1.00 \\
\hline Ítem 57 & .93 & Ítem 58 & 1.00 \\
\hline Ítem 75 & .93 & Ítem 76 & .93 \\
\hline \multicolumn{4}{|l|}{ Imperfección/ } \\
\hline \multicolumn{4}{|l|}{ Vergüenza } \\
\hline Ítem 5 & .97 & & \\
\hline Ítem 23 & 1.00 & & \\
\hline Ítem 41 & 1.00 & & \\
\hline Ítem 59 & .97 & & \\
\hline Ítem 77 & .93 & & \\
\hline
\end{tabular}

Nota. ${ }^{*} \mathrm{p}<.50$. 
Tabla 5.2

Coeficiente $V$ de Aiken para los ítems de la dimensión deterioro en autonomía y desempeño

\begin{tabular}{lccc}
\hline Esquema & V de Aiken & Esquema & V de Aiken \\
\hline Fracaso & & Dependencia & \\
Ítem 6 & 1.00 & Ítem 7 & .93 \\
Ítem 24 & 1.00 & Ítem 25 & .80 \\
Ítem 42 & 1.00 & Ítem 43 & .97 \\
Ítem 60 & 1.00 & Ítem 61 & .93 \\
Ítem 78 & 1.00 & Ítem 79 & 1.00 \\
\hline Vulnerabilidad & al & & Apego Confuso/ Yo \\
Peligro & 1.00 & Inmaduro & \\
Ítem 8 & 1.00 & Ítem 9 & .90 \\
Ítem 26 & 1.00 & Ítem 27 & .93 \\
Ítem 44 & 1.00 & Ítem 45 & .97 \\
Ítem 62 & 1.00 & Ítem 63 & 1.00 \\
Ítem 80 & & Ítem 81 & .97 \\
\hline
\end{tabular}

Tabla 5.3

Coeficiente $V$ de Aiken para los ítems de la dimensión límites deficitarios

\begin{tabular}{lccc}
\hline Esquema & V de Aiken & Esquema & V de Aiken \\
\hline Grandiosidad/ & & Autocontrol & \\
Autorización & & Insuficiente & \\
Ítem 14 & 1.00 & Ítem 15 & .93 \\
Ítem 32 & 1.00 & Ítem 33 & .97 \\
Ítem 50 & 1.00 & Ítem 51 & 1.00 \\
Ítem 68 & 1.00 & Ítem 69 & .87 \\
Ítem 86 & 1.00 & Ítem 87 & 1.00 \\
\hline
\end{tabular}


Tabla 5.4

Coeficiente $V$ de Aiken para los ítems de la dimensión dirigido por las necesidades de los demás

\begin{tabular}{lcrc}
\hline Esquema & V de Aiken & Esquema & V de Aiken \\
\hline Subyugación & .97 & Autosacrificio & \\
Ítem 10 & 1.00 & Ítem 11 & 1.00 \\
Ítem 28 & .97 & Ítem 29 & 1.00 \\
Ítem 46 & 1.00 & Ítem 47 & 1.00 \\
Ítem 64 & 1.00 & Ítem 65 & .97 \\
Ítem 82 & Ítem 83 & .93 \\
\hline Búsqueda de & & & \\
Aprobación & 1.00 & & \\
Ítem 16 & .93 & & \\
Ítem 34 & .97 & & \\
Ítem 52 & 1.00 & & \\
Ítem 70 & 1.00 & & \\
Ítem 88 & & & \\
\hline
\end{tabular}

Tabla 5.5

Coeficiente $V$ de Aiken para los ítems de la dimensión sobrevigilancia e inhibición

\begin{tabular}{cccc}
\hline Esquema & V de Aiken & Esquema & V de Aiken \\
\hline Inhibición Emocional & & Metas Inalcanzables & \\
Ítem 12 & 1.00 & Ítem 13 & 1.00 \\
Ítem 30 & 1.00 & Ítem 31 & .93 \\
Ítem 48 & 1.00 & Ítem 49 & 1.00 \\
Ítem 66 & 1.00 & Ítem 67 & 1.00 \\
Ítem 84 & 1.00 & Ítem 85 & 1.00 \\
\hline
\end{tabular}


Continuación de la Tabla 5.5:

\begin{tabular}{lclc}
\hline Esquema & V de Aiken & Esquema & V de Aiken \\
\hline $\begin{array}{l}\text { Negatividad/ } \\
\text { Pesimismo }\end{array}$ & Castigo & \\
\multicolumn{1}{l}{ Ítem 17 } & .97 & Ítem 18 & 1.00 \\
Ítem 35 & 1.00 & Ítem 36 & 1.00 \\
Ítem 53 & .97 & Ítem 54 & 1.00 \\
Ítem 71 & .93 & Ítem 72 & 1.00 \\
Ítem 89 & .97 & Ítem 90 & 1.00 \\
\hline
\end{tabular}

Considerando el número de acuerdos de los doce jueces, los resultados sugieron que se modifique el criterio de "calidad en la redacción" en ítems donde hayan menos de diez acuerdos en los doce jueces, de esta manera se modificó:

El ítem 55 del esquema Privación Emocional (V = .70) "La mayor parte de mi vida, no he tenido a nadie que realmente me escuchase, me comprendiese o que conectase con mis verdaderas necesidades y sentimientos", se cambie por: "La mayor parte de mi vida, no he tenido a nadie que realmente me escuche o comprenda mis verdaderas necesidades y sentimientos".

El ítem 25 del esquema Dependencia $(\mathrm{V}=.60)$ "Me veo a mi mismo como una persona dependiente, a lo que se refiere al funcionamiento de cada día", se cambie por: "Me veo a mi mismo como una persona dependiente, en mi desempeño diario".

El ítem 9 del esquema Apego Confuso $(\mathrm{V}=.70)$ "No he sido capaz de independizarme de mis padres, en la medida en las que las otras personas de mi edad parecen haberlo hecho", se cambie por: "No he sido capaz de independizarme de mis padres, como otras personas de mi edad parecen haberlo hecho".

El ítem 69 del esquema Autocontrol Insuficiente (V=.70) "No consigo obligarme a hacer aquellas cosas que no me divierten, incluso cuando sé que son para mi propio beneficio", se cambie por: "No puedo obligarme a hacer aquellas cosas que no disfruto, incluso cuando sé que son para mi propio beneficio". 
Se modificó los ítems señalados y se volvió a solicitar la revisión de la claridad de la redacción de los ítems. Se obtuvo un consenso homogéneo de aceptación entre los jueces expertos y se procedió a la aplicación de dicho cuestionario de ítems modificados.

\subsection{Evidencias de validez vinculadas a la estructura interna}

Se realizó un análisis factorial confirmatorio (AFC) en el programa estadístico R (R Core Team, 2013) con el fin de analizar el ajuste global de la matriz de los datos recogidos y su aproximación con los modelos propuestos. Esto se realizó con el estimador de mínimos cuadrados ponderados diagonalmente (Diagonally Weighted Least Squares - DWLS por sus siglas en inglés) ya que utiliza las correlaciones policóricas como entrada para crear la matriz de covarianza asintótica y se emparejó con ajustes de estimación robusta como el método de mínimos cuadrados ponderados con corrección de medias y varianzas (Weighted Least Squares Mean and Variance Adjusted - WLSMV por sus siglas en inglés) (Newsom, 2015; Li, 2014). El WLSMV se basa en los resultados obtenido por DWLS para recalcular, mediante la matriz de pesos, los errores de estándar robustos y realizar ajustes de la media y varianza; de manera que, mejora los índices de ajuste, estándar de error y chi-cuadrado (Newsom, 2015).

De igual manera, se recomienda utilizar los métodos robustos de mínimos cuadrados ponderados con corrección de medias y varianzas (WLSMV) y el método de mínimos cuadrados no ponderados con corrección de medias y varianzas (ULSMV); puesto que han demostrado superioridad sobre la teoría normal de máxima verosimilitud (ML) y la probabilidad máxima robusta (MLR) con correcciones sólidas en el análisis de los modelos de factores confirmatorios ordinales como las respuestas Likert; así como, en las estimaciones de carga de factores en todas las condiciones de simulación y estimaciones de error estándar más precisas, en la mayoría de condiciones (Forero y Maydeu-Olivares, 2009; Li, 2014).

En cuanto al análisis del ajuste global del modelo, se tomará en cuenta el índice de ajuste comparativo de Bentler en su versión robusta (CFIr), el índice de Tucker-Lewis en su versión robusta (TLIr), el error cuadrático medio de aproximación en su versión robusta (RMSEAr) y la raíz del residuo estandarizado medio en su versión robusta (SRMRr). 
Según Hu y Bentler (1999), si se cumple que el CFIr y el TLIr son mayores que .95 , además, que el RMSEA es menor que .08 y el SRMR es menor que .06; entonces, se considera un buen ajuste del modelo planteado. En otras palabras, la matriz de los datos recogidos se aproxima al modelo propuesto.

De esta manera, se estableció como modelos a contrastar el modelo 1 del autor original (Young, 2005), quien indicaba que existía una estructural de 18 factores de primer orden y 5 factores de segundo orden. El modelo 2 corresponde con la estructura encontrada en la investigación de Calvete et al. (2013) con 3 factores de segundo orden y 18 factores de primer orden. Para el modelo 3, solo se consideró los 5 factores de segundo orden del modelo original (Young, 2005). Luego, para el modelo 4, solo se consideró los 3 factores de segundo orden del modelo de Calvete et al. (2013). Finalmente, el modelo 5 de Young (2005) con 18 esquemas de primer orden.

Tabla 5.6

Resumen de los factores de primer y segundo orden, según los modelos probados

\begin{tabular}{lcc}
\hline \multicolumn{1}{c}{ Modelos } & Factores de primer orden & Factores de segundo orden \\
\hline Modelo 1 (Young, 2005) & 18 & 5 \\
Modelo 2 (Calvete et al., 2013) & 18 & 3 \\
Modelo 3 (Young, 2005) & - & 5 \\
Modelo 4 (Calvete et al., 2013) & - & 3 \\
Modelo 5 (Young, 2005) & 18 & - \\
\hline
\end{tabular}

En la Tabla 5.7, se presentan los resultados del ajuste de los cinco modelos analizados teóricamente. Los cuatro primeros modelos tuvieron dificultad ya que mostraron desajuste según los índices comparativos de CFIr y TLIr menores a .95, la medida residual SRMRr mayor a .06; excepto, la medida residual de RMSEAr ya que fue menor al .05, siendo la única aceptable.

De otro lado, el modelo con mejor ajuste fue el modelo de 18 factores de primer orden (modelo 5), el cual se deriva del modelo original que menciona 18 esquemas desadaptativos. Los índices de ajuste comparativo del modelo $\left(\mathrm{x}^{2}[4005, N=562]=\right.$ $53490.51, p<.001)$ fueron buenos $(\mathrm{CFIr}=.96, \mathrm{TLIr}=.95) ; \mathrm{y}$ las medidas residuales estuvieron dentro de los rangos aceptables $(\mathrm{RMSEAr}=.03, \mathrm{SRMRr}=.06)$. 
Tabla 5.7

Índices de ajuste para los modelos de la estructura factorial del YSQ-S3

\begin{tabular}{lcccccc}
\hline \multicolumn{1}{c}{ Modelo } & $\mathrm{x}^{2}$ & $\mathrm{gl}$ & $\mathrm{CFIr}$ & TLIr & RMSEAr & SRMRr \\
\hline Modelo 1 (Young, 2005) & 53490.51 & 4005 & .94 & .94 & .04 & .07 \\
Modelo 2 (Calvete et al., 2013) & 53401.50 & 4005 & .94 & .94 & .04 & .07 \\
Modelo 3 (Young, 2005) & 53490.51 & 4005 & .93 & .92 & .04 & .07 \\
Modelo 4 (Calvete et al., 2013) & 53401.50 & 4005 & .93 & .93 & .04 & .07 \\
Modelo 5 (Young, 2005) & 53490.51 & 4005 & .96 & .95 & .03 & .06 \\
\hline
\end{tabular}

A continuación, en la tabla 5.8, se presentan los factores o esquemas con sus respectivas cargas factoriales de los ítems y los valores del coeficiente de correlación múltiple al cuadrado $\left(\mathrm{R}^{2}\right)$. Se evidencia que los valores de las cargas factoriales de los ítems, en general, fueron mayores a .40; excepto en los ítems 49 y 85, que presentaron cargas factoriales de .31 y .39 , respectivamente, correspondientes al factor de metas inalcanzables.

De otro lado, los valores de $\mathrm{R}^{2}$ eran superiores a .30 en todos los ítems de los factores, excepto en los factores de Privación Emocional y Metas Inalcanzables. El factor de Privación Emocional explica poca varianza en el ítem 1, solo el 19.8\%. De igual forma, el factor de Metas Inalcanzables explica un porcentaje de varianza leve del 9.6\% y 15\%, respectivamente en los ítems 49 y 85 .

Tabla 5.8

Factores y cargas factoriales de los respectivos ítems

\begin{tabular}{|c|c|c|c|c|c|}
\hline Factor & $\begin{array}{l}\text { Carga } \\
\text { factorial }\end{array}$ & $\mathrm{R}^{2}$ & Factor & $\begin{array}{l}\text { Carga } \\
\text { factorial }\end{array}$ & $\mathrm{R}^{2}$ \\
\hline Privación Emocional & & & ono & & \\
\hline Ítem 1 & .45 & .20 & Ítem 2 & .74 & .55 \\
\hline Ítem 19 & .77 & .59 & Ítem 20 & .72 & .52 \\
\hline Ítem 37 & .85 & .72 & Ítem 38 & .84 & .70 \\
\hline Ítem 55 & .74 & .55 & Ítem 56 & .90 & .65 \\
\hline Ítem 73 & .59 & .34 & Ítem 74 & .80 & .64 \\
\hline
\end{tabular}


Continuación de la tabla 5.8:

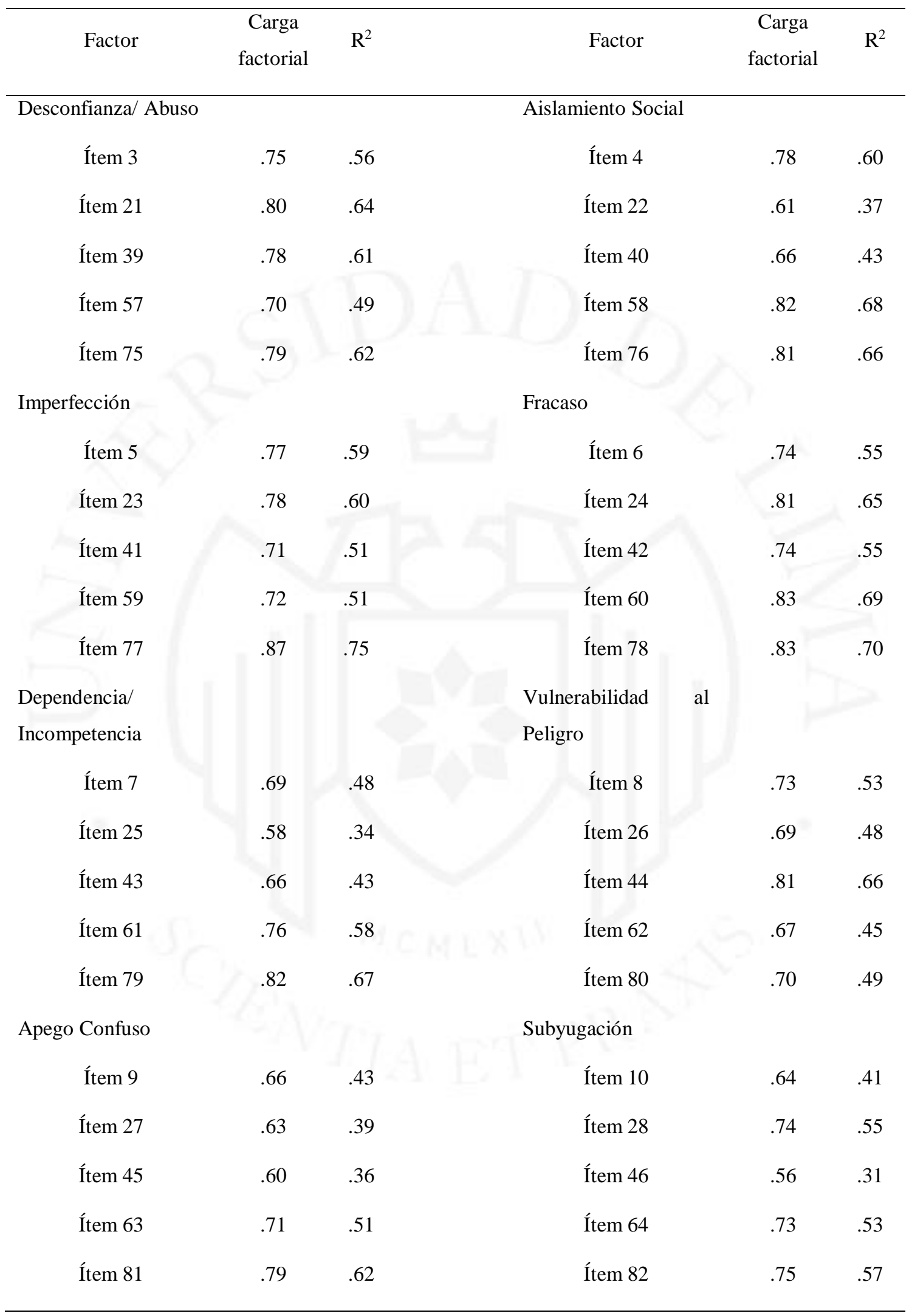


Continuación de la tabla 5.8:

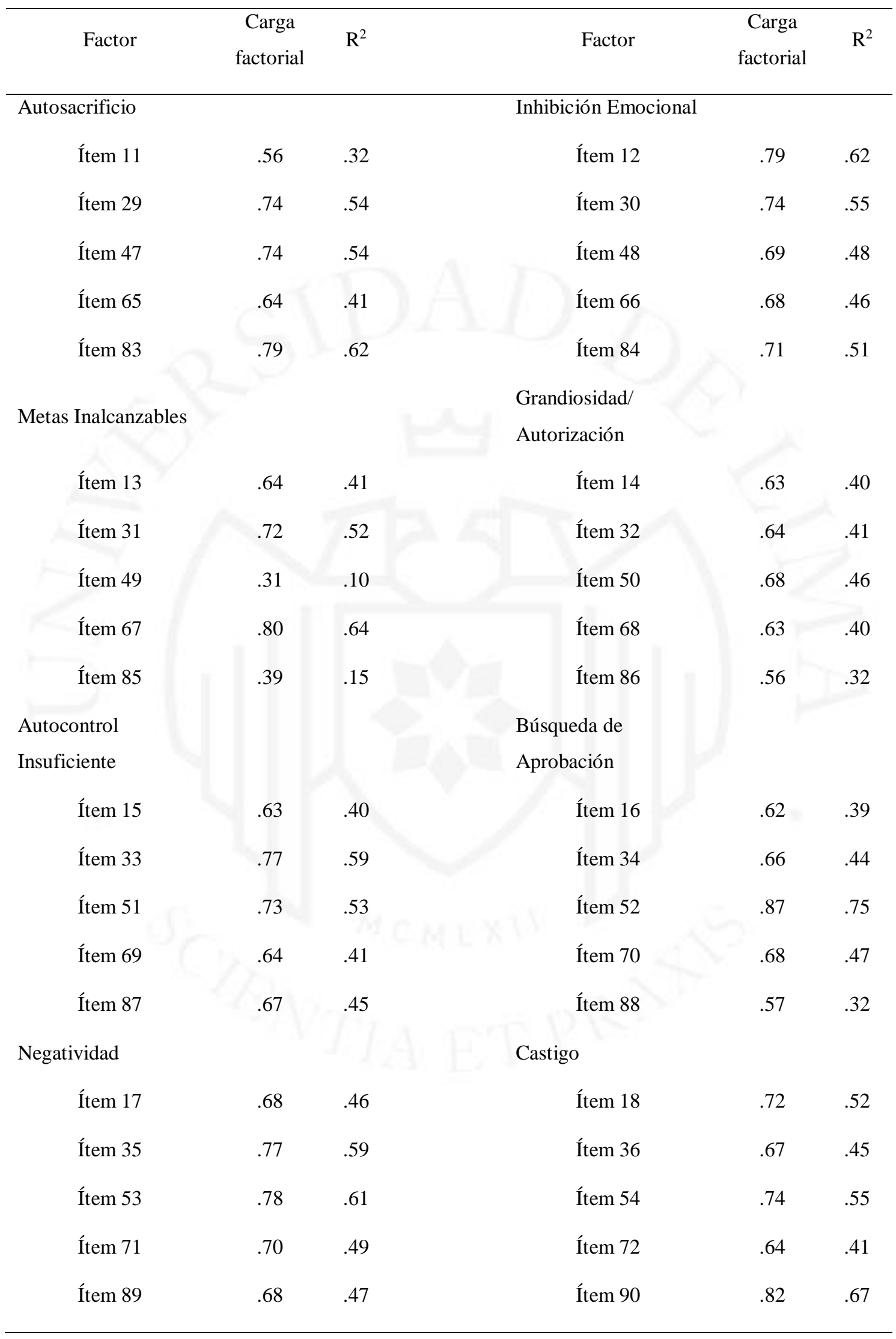


En la tabla 5.9, se muestran los estadísticos descriptivos de tendencia central, índices de dispersión y el análisis de la prueba de normalidad de los 18 esquemas o factores del cuestionario mediante el cálculo de la media de la puntuación directa. Cabe resaltar que, cada esquema podría obtener una puntuación directa de 5 como mínimo y de 30 como máximo, ya que cada esquema posee 5 ítems y éstos se valoran del 1 al 6 . En ese sentido, la media de la puntuación directa es obtenida por la puntuación directa del esquema entre el número de ítems. Dicha puntuación media de cada esquema es utilizada para comparar las puntuaciones, debido a la inexistencia de datos normativos (Cid, 2015).

Tabla 5.9

Estadísticos descriptivos para los 18 esquemas

\begin{tabular}{|c|c|c|c|c|c|c|c|}
\hline & Esquema & Media PD & Mediana & $\mathrm{DE}$ & RIQ & As. & Ku. \\
\hline 1 & Privación Emocional & 2.56 & 2.20 & 1.34 & 2.20 & 0.74 & -0.43 \\
\hline 2 & Abandono/ Inestabilidad & 2.48 & 2.20 & 1.24 & 1.80 & 0.81 & -0.13 \\
\hline 3 & Desconfianza/ Abuso & 2.33 & 2.00 & 1.16 & 1.60 & 0.84 & 0.06 \\
\hline 4 & Aislamiento Social & 1.94 & 1.60 & 1.12 & 1.40 & 1.37 & 1.24 \\
\hline 5 & Imperfección/ Vergüenza & 2.43 & 2.00 & 1.19 & 2.00 & 0.79 & -0.07 \\
\hline 6 & Fracaso & 1.92 & 1.80 & 0.95 & 1.40 & 1.17 & 1.03 \\
\hline 7 & Dependencia/ Incompetencia & 2.46 & 2.20 & 1.23 & 2.00 & 0.69 & -0.42 \\
\hline 8 & Vulnerabilidad al Peligro & 2.13 & 1.80 & 1.07 & 1.60 & 1.06 & 0.60 \\
\hline 9 & Apego Confuso/ Yo Inmaduro & 2.00 & 1.60 & 1.11 & 1.60 & 1.31 & 1.24 \\
\hline 10 & Subyugación & 2.89 & 2.80 & 1.15 & 1.60 & 0.27 & -0.44 \\
\hline 11 & Autosacrificio & 2.68 & 2.60 & 1.21 & 2.00 & 0.46 & -0.64 \\
\hline 12 & Inhibición Emocional & 2.32 & 2.00 & 1.11 & 1.60 & 0.87 & 0.12 \\
\hline 13 & Metas Inalcanzables & 3.26 & 3.20 & 1.25 & 1.80 & 0.13 & -0.59 \\
\hline 14 & Grandiosidad & 2.71 & 2.60 & 1.20 & 2.00 & 0.45 & -0.59 \\
\hline 15 & Autocontrol Insuficiente/ Autodisciplina & 2.62 & 2.40 & 1.22 & 1.80 & 0.59 & -0.48 \\
\hline 16 & Búsqueda de Aprobación & 2.46 & 2.20 & 1.21 & 1.80 & 0.67 & -0.38 \\
\hline 17 & Negatividad/ Pesimismo & 2.48 & 2.20 & 1.17 & 1.80 & 0.64 & -0.34 \\
\hline 18 & Castigo & 3.28 & 3.20 & 1.14 & 1.60 & -0.01 & -0.56 \\
\hline
\end{tabular}

Nota. $\mathrm{DE}$ = desviación estándar; RIQ = rango intercuartílico; As = asimetría $; \mathrm{Ku}=$ curtosis. 


\subsection{Evidencias de validez vinculadas a las relaciones con otras variables}

Las evidencias de validez vinculadas a las relaciones con otras variables se abordó mediante la comparación del subgrupo clínico $(N=324)$ y el subgrupo no clínico $(N=$ 238). Para ello, se consideró la distribución de las medias muestrales, que consiste en tomar muestras de cierta población y hacer el cálculo de las medias para encontrar la distribución de probabilidad. Se empleó la prueba t de Student pues determina las diferencias entre dos medias muestrales y permite la construcción de intervalo de confianza para la diferencia entre las medias de dos muestras. Cabe mencionar que, la distribución se aproximará más a una distribución normal, a medida que posea un tamaño grande de la muestra, al menos de 30 elementos. Ello parte del teorema del límite central que establece la distribución de las medias muestrales, se aproxima a una distribución normal, en muestras aleatorias grandes; siendo este teorema cierto para todas las distribuciones (Vargas, 2008).

En concordancia con lo anterior, se utilizó la prueba t de Student para dos muestras independientes mediante el programa estadístico del SPSS (International Business Machines Corporation, 2017). Los resultados señalaron que el subgrupo clínico obtuvo puntuaciones media estadísticamente significativas más altas que el subgrupo no clínico en todos los esquemas y en la puntuación total $(p<.001)$.

Luego, se estimó los tamaños del efecto mediante el estadístico de la $d$ de Cohen. Se observó una diferencia del tamaño del efecto de .96 entre las puntuaciones media total del cuestionario de ambos subgrupos, superando el límite de la categoría "grande" (Cohen, 1988); obteniendo el subgrupo clínico puntuaciones media más altas que el subgrupo no clínico en todos los esquemas y en la puntuación total del cuestionario.

De forma específica, se distingue una diferencia del tamaño del efecto de .80 , considerada como una diferencia "grande", en torno al esquema de Autosacrificio; al observar las diferencias de las puntuaciones medias de ambos subgrupos. De otro lado, hubo una diferencia del tamaño del efecto "mediano" para todos los esquemas restantes, obteniendo valores $d$ de cohen entre .53 y .77 (Cohen, 1988).

A continuación, en la tabla 5.10, se muestran los datos descriptivos de los datos de ambos subgrupos. 
Tabla 5.10

Comparación de las medias y medianas de los esquemas en función al tipo de muestra

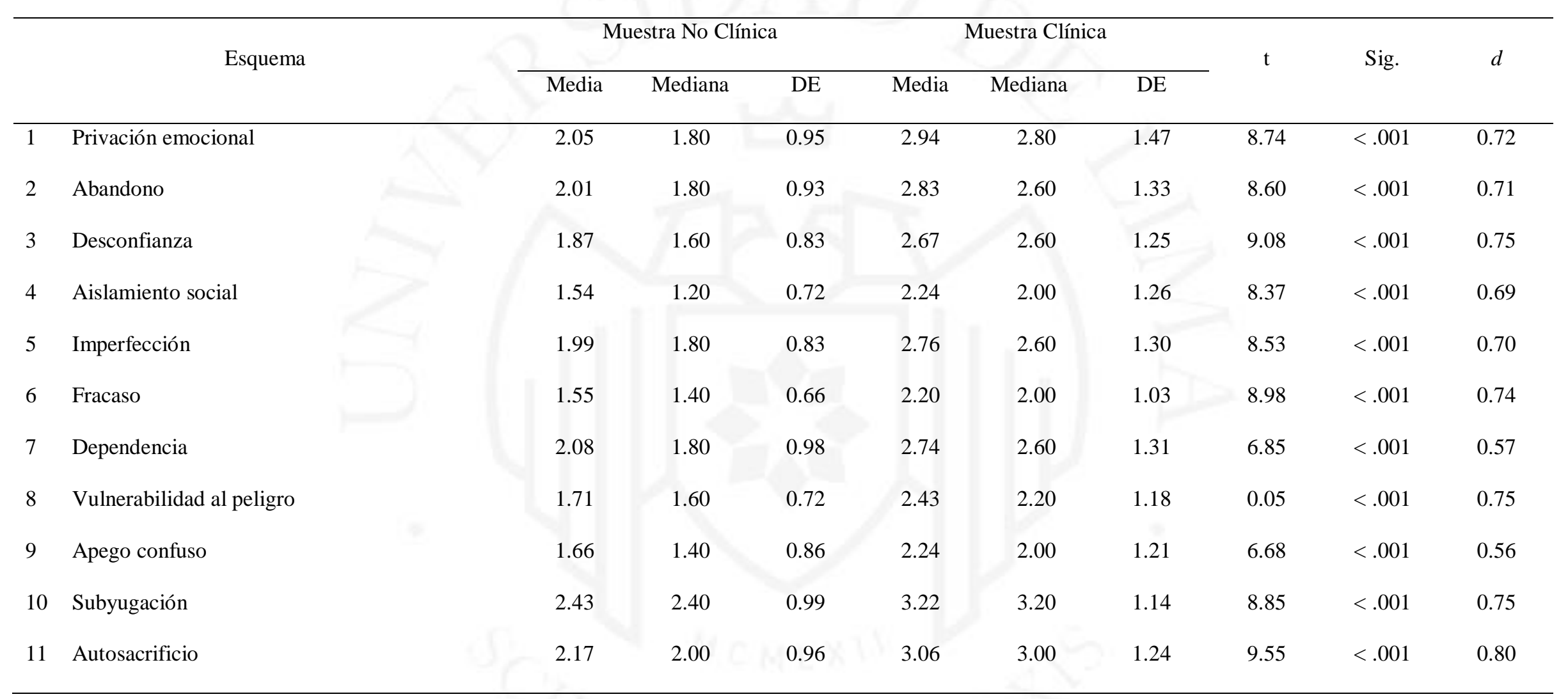


Continuación de la Tabla 5.10:

\begin{tabular}{|c|c|c|c|c|c|c|c|c|c|c|}
\hline \multirow{2}{*}{\multicolumn{2}{|c|}{ Esquema }} & \multicolumn{3}{|c|}{ Muestra No Clínica } & \multicolumn{3}{|c|}{ Muestra Clínica } & \multirow{2}{*}{$\mathrm{t}$} & \multirow{2}{*}{ Sig. } & \multirow{2}{*}{$d$} \\
\hline & & Media & Mediana & $\mathrm{DE}$ & Media & Mediana & $\mathrm{DE}$ & & & \\
\hline 12 & Inhibición emocional & 1.91 & 1.80 & 0.84 & 2.63 & 2.40 & 1.19 & 8.33 & $<.001$ & 0.69 \\
\hline 13 & Metas inalcanzables & 2.81 & 2.80 & 1.18 & 3.59 & 3.60 & 1.19 & 7.79 & $<.001$ & 0.66 \\
\hline 14 & Grandiosidad & 2.22 & 2.00 & 0.94 & 3.07 & 3.20 & 1.24 & 9.17 & $<.001$ & 0.77 \\
\hline 15 & Autocontrol insuficiente & 2.13 & 2.00 & 0.98 & 2.98 & 3.00 & 1.26 & 9.03 & $<.001$ & 0.76 \\
\hline 16 & Búsqueda de aprobación & 2.08 & 1.80 & 1.03 & 2.75 & 2.80 & 1.25 & 6.95 & $<.001$ & 0.58 \\
\hline 17 & Negatividad/ pesimismo & 2.06 & 1.80 & 0.91 & 2.79 & 2.70 & 1.24 & 8.12 & $<.001$ & 0.68 \\
\hline \multirow[t]{2}{*}{18} & Castigo & 2.94 & 2.90 & 1.14 & 3.53 & 3.60 & 1.08 & 6.23 & $<.001$ & 0.53 \\
\hline & Puntuación total & 37.19 & 35.50 & 11.83 & 50.30 & 50.67 & 15.98 & 11.49 & $<.001$ & 0.96 \\
\hline
\end{tabular}




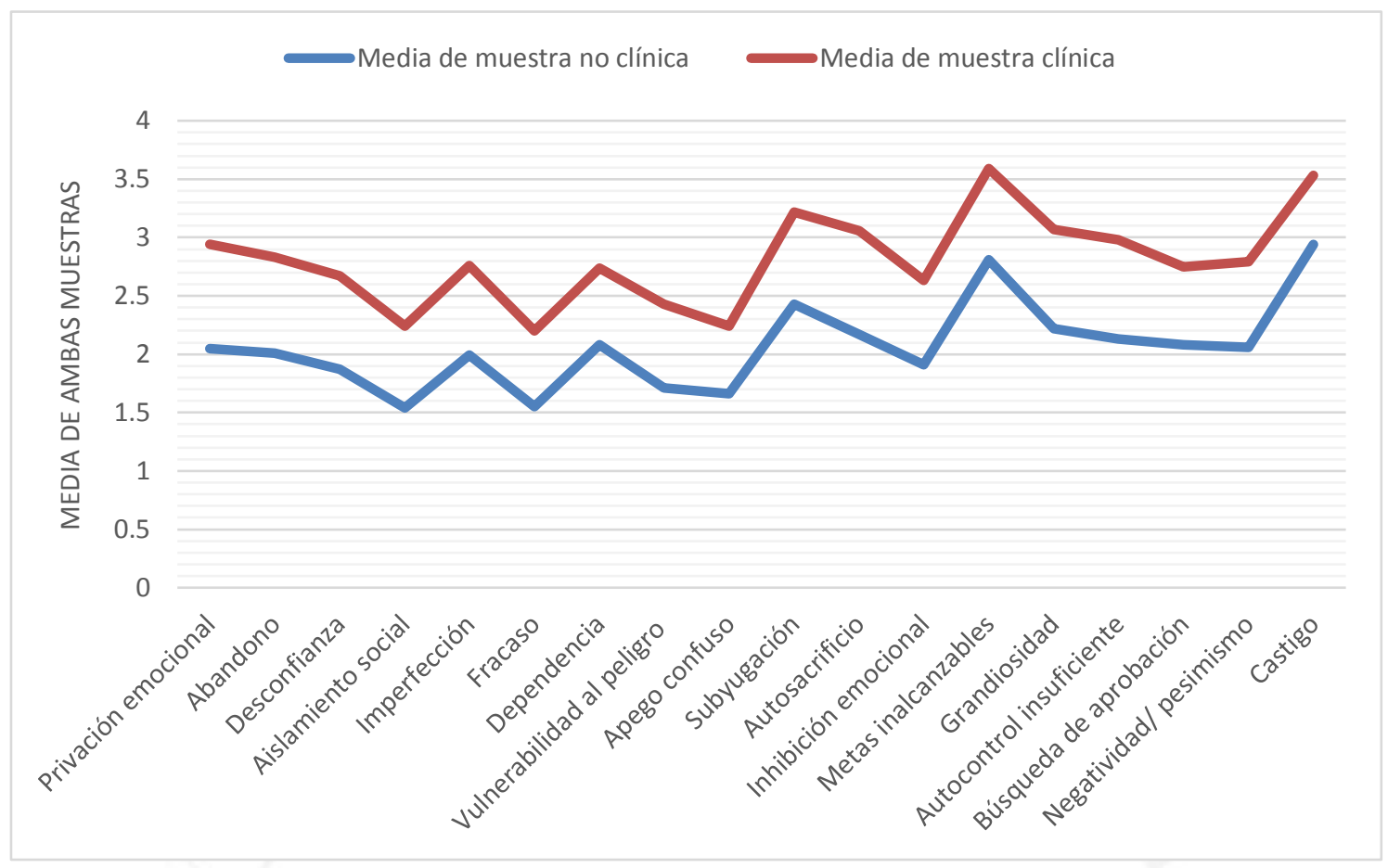

Figura 5.1. Puntuación media observada al comparar los esquemas entre el subgrupo clínico y no clínico.

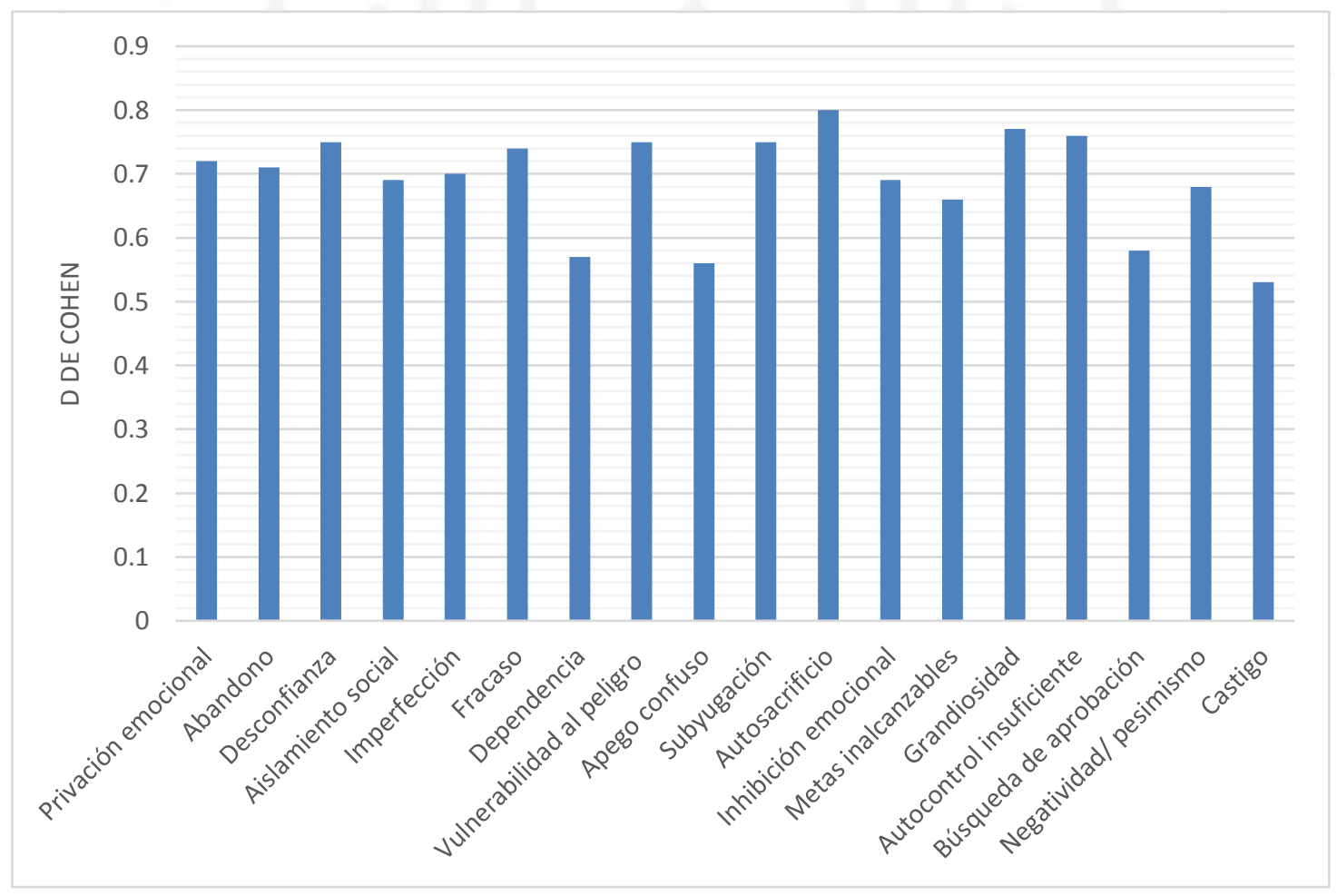

Figura 5.2. Tamaño del efecto observado al comparar los esquemas entre el subgrupo clínico y no clínico. 


\subsection{Estimación de la confiabilidad del cuestionario de esquemas de Young}

Según las recomendaciones de los Standars for Educational and Psychological Testing (American Educational Research Association, American Psychological Association y National Council on Measurement in Education, 2014), se reporta en la presente investigación el cálculo del error estándar de medida junto con el coeficiente de fiabilidad, debido a que favorece una interpretación apropiada de los resultados de los tests psicológicos (Gempp, 2006).

Cabe mencionar que el error estándar de medida se refiere a la discrepancia entre la puntuación observada y la puntuación verdadera, siendo inevitable dicha discrepancia. La presentación del error estándar de medida se expresa en las mismas unidades de escala de puntuaciones del test, permitiendo la interpretación directa; a diferencia de los coeficientes de estimación de confiabilidad. Además, permite informar a los usuarios para que lo tengan en consideración al tomar decisiones. De igual forma, complementa el objetivo del reporte de coeficiente de fiabilidad, ya que evidencia cuán libre de error se encuentra la estimación de la puntuación verdadera de la prueba (Gempp, 2006).

Dado que la confiabilidad no puede calcularse directamente, se estimó las evidencias de confiabilidad de las puntuaciones derivadas del cuestionario de esquemas mediante el coeficiente Omega (McDonald, 1999) en el programa R (R Core Team, 2013). Dicho coeficiente es apropiado para utilizarse en datos ordinales (Gadermann, Guhn y Zumbo, 2012), trabaja con cargas factoriales permitiendo cálculos más estables y no depende del número de ítems. Además, posee una adecuada medida de confiabilidad, incluso, si los valores que conforman los ítems son muy diferentes (Ventura-León y Caycho-Rodríguez, 2017).

Según Campos-Arias y Oviedo (2008), los valores de confiabilidad del coeficiente omega ubicados entre .70 y .90, se consideran aceptables. Los resultados de la tabla 5.11 muestran evidencias de confiabilidad, ya que se obtuvieron coeficientes dentro del rango antes señalado en todos los esquemas o factores. Igualmente, se presentan los valores de error estándar de medida, respecto a las puntuaciones medias obtenidas de cada uno de los esquemas, ubicados entre .27 y .57 . Estos valores podrían ser empleados para calcular los intervalos de confianza de las puntuaciones observadas y que pudiera aproximarnos a las puntuaciones verdaderas (Gempp, 2006). 


\section{Tabla 5.11}

Coeficiente omega para los 18 esquemas de primer orden del YSQ-S3

\begin{tabular}{|c|c|c|c|}
\hline & Esquema & Coeficiente Omega & Error Estándar de Medida \\
\hline 1 & Privación Emocional & .88 & .46 \\
\hline 2 & Abandono/Inestabilidad & .89 & .41 \\
\hline 3 & Desconfianza/Abuso & 90 & .37 \\
\hline 4 & Aislamiento social & .87 & .40 \\
\hline 5 & Imperfección/Vergüenza & .89 & .39 \\
\hline 6 & Fracaso & .92 & .27 \\
\hline 7 & Dependencia/Incompetencia & .85 & .48 \\
\hline 8 & Vulnerabilidad al Peligro o a la Enfermedad & .86 & .40 \\
\hline 9 & Apego Confuso/Yo Inmaduro & .84 & .44 \\
\hline 10 & Subyugación & .82 & .49 \\
\hline 11 & Autosacrificio & .85 & .47 \\
\hline 12 & Inhibición Emocional & .89 & .37 \\
\hline 13 & Metas Inalcanzables & .79 & .57 \\
\hline 14 & Grandiosidad & .82 & .51 \\
\hline 15 & Autocontrol Insuficiente/Autodisciplina & .84 & .49 \\
\hline 16 & Búsqueda de Aprobación & .82 & .51 \\
\hline 17 & Negatividad/Pesimismo & .87 & .42 \\
\hline 18 & Castigo & .87 & .41 \\
\hline
\end{tabular}




\section{CAPÍTULO VI: DISCUSIÓN}

El presente estudio examinó las propiedades psicométricas, específicamente, las evidencias de validez vinculadas al contenido, a la estructura interna y a las relaciones con otras variables; así como, la estimación de la confiabilidad de la versión española del YSQ-S3 en una muestra mixta peruana de 562 personas, 57.65\% (muestra clínica) y 42.35\% (muestra no clínica).

En lo que concierne a las evidencias de validez vinculadas al contenido, se siguió con los lineamientos estipulados en los estándares para pruebas educativas y psicológicas (AERA, APA y NCME, 2014), que indican que la adaptación de las pruebas deben tener equivalencia de medición y, a su vez, esto requiere que las pruebas estén captando construcciones equivalentes, tengan características y propiedades de medición similares, $\mathrm{y}$, que se administren en condiciones de prueba equivalentes.

Para la evidencia de equivalencia de constructo, se buscó la valoración de jueces expertos que midieran el grado de representación del ítem al dominio, considerando los criterios de: representación del dominio, relevancia en el dominio y claridad en la redacción (Sireci y Faulkner-Bond, 2014). Dichos expertos indicaron la modificación de 4 ítems $(9,25,55$ y 69), debido a que no cumplían con el criterio de claridad en la redacción. Esto guarda correspondencia con lo indicado por Ercikan y Lyons-Thomas (2013) ya que se debe considerar las modificaciones lingüísticas debido a la autenticidad cultural y el lenguaje del grupo cultural objetivo, al momento de realizar una adaptación de un instrumento psicológico. En su mayoría, las palabras que se cambiaron fueron verbos en su conjugación subjuntivo imperfecto: "escuchase", "comprendiese", "guiase", etc.; por verbos en su conjugación subjuntivo presente: "escuche", "comprenda", "guíe". Además, los expertos tuvieron en consideración la extensión de las oraciones, ya que, en su consideración, tenían que ser lo más concisas y simples de comprender al ser un cuestionario aplicado, también, a un subgrupo clínico. De igual forma, consideraron las características de medición de la prueba y la revisión en las instrucciones iniciales.

Una vez que se modificó los ítems señalados, se procedió a solicitar la revisión de los ítems, requiriendo su conformidad y se obtuvo un consenso homogéneo de aceptación 
entre los jueces expertos; conllevando a la aplicación de dicho cuestionario de ítems modificados.

En cuanto a las evidencias de validez vinculadas a la estructura interna, se realizó mediante un análisis factorial confirmatorio, empleando el método de mínimos cuadrado ponderados con corrección de medias y varianzas (WLSMV). Los índices de ajuste global del modelo empleados fueron CFIr, TLIr, RMSEAr y SRMRr, en su versión robusta; con el fin de comparar 5 modelos teóricos.

En base a investigaciones anteriores, se buscó replicar varios modelos, entre ellos, la estructura factorial original (Young, 2005); así como, el modelo de una estructura factorial del cuestionario de esquemas, en su versión reducida, de Calvete et al. (2013), quien realizó estudios de las propiedades psicométricas de la traducción oficial en español del cuestionario de esquemas.

El modelo con mejor ajuste fue el modelo 5 (Young, 2005) que corresponde a una estructura de 18 factores de primer orden, el cual se deriva del modelo original. Este hallazgo es respaldado por el reciente estudio realizado en Chile (Quiñones et al., 2018), país fronterizo, quienes obtuvieron resultados similares a la presente investigación. Sus datos recolectados de una muestra mixta replicaron la estructura factorial de 18 esquemas desadaptativos. Esto concuerda con lo revisado en la literatura de investigaciones que han examinado las propiedades psicométricas del YSQ-S3 y, en su mayoría, confirman la estructura factorial de primer orden tanto en estudios occidentales como orientales (Bach et al., 2015; Hawke y Provencher, 2012; Kriston et al., 2013; Lee et al., 2015; Lyrakos, 2014; Quiñones et al., 2018; Rijo, 2009; Sardarzadeh, 2018). Sin embargo, algunas investigaciones tuvieron dificultades para encontrar índices de ajuste aceptable para el modelo de primer orden (Hawke y Provencher, 2012; Kriston et al. 2013; Lee et al., 2015; Oettingen et al., 2017; Rijo, 2009; Sakulsriprasert et al., 2016).

Además, la teoría de esquemas sugiere cinco dominios de segundo orden (Young y Klosko, 2001); no obstante, se cuestiona el número de dimensiones que agruparían a los esquemas (Cid, 2015), incluso, la existencia de dichos dominios (Lockwood, 2011). Además, la composición de los dominios ha variado considerablemente entre los estudios y no existe una coincidencia exacta con la propuesta teórica original (Bach, Lockwood y Young, 2017; Cecero, Nelson y Gillie, 2004; Lee et al., 1999; Schmidt et al., 1995); excepto, la investigación llevada en Ucrania (Sardarzadeh, 2018) que confirma la 
estructura teórica original, tanto de primer como de segundo orden, en muestra no clínica. Cabe mencionar que, en la mayoría de investigaciones, donde solo utilizan muestras no clínicas, generalmente, estudiantes universitarios, se obtiene resultados más próximos a lo propuesto por la teoría de Young (1999) y, esto puede estar sustentado, dado que la creación del cuestionario se realizó en extensas muestras aleatorias y representativas de estudiantes universitarios.

De otro lado, debido a la dificultad de encontrar soluciones factoriales de segundo orden; los estudios de Alemania (Kriston, et al., 2013), Polonia (Oettingen et al., 2017), España (Calvete et al., 2013) y Dinamarca (Bach, et al., 2015) sugieren un modelo bifactor, es decir, un modelo con un factor común o genérico y factores específicos relacionados. Sin embargo, cabe la posibilidad que se pueda realizar un análisis factorial exploratorio con el fin de identificar el agrupamiento de los esquemas desadaptativos en factores secundarios, cuántos y cuáles serían; ya que, no existe investigación previa llevada a cabo en Sudamérica que explore dichos factores de la última versión del cuestionario (YSQ-S3).

En cuanto a las evidencias de validez vinculadas a las relaciones con otras variables, se observó que las puntuaciones de la media del subgrupo clínico presenta puntuaciones estadísticamente significativas más altas que las puntuaciones de la media del subgrupo no clínico en todos los esquemas y en la puntuación total del cuestionario. Dicha diferencia entre subgrupos fue de tamaño grande (Cohen, 1988); obteniendo el subgrupo clínico puntuaciones media más altas en la puntuación total de la prueba y en el esquema de Autosacrificio; en cambio, se obtuvo diferencias con un tamaño del efecto "moderado" en los esquemas restantes (Cohen, 1988). Esto es consistente con la literatura de versiones anteriores del instrumento (Bach et al., 2015; Hawke y Provencher, 2012; Kriston et al., 2013; Lyrakos, 2014; Rijo, 2009; Saariaho et al., 2009; Quiñones et al., 2018).

Dicha diferencia puede entenderse sobre la premisa que el subgrupo clínico emite respuestas extremas en la mayoría de ítems del cuestionario, es decir, responda puntuaciones altas de 5 y 6 ; ya que esto podría indicar una clara perturbación cognitiva, emocional y de interacción mantenidas en un plazo de tiempo estable. Dicho malestar psicológico experimentado, generalmente, se refleja al responder los ítems del cuestionario que abordan justamente las creencias profundamente arraigadas y aprendidas 
a muy temprana edad (Young, 1999). Por lo cual, no es lejano concebir que, dicho subgrupo, atienda a un tratamiento psicológico y/o psiquiátrico.

Sin embargo, el subgrupo no clínico, también, emite variedad en sus respuestas y, esto, se corrobora con la teoría de los esquemas que menciona que los esquemas subyacen a la psicopatología en poblaciones clínicas y no clínicas (Young y Klosko, 2001). Mas se vuelven exagerados y extremos en el subgrupo clínico, ya que prima un patrón de respuesta de puntuaciones altas en la mayoría de los ítems que evalúan los esquemas (Lee, Taylor y Dunn, 1999).

Además, es interesante observar que el subgrupo clínico tuvo una diferencia concebida como "grande" en el esquema de Autosacrificio, respecto al subgrupo no clínico. Esto podría indicarnos que las personas que conformaron la muestra del subgrupo clínico mantienen un exceso de atención por satisfacer voluntariamente las necesidades de los demás en situaciones cotidianas a expensas de la propia gratificación y que poseen una sensibilidad aguda hacia el dolor de los demás. Siendo éstas cualidades llevadas al extremo lo que marca una clara diferencia respecto al subgrupo no clínico.

De esta manera, el cuestionario, al ser capaz de distinguir la muestra clínica de la no clínica, permite su aplicación en la práctica clínica (Quiñones et al., 2018). Con ello, permite identificar experiencias tempranas negativas, las cuales suponen factores de riesgo para desarrollar cuadros clínicos, pudiendo predecir los mismos, tal como la sintomatología positiva de la esquizofrenia (Bortolon et al., 2013), lo cual permite abrir nuevos horizontes de investigaciones en relación a evidencia de validez predictiva.

En congruencia con los estándares de AERA, APA y NCME (2014) se calculó el error estándar de medida junto con el coeficiente de fiabilidad ya que favorece una interpretación apropiada de los resultados de los tests psicológicos (Gempp, 2006). Dado que la confiabilidad no puede calcularse directamente, se estimó las evidencias de confiabilidad de las puntuaciones derivadas del cuestionario de esquemas mediante el coeficiente Omega (McDonald, 1999) en el programa R (R Core Team, 2013); el cual alcanzó valores de confiabilidad del coeficiente omega ubicados entre .70 y .90, considerándolos aceptables. De igual forma, los valores de errores estándar de medición se ubicaron entre .27 y .57 para los esquemas. Este valor podría ser empleado para calcular los intervalos de confianza de las puntuaciones observadas y que pudiera aproximarnos a las puntuaciones verdaderas. 
Los hallazgos de esta investigación deben interpretarse con cautela porque no está exento de limitaciones. Primero es importante recordar que se necesita precaución para generalizar nuestros hallazgos porque el rango de edad de ambas muestras fue relativamente joven, entre 18 a 28 años de edad, conformando aproximadamente el $40 \%$ de las edades en ambas muestras.

Segundo, pudo ser posible la existencia de un sesgo o deseabilidad social de los informantes, ya que se vieron expuestos a ítems que describían ciertas características o experiencias tempranas que pudieron ser incómodas o movilizar a nivel emocional. Por ejemplo, en el caso de la muestra clínica, algunas personas sollozaron mientras respondían el cuestionario. Ante lo cual, se les brindó soporte emocional, se les indicó la posibilidad de tomar un descanso, se les recordó acerca de la naturaleza voluntaria de su participación y que podría retirarse en cualquier momento, sin que esto lo perjudique de ninguna forma. Sin embargo, optaron por continuar, en la mayoría de los casos, un total de 3 personas dejaron de continuar con su participación.

Tercero, el tiempo de ejecución de la prueba pudo ocasionar cierto cansancio o fatiga, ya que el cuestionario consta de noventa ítems y tiene una duración aproximada de veinte minutos; pudiendo influenciar en las respuestas que emitían frente a los ítems. A nuestro entender, este es el primer estudio que valida las propiedades psicométricas de la versión española del YSQ-S3 en una muestra mixta peruana, halla las evidencias de validez relacionadas a la estructura interna mediante un análisis factorial confirmatorio y estima la confiabilidad empleando el coeficiente omega.

En gran parte, de acuerdo con los hallazgos anteriores en otros países del instrumento, llegamos a la conclusión que la investigación descrita, que adaptó la traducción española oficial del cuestionario de esquemas (YSQ-S3) en una muestra mixta peruana; presenta un cuestionario adecuado que puede ser útil para los investigadores y clínicos.

En ese sentido, se fomentan oportunidades de desarrollar nuevas investigaciones tomando como referencia el presente estudio. Se podría considerar al momento de evaluar los esquemas desadaptativos tempranos mediante un cuestionario adaptado a la realidad peruana; lo cual, provee de una información más precisa al momento de tomar decisiones, considerando nuestro contexto socio-cultural. 
Así como, ser una herramienta de apoyo formativo en los profesionales de la salud mental que se formen en la terapia de esquemas y/o deseen explorar variables transdiagnósticas; con el fin de obtener una perspectiva más amplia en beneficio del tratamiento de las personas. Éstos últimos deben tener en cuenta utilizar las puntuaciones media de los esquemas y de la puntuación total de la prueba, ya que facilitan la interpretación de las puntuaciones obtenidas por los encuestados (Hawke y Provencher, 2012). Además, de tomar importancia en los ítems de cada esquema que poseen las puntuaciones más altas, entre 5 y 6, en la escala de Likert (Young y Klosko, 2001). 


\section{CONCLUSIONES}

Los resultados obtenidos nos permiten concluir los siguientes aspectos:

- En cuanto a las evidencias de validez vinculadas al contenido de la traducción española del cuestionario de esquemas (YSQ-S3), los jueces expertos recomendaron la modificación en la claridad de redacción de 4 ítems y se procedió con la aplicación de dicho cuestionario de ítems modificados.

- Las evidencias de validez relacionadas a la estructura interna de la traducción española del cuestionario de esquemas (YSQ-S3), evidenció adecuados índices de ajuste al modelo de 18 factores o esquemas de primer orden.

- Las evidencias de validez vinculadas a las relaciones con otras variables, demostró diferencias estadísticamente significativas en las puntuaciones media de ambos subgrupos; obteniendo el subgrupo clínico puntuaciones media más altas que el subgrupo no clínico en todos los esquemas y en la puntuación total del cuestionario. Dicha diferencia entre subgrupos fue de tamaño grande (Cohen, 1988) en la puntuación total de la prueba y en el esquema de Autosacrificio.

- La estimación de la confiabilidad de las puntuaciones derivadas de los ítems del cuestionario de esquemas (YSQ-S3), mediante el coeficiente omega, fue satisfactoria. 


\section{RECOMENDACIONES}

Las conclusiones abordadas nos sugieren recomendar lo siguiente:

- Se recomienda el uso del instrumento para evaluar los esquemas desadaptativos tempranos a personas mayores de 18 años, que residan en Lima Metropolitana, posean un grado de instrucción mínimo de secundaria completa, que asistan o no a consultorios externos para una atención psicológica o psiquiátrica. Para ello, considerar las puntuaciones media de cada esquema, ya que facilita la interpretación de las puntuaciones obtenidas; y, una aplicación individual.

- Se recomienda realizar otros estudios de validación del instrumento con muestras más representativas y un tipo de muestreo que permita que los resultados sean generalizables; con el fin de corroborar los hallazgos de la presente investigación.

- Sería recomendable que se realicen estudios donde se explore la estabilidad temporal del cuestionario de esquemas, en una muestra clínica o mixta, ya que existe poca información al respecto.

- Se recomienda estudiar las relaciones existentes entre los esquemas desadaptativos y los diferentes cuadros psicopatológicos; con el fin de llevar a cabo programas de prevención e intervención psicoterapéuticos.

- Se recomienda el uso de técnicas de análisis psicométricos modernos que suplen las limitaciones de técnicas antiguas, considerando la naturaleza ordinal de los datos, como el coeficiente omega para la estimación de la confiabilidad de las puntuaciones derivadas de los ítems del instrumento que se emplee.

- Se recomienda desarrollar nuevas investigaciones tomando como referencia la versión del instrumento adaptado. 


\section{REFERENCIAS}

Agudelo, D., Casadiegos, C. y Sanchez, D. (2009). Relación entre esquemas maladaptativos tempranos y características de ansiedad y depresión en estudiantes universitarios. Universitas Psychologica, 8(1), 87-104, Recuperado de: http://www.redalyc.org/pdf/647/64712168008.pdf

Aguirre, H. (2017). Esquemas maladaptativos tempranos en pacientes dependientes de sustancias psicoactivas internados en un centro de rehabilitación de Lima. (Tesis de licenciatura). Recuperado de: http://cybertesis.urp.edu.pe

Aiken, L. (1985). Three coefficients for analyzing the reliability and validity of ratings. Educational and Psychological Measurement, 45, 131-142. https://doi.org/10.1177/001316448004000419

Alarcón, R. (2008). Métodos y diseño de investigación del comportamiento (2ª ed.). Lima: Universidad Ricardo Palma.

Alfasfos, L. (2009). The early maladaptive schemas and their correlations with the psychiatric symptoms and their personality accentuations for palestianian students. (Tesis doctoral). Recuperado de http://ediss.sub.unihamburg.de/volltexte/2010/4827/pdf/ohne_appendix_printed.pdf

Álvarez, C. (2011). Adaptación del cuestionario de los esquemas de young-versión colombiana- en estudiantes de psicología. (Tesis de licenciatura). Universidad de Lima.

American Educational Research Association. (AERA), American Psychological Association (APA) y National Council of Measurement in Education (NCME). (2014). Standards for educational and psychological testing. Washington, DC: AERA.

American Psychiatric Association (APA) (2002). DSM-IV Manual diagnóstico y estadístico de los trastornos mentales. Barcelona: Masson, S. A. Recuperado de: https://psicovalero.files.wordpress.com/2014/06/manual-diagnc3b3stico-yestadc3adstico-de-los-trastornos-mentales-dsm-iv.pdf 
American Psychological Association (APA) (2014). DSM-V Manual diagnóstico y estadístico de los trastornos mentales ( $5^{\mathrm{a}}$ ed.). Madrid: Editorial Médica Panamericana S.A.

Bach, B., Simonsen, E., Christoffersen, P. y Kriston, L. (2015). The young schema questionnaire 3 short form (YSQ-S3): Psychometric properties and association with personality disorders in a danish mixed sample. European Journal of Psychological Assessment, 33(2), 134-143. https://doi.org./10.1027/1015$5759 / \mathrm{a} 000272$

Bach, B., Lee, C., Lykke, E. y Simonsen, E. (2015). How do dsm-5 personality traits align with schema therapy constructs? Journal of Personality Disorders, 30(4), 50229. https://doi.org/10.1521/pedi_2015_29_212

Bach, B., Lockwood, J. y Young, J. (2017). A new look at the schema therapy model: Organization and role of early maladaptive schemas. Cognitive Behaviour Therapy, 47(4), 328-349. http://doi.org/10.1080/16506073.2017.1410566

Banco Mundial (2018). Healing minds, changing lives: a movement for community-based mental health care in Peru - delivery innovations in a low-income community, 2013-2016 (English). Recuperado del sitio de Internet del Banco Mundial: http://documents.worldbank.org/curated/en/407921523031016762/Healingminds-changing-lives-a-movement-for-community-based-mental-health-care-inPeru-delivery-innovations-in-a-low-income-community-2013-2016

Bamelis, L., Evers, S., Spinhoven, P. y Arntz, A. (2014). Results of a multicenter randomized controlled trial of the clinical effectiveness of schema therapy for personality disorders. The American Journal of Psychiatry, 171, 305-322.

Beck, A., Rush, J., Shaw, B. y Emery, G. (1979). Terapia cognitiva de la depresión. Bilbao: Editorial Desclée de Brouwer. Recuperado de: https://books.google.com.pe

Beck, A. y Freeman, A. (1995). Terapia cognitiva de los trastornos de la personalidad. Buenos Aires: Paidós. Recuperado de 
https://tuvntana.files.wordpress.com/2015/06/beck-terapia-cognitiva-de-lostrastornos-de-personalidad.pdf

Bloom, D., Cafiero, E., Jané-Llopis, E., Abrahams-Gessel, S., Bloom, L., Fathima, S.,...Weinstein, C. (setiembre, 2011). The global economic burden of noncommunicable diseases. Trabajo presentado en el evento World Economic Forum. Recuperado de: http://www3.weforum.org/docs/WEF_Harvard_HE_GlobalEconomicBurdenNo nCommunicableDiseases_2011.pdf

Bortolon, C., Capdevielle, D., Boulenger, J., Gely-Nargeot, M y Raffard, S. (2013). Early maladaptive schemas predict positive symptomatology in schizophrenia: A crosssectional study. Psychiatry Research, 209(3), 361-366. https://doi.org/10.1016/j.psychres.2013.03.018

Calvete, E., Orue, I. y González-Diez, Z. (2013). An examination of the structure and stability of early maladaptative schemas by means of the young schema questionnaire-3. European Journal of Psychological Assessment, 29, 283-290.

Campo-Arias, A. y Oviedo, H. (2008). Propiedades psicométricas de una escala: la consistencia interna. Revista de Salud Pública, 10(5), 831-839. Recuperado de: http://www.redalyc.org/pdf/422/42210515.pdf

Caputto, I., Cordero, S., Keegan, E. y Arana, F. (2015). Perfeccionismo y esquemas desadaptativos tempranos: un estudio con estudiantes universitarios. Ciencias Psicológicas, 9(2), 245-257. Recuperado de: http://www.scielo.edu.uy/scielo.php?script=sci_arttext\&pid=S1688$42212015000300003 \& \operatorname{lng}=$ es\&tlng=es

Carranza, F. (2017). Relación entre esquemas maladaptativos tempranos y autoestima en adolescentes mujeres del $5^{\circ}$ año de secundaria en una institución educativa pública de Lima-2017. (Tesis de licenciatura). Recuperado de: http://repositorio.uap.edu.pe

Castrillón, D., Chaves, L., Ferrer, A., Londoño, N., Maestre, K, Marín, C y Schnitter, M. (2005). Validación del young schema questionnaire long form (YSQ-L2) en 
población colombiana. Revista Latinoamericana de Psicología, 37(3), 541-560. Recuperado de: http://www.redalyc.org/pdf/805/80537307.pdf

Castañeda, P. y Fernández, M. (2017). Esquemas maladaptativos tempranos y dependencia emocional en mujeres víctimas de violencia de pareja. (Tesis de licenciatura). Recuperado de: http://repositorio.uss.edu.pe

Chávez, D. (2017). Propiedades psicométricas del cuestionario de esquemas maladaptativos de young en adolescentes de otuzco. (Tesis de Licenciatura). Universidad César Vallejo. Recuperado de: http://repositorio.ucv.edu.pe

Cid, J. (2015). El Esquema como organizador de la personalidad y sus trastornos: Estudio psicométrico de la adaptación española del young schema questionnaireshort form. (Tesis doctoral, Universidad Autónoma de Barcelona). Recuperado de: http://www.tesisenred.net

Cipriano, D. (2017). Esquemas desadaptativos tempranos y dependencia emocional en estudiantes de 5to de secundaria de las instituciones educativas públicas de Nuevo Chimbote en el año 2016. (Tesis de licenciatura). Recuperado de: http://repositorio.ucv.edu.pe

Cohen, J. (1988). Statistical power analysis for the behavioral sciences. Hillsdale, NY: Lawrence Erlbaum Associates. Recuperado de: http://www.utstat.toronto.edu

De la Cruz, J. (2019). Prevalencia de los esquemas maladaptativos tempranos en adolescentes con bajo, medio y alto nivel de conducta antisocial en una institución educativa del Callao. (Tesis de licenciatura). Recuperado de: http://repositorio.unfv.edu.pe

Du Toit, S., Du Toit, M., Mels, G. y Cheng, Y. (2005). Analysis of complex survey data using Lisrel. (Unpublished report). Lincolnwood, IL: Scientific Software International, Inc.

Ercikan, K. y Lyons-Thomas, J. (2013). Adapting tests for use in other languages and cultures. En K. Geisinger, B. Bracken, J. Carlson, J. Hansen, N. Kuncel, S. Reise y M. Rodriguez (Eds.), APA handbooks in psychology. APA handbook of testing 
and assessment in psychology, Vol. 3. Testing and assessment in school psychology and education (pp. 545-569). Washington, DC, US: American Psychological Association. http://doi.org/10.1037/14049-026

Escurra, L. (1988). Cuantificación de la validez de contenido por el criterio de jueces. Revista de Psicología, 6(1-2), 103-111. Recuperado de: http://revistas.pucp.edu.pe/index.php/psicologia/article/view/4555

Forero, J. y Maydeu-Olivares, A. (2009). Estimation of IRT graded response models: Limited versus full information methods. Psychological Methods, 14(3), 275-279. https://doi.org/10.1037/a0015825

Gadermann, A., Guhn, M. y Zumbo, B. (2012). Estimating ordinal reliability for likerttype and ordinal item response data: A conceptual, empirical and practical guide. Practical Assessment, Research \& Evaluation, 17(3), 1 - 13. Recuperado de: https://pareonline.net/getvn.asp?v=17\&n=3

García, V. y Pinto, K. (2018). Estilos de socialización parental y esquemas desadaptativos tempranos en adolescentes de 4to y 5to de secundaria de instituciones educativas estatales del distrito de Characato y Sabandía. (Tesis para obtener el título de licenciado en Psicología). Universidad Nacional de San Agustín. Recuperado de: http://repositorio.unsa.edu.pe

Gempp, R. (2006). El error estándar de medida y la puntuación verdadera de los tests psicológicos: Algunas recomendaciones prácticas. Terapia Psicológica, 24(2), 117-129. Recuperado de: http://www.redalyc.org/html/785/78524201/

Grebot, E., y Dardard, J. (2010). Cognitive schemas, addictive beliefs and defenses in cannabis addiction in young adults. Psychologie Française, 55(4), 373-387. https://doi.org/10.1016/j.psfr.2010.09.002

Haaland, A., Vogel, P., Launes, G., Haaland, V., Hansen, B., Solem, S....Himle, J. (2011). The role of early maladaptative schemas in predicting exposure and response prevention outcome for obsessive-compulsive disorder. Behaviour Research and Therapy, 49(11), 781-788. https://doi.org/10.1016/j.brat.2011.08.007 
Hawke, L., Provencher, M. y Arntz, A. (2011). Early maladaptive schemas in the risk for bipolar spectrum disorders. Journal of Affective Disorders, 133, 428-436. Recuperado de: https://www.ncbi.nlm.nih.gov/pubmed/21621272

Hawke, L. y Provencher, M. (2012).The canadian french young schema questionnaire: confirmatory factor analysis and validation in clinical and nonclinical samples. Canadian Journal of Behavioural Science, 44(1), 40-49. https://doi.org/10.1037/a0026197

Hernández, R., Fernández, C., y Baptista, M. (2014). Metodología de la investigación (6a ed.). México D. F: McGraw-Hill.

Hilario, J. (2016). Adaptación y propiedades psicométricas del cuestionario de esquemas de Young-forma abreviada (YSQ-SF) en universitarios de villa el salvador. (Tesis de licenciatura, Universidad Autónoma del Perú). Recuperado de: http://studylib.es/doc/8093480/hilario-sanez---repositorio-de-la-universidadaut\%C3\%B3noma-del

Holguin, J. (2018). Esquemas maladaptativos tempranos e insatisfacción corporal en estudiantes de una institución educativa nacional de Trujillo. (Tesis de licenciatura). Recuperado de: http://repositorio.upn.edu.pe

Hu, L. y Bentler, P. (1999). Cut-off criteria for fit indexes in covariance structure analysis: Conventional criteria versus new alternatives. Structural Equation Modeling, 6(1), 1-55. https://doi.org/10.1080/10705519909540118

Huerta, R., Ramírez, N., Ramos, J., Murillo, L., Falcón, C., Misare, M. y Sánchez, J. (2016). Esquemas cognitivos disfuncionales y dependencia emocional en mujeres con y sin violencia en la relación de pareja de la ciudad de Lima. Revista de Investigación en Psicología, 19(2), 145-162. Recuperado de: http://revistasinvestigacion.unmsm.edu.pe/index.php/psico/article/view/12895

International Business Machines Corporation. (2017). IBM SPSS statistics for windows (Version 25.0) [Computer software]. Recuperado de: https://www.ibm.com/pees/analytics/spss-statistics-software

Instituto de análisis y comunicación "Integración" (30 de noviembre de 2016). 80\% de peruanos con problemas de salud mental no son atendidos [Mensaje en un Blog]. Recuperado de: http://www.integracion.pe/data-2016-salud/ 
Iturregui, C. (2017). Esquemas disfuncionales tempranos y dependencia emocional en estudiantes universitarios de Lima Norte - 2017. (Tesis de licenciatura). Recuperado de: http://repositorio.upch.edu.pe

Jones, C., Leung, N. y Harris, G. (2007). Dysfunctional core beliefs in eating disorders: A review. Journal of Cognitive Psychotherapy, 21(2), 156-171. Recuperado de: https://www.researchgate.net/publication/233511232_Dysfunctional_Core_Belie fs_in_Eating_Disorders_A_Review

Kane, M. (2006). Validation. En R. L. Brennan (Eds.), Educational measurement, (4 ed., pp. 17-64). Wesport, CT: American Council on Education y Praeger Publishers.

Kantona, Z. y Körmendi, A. (2012). Examination of the young maladaptive schemes in a group of gamblers Anonymous. Psychiatria Hungarica, 27(6), 435-445. Recuperado de: https://www.ncbi.nlm.nih.gov/pubmed/23429338

Kass, R. y Tinsley, H. (1979). Factor analysis. Journal of Leisure Research, 11, 120-138. Recuperado de: https://www.researchgate.net/publication/279590384_Factor_Analysis

Khosravi, S., Ebrahimi, M., Shayan, A., Havasian, M. y Jamshidi, F. (2017). Investigation of early maladaptive schemas in patients with bipolar disorder compared to healthy individuals. Journal of Pharmaceutical Sciences and Research, 9(6), 771774. Recuperado

de: http://jpsr.pharmainfo.in/Documents/Volumes/vol9Issue06/jpsr09061703.pdf

Kriston, L., Schäfer, J., Jacob, G., Härter, M., y Hölzel, L. (2013). Reliability and validity of the German version of the Young Schema Questionnaire - Short Form 3 (YSQS3). European Journal of Psychological Assessment, 29(3), 205-212. https://doi.org/10.1027/1015-5759/a000143

Lee, C., Taylor, G. y Dunn, J. (1999). Factor structure of the schema questionnaire in a large clinical sample. Cognitive Therapy and Research, 23, 441-451.

Lee, S., Choi, Y., Rim, H., Won, S. y Lee, D. (2015). Reliability and validity of the korean young schema questionnaire-short form-3 in medical students. Psychiatry Investigation, 12(3), 295-304. https://doi.org/10.4306/pi.2015.12.3.295. 
León, K. y Sucari, C. (2012). Adaptación del cuestionario de esquemas de young en adolescentes de dos distritos de Lima sur. (Tesis de licenciatura). Universidad Femenina del Sagrado Corazón.

Li, C. (2014). The performance of MLR, USLMV and WLSMV estimation in structural regression models with ordinal variables. (Tesis doctoral). Recuperado de: https://d.lib.msu.edu/etd/3268

Lochner, C., Seedat, S., du Toit, P., Nel, D., Niehaus, D., Sandler, R. y Stein, D. (2005). Obsessive-compulsive disorder and trichotillomania: a phenomenological comparison. BMC Pyschiatry, 5(2), 2-12. https://doi.org/10.1186/1471-244X-5-2.

Lockwood, G. (12 de febrero de 2011). Do schema domains exist? [Mensaje de un Blog]. Recuperado de: http://www.isst-online.com/node/226

Londoño, N., Schnitter, M., Marín, C., Calvete, E., Ferrer, A., Maestre, K.,...Castrillón, D. (2012). Young schema questionnaire-short Form : validación en Colombia. Universitas Psychologica, 11(1), 147-164. Recuperado de http://revistas.javeriana.edu.co/index.php/revPsycho/article/view/641

López, A., Cid, J., Obst, J., Rondón, J., Alfano, S., y Cellerino, C. (2011). Guías esquematizadas de tratamiento de los trastornos de la personalidad para profesionales, desde el modelo de Young, Klosko y Wheishar (2003). Ciencias Psicológicas, $\quad 5(1), \quad 83-115 . \quad$ Recuperado de http://www.scielo.edu.uy/pdf/cp/v5n1/v5n1a08.pdf

López, A., Rondón, J., Alfano, S. y Cellerino, C. (2012). Relaciones entre esquemas tempranos inadaptados y afectividad positiva y negativa. Ciencias Psicológicas, 6(2), 149-173. Recuperado de: http://www.scielo.edu.uy/scielo.php?script=sci_arttext\&pid=S1688$42212012000200005 \& \operatorname{lng}=$ es\&tlng=es

Lyrakos, D. (2014). The validity of young schema questionnaire 3rd version and the schema mode inventory 2nd version on the greek population. Psychology, 5(5), 461-477. https://doi.org/10.4236/ psych.2014.5505. 
Malacas, C. (2013). Esquemas Disfuncionales Tempranos en Consumidores de Sustancias Psicoactivas Internados en Comunidades Terapéuticas. (Tesis de licenciatura, Universidad Nacional Federico Villareal). Recuperado de: https://www.researchgate.net/publication/327829619_Esquemas_Disfuncionales _Tempranos_en_Consumidores_de_Sustancias_Psicoactivas_Internados_en_Co munidades_Terapeuticas

McDonald, R. (1999). Test theory: A unified treatment. Mahwah: Lawrence Erlbaum.

Navarro, M. (2009). Métodos y diseños de investigación. Tema 2: Metodología de investigación en psicología. Recuperado de: http://ocw.uv.es/ciencias-sociales-yjuridicas/metodos/2/112329-2metodo.pdf

Newsom, J. (2015). Practical approaches to dealing with nonnormal and categorical variables definitions and distinctions. En G.R. Hancock y R.O. Mueller (Eds.), Structural equation modeling (pp. 439-492). Charlotte, NC: Information Age.

Nilsson, K., Nielsen, K. y Halvorsen, M. (2015). Early maladaptive schemas: a comparison between bipolar disorder and major depressive disorder. Clinical Psychology \& Psychotherapy, 22(5), 387-391. https://doi.org/10.1002/cpp.1896

Nordahl, H., Holthe, H. y Haugum, J. (2005). Early maladaptive schemas in patients with or without personality disorders: Does schema modification predict symptomatic relief? Clinical Psychologyand Psychotherapy, 12,142-149. Recuperado de: https://onlinelibrary.wiley.com/doi/abs/10.1002/cpp.430

Ochoa, C. (16 de abril de 2015). Muestreo probabilístico: muestre estratificado [Mensaje en un Blog]. Recuperado de: https://www.netquest.com/blog/es/blog/es/muestreo-probabilistico-muestreoestratificado

Oettingen, J., Chodkiewicz, J., Mącik, D. y Gruszczyńska, E. (2017). Polish adaptation of the young schema questionnaire short form (YSQ-S3-PL). Psychiatria Polska, 1(82), 1-12. https://doi.org/10.12740/PP/OnlineFirst/76541. 
Organización Mundial de la Salud (2011). Atlas de salud mental 2011. Recuperado del sitio de Internet de la Organización Mundial de la Salud: http://aen.es/wpcontent/uploads/2011/10/AtlasOMS_SM2011.pdf

Organización Mundial de la Salud (2013). Plan de acción sobre salud mental 2013-2020. Recuperado del sitio de Internet de la Organización Mundial de la Salud: http://apps.who.int/iris/bitstream/10665/97488/1/9789243506029_spa.pdf

Pullido, D. (2015). Factores sociodemográficos y de salud, esquemas maladaptativos y satisfacción/ insatisfacción con la imagen corporal como predictores de la aceptación de cirugías plásticas estéticas (Tesis de Maestría). Recuperado de: https://repository.ucatolica.edu.co/handle/10983/2268

Püras, D. (mayo, 2015). Informe del relator especial sobre el derecho de toda persona al disfrute del más alto nivel possible de salud física y mental, Adicción: Visita a Malasia. Trabajo presentado en la Asamblea General de las Naciones Unidas, Malasia. Recuperado de: http://www.refworld.org.es/docid/5576e28d4.html

Quiñones, A., Ramírez, P., Cid, J., Melipillán, R., Ugarte, C. y Florenzano, R. (2018). Cuestionario de esquemas de young CEY-S3: Propiedades psicométricas en una muestra chilena mixta. Terapia Psicológica, 36(3), 144-155. Recuperado de: https://scielo.conicyt.cl/scielo.php?script=sci_arttext\&pid=S071848082018000300144

R Core Team. (2013). R: A language and environment for statistical computing (Version 3.6.0) [Computer software]. Recuperado de: http://www.R-project.org/.

Rijkeboer, M. y Van den Bergh, H. (2006). Multiple group confirmatory factor analysis of the young schema-questionnaire in a dutch clinical versus non-clinical population. Cognitive Therapy and Research, 30, 263-278. https://doi.org/10.1007/s10608-006-9051-8

Rijo, D. (2009). Esquemas mal-adaptativos precoces. Validação do conceito e dos métodos de avaliação. (Tesis doctoral). Recuperado de: https://estudogeral.sib.uc.pt/handle/10316/18486 
Rodríguez, E. (2009). The scheme therapy of Jeffrey Young. Avances en Psicología Latinoamericana, 17(1), 59-74. Recuperado de: http://www.unife.edu.pe/pub/revpsicologia/edgarrodriguez.pdf

Saariaho, T., Saariaho, A., Karila, I. y Joukamaa, M. (2009). The psychometric properties of the finnish young schema questionnaire in chronic pain patients and a nonclinical sample. Journal of Behavior Therapy and Experimental Psychiatry, 40(1), 158-68. https://doi.org/10.1016/j.jbtep.2008.07.005

Saavedra, Y. (2018). Esquemas emocionales y síntomas depresivos en mujeres víctimas de violencia de pareja de la ciudad de Chiclayo. (Tesis de licenciatura). Recuperado de: http://repositorio.uss.edu.pe/handle/uss/4774

Sakulsriprasert, C., Phukao, D., Kanjanawong, S., y Meemon, N. (2016). The reliability and factor structure of thai young schema questionnaire-short form 3. Asian Journal of Psychiatry, 24, 85-90. https://doi.org/10.1016/j.ajp.2016.09.011

Salvatierra, N. (2018). Esquemas desadaptativos tempranos y agresividad en estudiantes de secundaria de instituciones educativas públicas del distrito de Carabayllo, 2017. (Tesis de licenciatura). Recuperado de: http://repositorio.ucv.edu.pe

Sandín, B., Chorot, P., y Valiente, R. (2012). Transdiagnóstico: Nueva frontera en psicología clínica. Revista de Psicopatología y Psicología Clínica, 17(3), 185203. https://doi.org/10.5944/rppc.vol.17.num.3.2012.11839

Sardarzadeh, S. (2018). Reliability and validity of the ukrainian version of the young schema questionnaire - shor form 3 (YSQ-S3). Advances in Sciences and Humanities, 4(4), 56-61. https://doi.org/10.11648/j.ash.20180404.11

Saritas, D. y Gençöz, T. (2011). Psychometric properties of young schema questionnaireshort form 3 in turkish adolescent sample. Journal of Cognitive and Behavioral Psychoterapies, 11(1), 83- 96. Recuperado de: https://www.researchgate.net

Schmidt, N., Joiner, T., Young, J. y Telch, M. (1995). The schema questionnaire: investigation of psychometric properties and the hierarchical structure of a measure of maladaptive schemas. Cognitive Therapy and Research, 19, 295-321. https://doi.org/10.1007/BF02230402. 
Shah, R. y Waller, G. (2000). Parental style and vulnerability to depression: The role of core beliefs. The Journal of Nervous and Mental Disease, 188(1), 19-25. Recuperado de: https://www.researchgate.net/publication/317577405_Early_trauma_experiences _parenting_styles_and_personality_patterns_in_individuals_with_depression_fr om_India

Sireci, S. y Faulkner-Bond, M. (2014). Validity evidence based on test content. Psicothema, 26(1), 100-107. Recuperado de: http://www.redalyc.org/articulo.oa?id=72729538016

Soygüt, G., Karaosmanoglu, A. y Çakir, Z. (2009). Assessment of early maladaptative schemas: a psychometric study of the Turkish young schema questionnaire-short form-3. Turk Psikiyatri Dergisi 20(1), 75-84. Recuperado de: https://www.ncbi.nlm.nih.gov/pubmed/19306129

Unoka, Z., Tölgyes, T., Czobor, P. y Simon, L. (2010). Eating disorder behavior and early maladaptive schemas in subgroups of eating disorders. The Journal of Nervous and Mental Disease, 198(6), 425-431. https://doi.org/10.1097/NMD.0b013e3181e07d3d

Vargas, R. (2008). Estadística II. Recuperado de: http://www.esap.edu.co

Ventura-León, J. y Caycho-Rodríguez, T. (2017). El coeficiente Omega: un método alternativo para la estimación de la confiabilidad. Revista Latinoamericana de Ciencias Sociales, Niñez y Juventud, 15(1), 625-627. Recuperado de: http://www.redalyc.org

Voderholzer, U., Schwartz, C., Thiel, N., Kuelz, A., Hartmann, A., Scheidt, C.,...Zeeck, A. (2014). A comparison of schemas, schema modes and chilhood traumas in obsessive-compulsive disorder, chronic pain disorder and eating disorders. Psychopathology, 47(1), 24-32. https://doi.org/10.1159/000348484. Recuperado de: https://www.ncbi.nlm.nih.gov/pubmed/23689753

Wegener, I., Alfter, S., Geiser, F., Liedtke, R. y Conrad, R. (2013). Schema change without schema therapy: The role of early maladaptive schemata for a successful 
treatment of major depression. Psychiatry 76(1), 1-17. Recuperado de: https://www.researchgate.net

Young, J. (1999). Cognitive therapy for personality disorders: a schema-focused approach ( $3^{\mathrm{a}}$ ed.). Sarasota, FL: Profesional Resource Exchange.

Young, J. y Klosko, J. (2001). Reinventa tu vida. Barcelona: Paidós.

Young, J. (2005). Young schema questionnaire - short form 3 (YSQ-S3). New York: Schema Therapy Institute.

Young, J. y Klosko, J. (2007). Terapia de esquemas: Tratado de los trastornos de la personalidad. https://doi.org/10.22235/cp.v5i1.102

Young, J., Klosko, J. y Weishaar, M. (2015). Terapia de esquemas. Guía práctica. Bilbao: Desclée de Brouwer. 


\section{APÉNDICES}

Apéndice 1: Permiso del autor de la prueba original 


\section{Requesting authority}

Schema Therapy Online Support <support@schematherapy.com>

22 de agosto de $2017,14: 36$

Para: Andrea Alessandra Matute Cruces <20121937@aloe.ulima.edu.pe>

Cc: "CC: Mail" <admin@schematherapy.com>

Dear Andrea,

Dr. Young grants you permission to use the official Spanish translation of the YSQ-S3 for your research.

You cannot adapt the original English version yourself, since we have already granted Dr. Cid sole permission for the official Spanish translation. However, we will make sure that you obtain Dr. Cid's translation of the YSQ-S3 as quickly as possible.

Please contact me if you have not received the Spanish translation by September 10, 2017. We apologize for any inconvenience this delay causes for you.

Best wishes,

Sylvia Tamm

Executive Administrator

Schema Therapy Institute

support@schematherapy.com 


\section{Apéndice 2: Permiso del traductor oficial}

\section{Requesting authority}

Jordi Cid <jordi.cid@telefonica.net>

Para: Andrea Alessandra Matute Cruces <20121937@aloe.ulima.edu.pe>

13 de septiembre de $2017,1: 01$

Apreciada Andrea,

Siento la demora, entre mi trabajo donde voy bastante desbordado y mis vacaciones no se lo he podido mandar antes. Te envio el CEY-S3 y la rejilla de corrección del CEY-S3.

Te envío documento de uso de del CEY-S3 que me debes mandar rellenado y firmado. Es un documento que te autoriza al uso del CEY-S3. En el caso que para el proyecto de investigación que vas a realizar necesitas una carta/documento más formal para presentar a la universidad, no dudes en decirmelo, ya que entonces te haré una carta de conformidad para su uso del CEY-S3 con mi firma.

En breve te mando el resto de documentación requerida. No dudes en consultarme cualquier aspecto relacionado con el trabajo de investigación, será un placer ayudarte en lo que pueda.

Cordialmente,

Jordi Cid

De: Andrea Alessandra Matute Cruces [mailto:20121937@aloe.ulima.edu.pe]

Enviado el: miércoles, 13 de septiembre de 2017 7:25

Para: Jordi Cid

Asunto: Fwd: Requesting authority

[El texto citado está ocuito]

Libre de virus. www.avast.com

\section{3 archivos adjuntos}

iv] Información_Uso_CEY_Young.doc

$28 \mathrm{~K}$

- YSQ S3_Rejilla_puntuacion.pdf

$15 \mathrm{~K}$

2 YSQ_3_VESP.pdf

$116 \mathrm{~K}$ 


\section{Apéndice 3: Permiso a directora de hospital "Víctor Larco Herrera"}
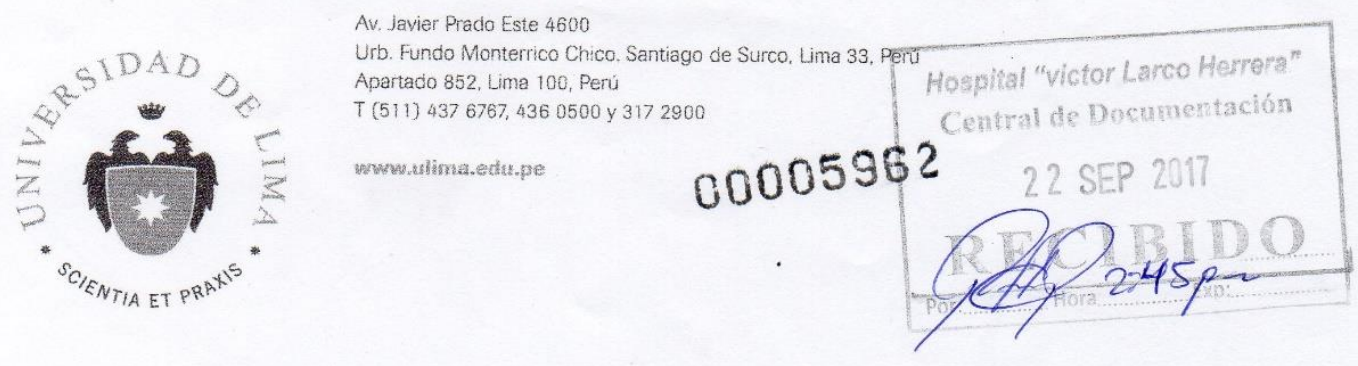

Lima, 21 de septiembre de 2017

Señora Médico

Noemi Angelica Collado Guzman

Directora General

Hospital Victor Larco Herrera

Presente

De mi consideración:

Es grato dirigirme a usted para presentarle a la Sita. ANDREA ALESSANDRA MATUTE CRUCES (código 20121937), alumna de la Carrera de Psicología de la Universidad de Lima, quien como parte de su proyecto de tesis titulado "Propiedades psicométricas de la tercera edición del cuestionario de esquema de Young - forma abreviada en pacientes clínicos de Lima Metropolitana", requiere aplicar dicho cuestionario (YSQ-S3 traducción en español), en una muestra clinica de 320 personas dentro de las instalaciones del hospital Victor Larco Herrera.

Dichos pacientes deberán cumplir con los cuadros clinicos del Eje I y II, de acuerdo al DSM - IV, es decir que posean trastornos mentales y de personalidad. Los criterios de exclusión serán personas que posean algún grado de retardo mental u orgánico.

El proceso de esta investigación será revisado por la profesora Sandra Inurritegui, docente la asignatura Seminario de Investigación II.

Hago propicia la ocasión para expresarle un cordial saludo.

Atentamente,

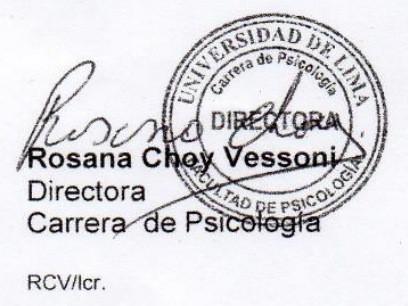




\section{Apéndice 4: Consentimiento informado}

La presente investigación es conducida por Andrea Matute Cruces, estudiante de último año de Psicología de la Universidad de Lima. El propósito de este estudio es analizar las características de un cuestionario que examina las diferentes formas de pensar en las personas. Si usted accede a participar en este estudio, se le pedirá responder unas afirmaciones que se les presentará en un cuestionario. Esto tomará aproximadamente 20 minutos de su tiempo.

Recuerde que su participación durante todo el proceso es completamente voluntaria e igualmente, puede retirarse de la misma en cualquier momento sin que eso lo perjudique de ninguna forma.

Los resultados obtenidos en este estudio serán confidenciales, tienen un fin estrictamente académico y de investigación, por ello es importante que responda con la mayor sinceridad posible. Si tiene alguna duda en alguno de los enunciados, puede preguntar en cualquier momento.

Para participar, usted debe:

- Residir en Lima - Perú.

- Encontrarse en un rango de edad entre 18 y 60 años.

- Tener como mínimo un grado de instrucción de secundaria completa.

Si usted tiene alguna duda o deseas mayor información con respecto a la investigación, puedes escribir a: 20121937@aloe.ulima.edu.pe. A través de este medio se te contestará gustosamente.

Desde ya le agradezco su participación.

Luego de haber sido informado(a):

- Confirmo que he leído y comprendido la información para participar en la investigación de Andrea Matute Cruces.

- Entiendo que mi participación es voluntaria y que soy libre de retirarme en cualquier momento de la investigación.

- Entiendo que los datos que proporcione durante este estudio serán confidenciales.

- Estoy de acuerdo en permitir que los datos recogidos se utilicen con fines académicos.

Nombre del Participante

Firma del Participante

Fecha 


\section{Apéndice 5: Ficha sociodemográfica}

Sexo: $M(） \quad F(\quad)$

Edad (años cumplidos):

Grado de instrucción (más alto concluido):

Primaria

Secundaria

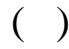

Técnica

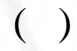

Universitaria

Posgrado

Actualmente, ¿recibes tratamiento psiquiátrico (prescripción de fármacos)?

Si

No ( )

Si la respuesta anterior es "sí", indique el tiempo que toma la medicación en años y meses.

Año (s)

Mes (es)

Actualmente, ¿recibes tratamiento psicológico?

Sí ( ) No ( )

Si la respuesta anterior es "sí", indique el tiempo que recibe el tratamiento psicológico.

Año (s)

Mes (es) 


\title{
Apéndice 6: Cuestionario de esquemas (traducción española)
}

\author{
CEY-S3 \\ Young J. \\ [Adaptación Española de Cid, J. y Torrubia, R.]
}

Nombre

Fecha 1

Instrucciones: A continuación encontrará una lista de frases que una persona puede utilizar para describirse a sí misma. Por favor, lea cada frase y decida el grado de exactitud con que te describe durante el último año. Cuando no esté seguro, basa su respuesta en lo que emocionalmente sienta no en lo que piense que es verdad.

Algunas frases hacen referencia a las relaciones con sus padres o con sus parejas. Si alguna de las personas ha fallecido, por favor responda a esos ítems basándose en sus relaciones cuando estaban vivas. Si en la actualidad no tiene pareja pero tuvo parejas en su pasado, por favor responda al ítem basándose en la relación de pareja más reciente y significativa.

Escoja la puntuación más elevada desde 1 a 6 que le describe y escriba el número en el espacio que se encuentra antes de la frase:

\section{ESCALA DE PUNTUACIONES}

\begin{tabular}{|llll|}
\hline $\mathbf{1}=$ & Totalmente falso & $\mathbf{4}=$ & En ocasiones verdadero \\
$\mathbf{2}=$ & La mayoría de veces falso & $\mathbf{5}=$ & La mayoría de veces verdadero \\
$\mathbf{3}=$ & Más verdadero que falso & $\mathbf{6}=$ & Me describe perfectamente \\
\hline
\end{tabular}
1.
La mayor parte de mi vida, no he tenido a nadie que me cuide, con quién compartir o que se preocupe verdaderamente de las cosas que me ocurren.
2. Me siento aferrado a las personas a las que estoy muy unido porque tengo miedo de que me abandonen.
3. _ Presiento que la gente se aprovechará de mí.
4. __ No me aceptan en ningún lugar.
5. _ Ningún hombre/mujer que yo desee podría amarme cuando viese mis defectos.
Casi nada de lo que hago en el trabajo (o en la escuela) está tan bien hecho como lo que otras personas pueden hacer.
7. _ _ No me siento capaz de arreglármelas por mí mismo en las cosas de cada día.
8. _ N No puedo escapar a la sensación de que algo malo va a ocurrir.
9. $\quad$ No he sido capaz de independizarme de mis pad $\quad$ personas de mi edad parecen haberlo hecho.
10. Pienso que si hago lo que quiero, sólo me encontraré problemas.
11. Soy el que normalmente acabo cuidando de las personas cercanas a mí 


\begin{tabular}{|llll|}
\hline $1=$ & Totalmente falso & $\mathbf{4}=$ & En ocasiones verdadero \\
$\mathbf{2}=$ & La mayoría de veces falso & $\mathbf{5}=$ & La mayoría de veces verdadero \\
$\mathbf{3}=$ & Más verdadero que falso & $\mathbf{6}=$ & Me describe perfectamente \\
\hline
\end{tabular}

12.

13.

14.

15.

16.

17.

18.

19.

20.

21.

22.

23.

24.

25.

26.

27.

28.

29.

30.

31.

32.

Soy demasiado tímido para expresar sentimientos positivos hacia los demás (p. ej., afecto, preocupación...).

Tengo que ser el mejor en la mayoría de las cosas que hago; no puedo aceptar ser el segundo mejor.

Me es muy difícil aceptar un "no" como respuesta cuando quiero algo de los demás.

Parece que no pueda disciplinarme para acabar tareas rutinarias o aburridas.

Tener dinero y conocer a personas importantes me hace sentir valioso.

Incluso cuando las cosas parecen ir bien, siento que es una cosa temporal.

Si cometo un error, merezco ser castigado.

En general, las personas no han estado a mi lado para darme cariño, apoyo y afecto.

Necesito tanto a los demás que me preocupa perderlos.

Siento que no puedo bajar la guardia cuando estoy con otras personas, si no ellos me harán daño intencionadamente.

Soy básicamente diferente de las otras personas.

Nadie que yo desee, querría estar cerca de mí si me conociese realmente.

Soy incompetente cuando se trata de rendir en cualquier tarea.

Me veo a mí mismo como una persona dependiente, en lo que se refiere al funcionamiento de cada día.

Siento que en cualquier momento podría ocurrir un desastre (natural, criminal, financiero o médico).

Mi padre y/o mi madre se involucran demasiado en mi vida y mis problemas, y yo en la suya.

Siento que no tengo otra opción que ceder ante los deseos de los demás, de lo contrario se vengarán de mí o me rechazarán de alguna manera.

Soy una buena persona porque pienso más en los demás que en mí mismo.

Me resulta embarazoso tener que expresar mis sentimientos a los demás.

Intento hacer las cosas lo mejor que puedo; no puedo aceptar un "bastante bien".

Soy especial y no tendría que aceptar muchas de las restricciones que se les imponen a las otras personas. 


\begin{tabular}{|llll|}
\hline $1=$ & Totalmente falso & $\mathbf{4}=$ & En ocasiones verdadero \\
$\mathbf{2}=$ & La mayoría de veces falso & $\mathbf{5}=$ & La mayoría de veces verdadero \\
$\mathbf{3}=$ & Más verdadero que falso & $\mathbf{6}=$ & Me describe perfectamente \\
\hline
\end{tabular}

33. Si no puedo alcanzar un objetivo, me siento fácilmente frustrado y renuncio a él.

34. L L L L elogios son más valiosos para mí, si los demás se dan cuenta.

35. Si algo bueno ocurre, me preocupo porqué es probable que algo malo le siga.

36. Si no lo intento con toda mis fuerzas, supondría ser un perdedor.

37. _ Gran parte de mi vida, no me he sentido especial para nadie.

38. Me preocupa que las personas a las que me siento unido me dejen o me abandonen.

39. Es sólo una cuestión de tiempo el que alguien me traicione.

40. No me siento unido a nadie, soy un solitario.

41.

No merezco el amor, la atención y el respeto de los demás.

42.

La mayoría de las personas están más capacitadas que yo en temas de trabajo y de rendimiento.

43.

No tengo sentido común.

44.

Me preocupa que me puedan atacar.

45.

Es muy difícil para mis padres (o para alguno de ellos) y para mí ocultarnos intimidades, sin sentirnos traicionados o culpables.

46.

En las relaciones, dejo que la otra persona tome la iniciativa.

47.

Estoy tan ocupado haciendo cosas por las personas que me importan, que me queda poco tiempo para mí mismo.

48.

Me es difícil ser cálido y espontáneo.

49.

Debo cumplir todas mis responsabilidades.

50.

Odio que me limiten o que no se me deje hacer lo que yo quiero.

51.

Lo paso mal cuando tengo que sacrificar gratificaciones inmediatas para conseguir un objetivo a largo plazo.

52.

Si no recibo mucho cariño de los demás, me siento menos importantes.

53.

No puedes tener tanto cuidado, casi siempre algo irá mal.

54.

Si no hago un buen trabajo, sufriría las consecuencias. 


\begin{tabular}{|llll|}
\hline $1=$ & Totalmente falso & $\mathbf{4}=$ & En ocasiones verdadero \\
$\mathbf{2}=$ & La mayoría de veces falso & $\mathbf{5}=$ & La mayoría de veces verdadero \\
$\mathbf{3}=$ & Más verdadero que falso & $\mathbf{6}=$ & Me describe perfectamente \\
\hline
\end{tabular}

55.

56.

57.

58.

59.

60.

61.

62.

63.

64.

65.

66.

67.

68.

69.

70.

71.

72.

73.
La mayor parte de mi vida, no he tenido a nadie que realmente me escuchase, me comprendiese o que conectase con mis verdaderas necesidades y sentimientos.

Cuando siento que alguien que me importa va a alejarse de mí o se aparta de mí, me desespero.

Soy bastante desconfiado respecto a los motivos de los demás.

Me siento alejado o aislado del resto de personas.

Siento que no soy simpático.

No tengo tantas aptitudes en el trabajo como la mayoría de las personas.

No se puede confiar en mi juicio en las situaciones cotidianas.

Me preocupa perder todo mi dinero y acabar en la miseria.

A menudo siento como si mis padres (o uno de ellos) estuviesen viviendo a través de mí; no tengo una vida propia.

Siempre dejo que los demás decidan por mí, de manera que no sé lo que verdaderamente quiero para mí mismo.

Siempre he sido el que escucha los problemas de los demás.

Me controlo tanto que las personas piensan que no tengo emociones o que soy insensible.

Siento una presión constante para lograr y dar las cosas por acabadas.

Siento que no tendría por qué seguir las normas básicas ni los convencionalismos que los demás siguen.

No consigo obligarme a hacer aquellas cosas que no me divierten, incluso cuando sé que son para mi propio beneficio.

Si hago comentarios en una reunión o me presentan en situaciones sociales, es importante para mi obtener el reconocimiento y la admiración.

No importa lo duro que trabaje, me preocupa que me pueda arruinar y perderlo casi todo.

No importa si cometo un error. Cuando me equivoco, debo pagas las consecuencias.

Raramente he tenido a una persona fuerte o sabia que me diese un buen consejo o que me guiase cuando no estaba seguro de lo que hacer. 


\begin{tabular}{|llll|}
\hline $1=$ & Totalmente falso & $\mathbf{4}=$ & En ocasiones verdadero \\
$\mathbf{2}=$ & La mayoría de veces falso & $\mathbf{5}=$ & La mayoría de veces verdadero \\
$\mathbf{3}=$ & Más verdadero que falso & $\mathbf{6}=$ & Me describe perfectamente \\
\hline
\end{tabular}

74.

75.

76.

77.

78.

79.

80.

81.

82.

83.

84.

85.

86.

87.

88.

89.

90.
Algunas veces estoy tan preocupado por la posibilidad de que las personas me deje que les aparto de mí.

Normalmente estoy al acecho de las intenciones ocultas de los demás.

Siempre me siento poco integrado en los grupos.

En mí hay demasiadas cosas básicas que son inaceptables, como para poder abrirme a los demás.

No tengo tanta inteligencia como la mayoría de las personas en lo que se refiere al trabajo (o los estudios).

No confío en mi habilidad para resolver los problemas que van surgiendo en el día a día.

Me preocupa estar empezando a sufrir una enfermedad grave, aunque ningún médico me ha diagnosticado nada importante.

A menudo siento que no tengo una identidad independiente de las de mis padres o pareja.

Tengo muchas dificultades para exigir que mis derechos sean respetados y que mis sentimientos sean tenidos en cuenta.

Las personas me ven como alguien que hace demasiadas cosas para los demás y no las suficientes para sí mismo.

La gente me ve como alguien emocionalmente rígido.

No me permito eludir fácilmente mis responsabilidades o buscar excusas para mis errores.

Siento que lo que tengo que ofrecer es de un mayor valor que lo que pueden aportar los demás.

Raramente he sido capaz de mantenerme firme en mis propósitos.

Muchos halagos y cumplidos me hacen sentir una persona valiosa.

Me preocupa que una decisión equivocada me puede llevar al desastre.

Soy una mala persona que merece ser castigada. 


\section{Apéndice 7: Propuesta del cuestionario de esquemas \\ CUESTIONARIO DE ESQUEMAS (YSQ-S3) \\ Young J. \\ [Adaptación Peruana]}

Nombre

Fecha 1

Instrucciones: A continuación encontrará una lista de frases que una persona puede utilizar para describirse a sí misma. Por favor, lea cada frase y decida el grado de exactitud con que te describe durante el último año. Cuando no esté seguro, basa su respuesta en lo que emocionalmente sienta no en lo que piense que es verdad.

Algunas frases hacen referencia a las relaciones con sus padres o con sus parejas. Si alguna de las personas ha fallecido, por favor responda a esos ítems basándose en sus relaciones cuando estaban vivas. Si en la actualidad no tiene pareja pero tuvo parejas en su pasado, por favor responda al ítem basándose en la relación de pareja más reciente y significativa.

Escoja la puntuación más elevada desde 1 a 6 que le describe y escriba el número en el espacio que se encuentra antes de la frase:

\section{ESCALA DE PUNTUACIONES}

\begin{tabular}{|llll|}
\hline $\mathbf{1}=$ & Totalmente falso & $\mathbf{4}=$ & En ocasiones verdadero \\
$\mathbf{2}=$ & La mayoría de veces falso & $\mathbf{5}=$ & La mayoría de veces verdadero \\
$\mathbf{3}=$ & Más verdadero que falso & $\mathbf{6}=$ & Me describe perfectamente \\
\hline
\end{tabular}

1.

3.

4.

5.

6.

7.

8.

9.

10.

11.
La mayor parte de mi vida, no he tenido a nadie que me cuide, con quién compartir o que se preocupe verdaderamente de las cosas que me ocurren.

Me siento aferrado a las personas a las que estoy muy unido porque tengo miedo de que me abandonen.

Presiento que la gente se aprovechará de mí.

No me aceptan en ningún lugar.

Ningún hombre/mujer que yo desee podría amarme cuando viese mis defectos.

Casi nada de lo que hago en el trabajo (o en la escuela) está tan bien hecho como lo que otras personas pueden hacer.

No me siento capaz de arreglármelas por mí mismo en las cosas de cada día.

No puedo escapar a la sensación de que algo malo va a ocurrir.

No he sido capaz de independizarme de mis padres, como otras personas de mi edad parecen haberlo hecho.

Pienso que si hago lo que quiero, sólo me encontraré problemas.

Soy el que normalmente acabo cuidando de las personas cercanas a mí 


\begin{tabular}{|llll|}
\hline $1=$ & Totalmente falso & $\mathbf{4}=$ & En ocasiones verdadero \\
$\mathbf{2}=$ & La mayoría de veces falso & $\mathbf{5}=$ & La mayoría de veces verdadero \\
$\mathbf{3}=$ & Más verdadero que falso & $\mathbf{6}=$ & Me describe perfectamente \\
\hline
\end{tabular}

12.

13.

14.

15.

16.

17.

18.

19.

20.

21.

22.

23.

24.

25.

26.

27.

28.

29.

30.

31.

32.

Soy demasiado tímido para expresar sentimientos positivos hacia los demás (p. ej., afecto, preocupación...).

Tengo que ser el mejor en la mayoría de las cosas que hago; no puedo aceptar ser el segundo mejor.

Me es muy difícil aceptar un "no" como respuesta cuando quiero algo de los demás.

Parece que no pueda disciplinarme para acabar tareas rutinarias o aburridas.

Tener dinero y conocer a personas importantes me hace sentir valioso.

Incluso cuando las cosas parecen ir bien, siento que es una cosa temporal.

Si cometo un error, merezco ser castigado.

En general, las personas no han estado a mi lado para darme cariño, apoyo y afecto.

Necesito tanto a los demás que me preocupa perderlos.

Siento que no puedo bajar la guardia cuando estoy con otras personas, si no ellos me harán daño intencionadamente.

Soy básicamente diferente de las otras personas.

Nadie que yo desee querría estar cerca de mí, si me conociese realmente.

Soy incompetente cuando se trata de rendir en cualquier tarea.

Me veo a mí mismo como una persona dependiente, en mi desempeño diario.

Siento que en cualquier momento podría ocurrir un desastre (natural, criminal, financiero o médico).

Mi padre y/o mi madre se involucran demasiado en mi vida y mis problemas, y yo en la suya.

Siento que no tengo otra opción que ceder ante los deseos de los demás, de lo contrario se vengarán de mí o me rechazarán de alguna manera.

Soy una buena persona porque pienso más en los demás que en mí mismo.

Me resulta embarazoso tener que expresar mis sentimientos a los demás.

Intento hacer las cosas lo mejor que puedo; no puedo aceptar un "bastante bien".

Soy especial y no tendría que aceptar muchas de las restricciones que se les imponen a las otras personas. 


\begin{tabular}{|llll|}
\hline $1=$ & Totalmente falso & $\mathbf{4}=$ & En ocasiones verdadero \\
$\mathbf{2}=$ & La mayoría de veces falso & $\mathbf{5}=$ & La mayoría de veces verdadero \\
$\mathbf{3}=$ & Más verdadero que falso & $\mathbf{6}=$ & Me describe perfectamente \\
\hline
\end{tabular}

33.

Si no puedo alcanzar un objetivo, me siento fácilmente frustrado y renuncio a él.

34.

Los elogios son más valiosos para mí, si los demás se dan cuenta.

35.

Si algo bueno ocurre, me preocupo porque es probable que algo malo le siga.

36.

Si no lo intento con toda mis fuerzas, supondría ser un perdedor.

37.

Gran parte de mi vida, no me he sentido especial para nadie.

38.

Me preocupa que las personas, a las que me siento unido, me dejen o me abandonen.

39.

Es sólo una cuestión de tiempo el que alguien me traicione.

40.

No me siento unido a nadie, soy un solitario.

41.

No merezco el amor, la atención y el respeto de los demás.

42.

La mayoría de las personas están más capacitadas que yo en temas de trabajo y de rendimiento.

43.

No tengo sentido común.

44.

Me preocupa que me puedan atacar.

45.

Es muy difícil para mis padres (o para alguno de ellos) y para mí ocultarnos intimidades, sin sentirnos traicionados o culpables.

46.

En las relaciones, dejo que la otra persona tome la iniciativa.

47.

Estoy tan ocupado haciendo cosas por las personas que me importan, que me queda poco tiempo para mí mismo.

48.

Me es difícil ser cálido y espontáneo.

49.

Debo cumplir todas mis responsabilidades.

50.

Odio que me limiten o que no se me deje hacer lo que yo quiero.

51.

Lo paso mal cuando tengo que sacrificar gratificaciones inmediatas para conseguir un objetivo a largo plazo.

52.

Si no recibo mucho cariño de los demás, me siento menos importantes.

53.

No puedes tener tanto cuidado, casi siempre algo irá mal.

54.

Si no hago un buen trabajo, sufriría las consecuencias. 


\begin{tabular}{|llll|}
\hline $1=$ & Totalmente falso & $\mathbf{4}=$ & En ocasiones verdadero \\
$\mathbf{2}=$ & La mayoría de veces falso & $\mathbf{5}=$ & La mayoría de veces verdadero \\
$\mathbf{3}=$ & Más verdadero que falso & $\mathbf{6}=$ & Me describe perfectamente \\
\hline
\end{tabular}

55.

56.

57.

58.

59.

60.

61.

62.

63.

64.

65.

66.

67.

68.

69.

70.

71.

72.

73.
La mayor parte de mi vida, no he tenido a nadie que realmente me escuche o comprenda mis verdaderas necesidades y sentimientos.

Cuando siento que alguien que me importa va a alejarse de mí o se aparta de mí, me desespero.

Soy bastante desconfiado respecto a los motivos de los demás.

Me siento alejado o aislado del resto de personas.

Siento que no soy simpático.

No tengo tantas aptitudes en el trabajo como la mayoría de las personas.

No se puede confiar en mi juicio en las situaciones cotidianas.

Me preocupa perder todo mi dinero y acabar en la miseria.

A menudo siento como si mis padres (o uno de ellos) estuviesen viviendo a través de mí; no tengo una vida propia.

Siempre dejo que los demás decidan por mí, de manera que no sé lo que verdaderamente quiero para mí mismo.

Siempre he sido el que escucha los problemas de los demás.

Me controlo tanto que las personas piensan que no tengo emociones o que soy insensible.

Siento una presión constante para lograr y dar las cosas por acabadas.

Siento que no tendría por qué seguir las normas básicas ni los convencionalismos que los demás siguen.

No consigo obligarme a hacer aquellas cosas que no disfruto, incluso cuando sé que son para mi propio beneficio.

Si hago comentarios en una reunión o me presentan en situaciones sociales, es importante para mí obtener el reconocimiento y la admiración.

No importa lo duro que trabaje, me preocupa que me pueda arruinar y perderlo casi todo.

No importa si cometo un error. Cuando me equivoco, debo pagas las consecuencias.

Raramente he tenido a una persona fuerte o sabia que me diese un buen consejo o que me guiase cuando no estaba seguro de lo que hacer. 


\begin{tabular}{|llll|}
\hline $1=$ & Totalmente falso & $\mathbf{4}=$ & En ocasiones verdadero \\
$\mathbf{2}=$ & La mayoría de veces falso & $\mathbf{5}=$ & La mayoría de veces verdadero \\
$\mathbf{3}=$ & Más verdadero que falso & $\mathbf{6}=$ & Me describe perfectamente \\
\hline
\end{tabular}

74.

75.

76.

77.

78.

79.

80.

81.

82.

83.

84.

85.

86.

87.

88.

89.

90.
Algunas veces, estoy tan preocupado por la posibilidad de que las personas me dejen, que les aparto de mí.

Normalmente estoy al acecho de las intenciones ocultas de los demás.

Siempre me siento poco integrado en los grupos.

En mí hay demasiadas cosas básicas que son inaceptables, como para poder abrirme a los demás.

No tengo tanta inteligencia como la mayoría de las personas en lo que se refiere al trabajo (o los estudios).

No confío en mi habilidad para resolver los problemas que van surgiendo en el día a día.

Me preocupa estar empezando a sufrir una enfermedad grave, aunque ningún médico me ha diagnosticado nada importante.

A menudo siento que no tengo una identidad independiente de las de mis padres o pareja.

Tengo muchas dificultades para exigir que mis derechos sean respetados y que mis sentimientos sean tenidos en cuenta.

Las personas me ven como alguien que hace demasiadas cosas para los demás y no las suficientes para sí mismo.

La gente me ve como alguien emocionalmente rígido.

No me permito eludir fácilmente mis responsabilidades o buscar excusas para mis errores.

Siento que lo que tengo que ofrecer es de un mayor valor que lo que pueden aportar los demás.

Raramente he sido capaz de mantenerme firme en mis propósitos.

Muchos halagos y cumplidos me hacen sentir una persona valiosa.

Me preocupa que una decisión equivocada me puede llevar al desastre.

Soy una mala persona que merece ser castigada. 


\section{Apéndice 8: Plantilla de Corrección}

Nombre

Fecha

1

Privación Emocional

1

19 37

55

73

Total

Media

Abandono / Inestabilidad

2

20

38

56

74

Total

Media

Desconfianza / Abuso

3

39

57

75

Total

Media

Aislamiento social

4

22

40

58

76

Total

Media

Imperfección / Vergüenza

5

23

41

59

77

Total

Media

Fracaso

6

24

42

60

78

Tota

Media

Dependencia / Incompetencia

7 25

43

61

79

Total

Media

Vulnerabilidad al peligro o a la enfermedad

8

26

44

62

80

Total

Media

Apego confuso / Yo inmaduro

9

27

45

63

81

Total

Media 
Subyugación

10 28

46

64

82

Total

Media

Autosacrificio

11

29

47

65

83

Total

Media

Inhibición emocional

12

30

48

66

84

Total

Media

Metas inalcanzables

13 31

49

67

85

Total

Media

Grandiosidad / Autorización

14 32

50

68

86

Total

Media

Autocontrol Insuficiente

15 33

51

69

87

Total

Media

Búsqueda de aprobación

16 34 52

70

88

Total

Media

Negatividad / Pesimismo

17

35

53

71

89

Total

Media

Castigo

18 36 54 72 90

Total Media 


\section{Apéndice 9: Criterio de jueces}

Estimado(a):

Presente.-

De mi consideración:

Teniendo en cuenta su experiencia; tengo el agrado de dirigirme a usted para solicitar su participación como juez experto en la validación de contenido de mi proyecto de tesis que se titula: "PROPIEDADES PSICOMÉTRICAS DEL CUESTIONARIO DE ESQUEMAS DE YOUNG (YSQ-S3) EN MUESTRA CLÍNICA DE UN HOSPITAL PÚBLICO DE LIMA METROPOLITANA"; para obtener el Título de Licenciatura en Psicología bajo la modalidad de tesis.

El objetivo del cuestionario es identificar los esquemas desadaptativos tempranos que son creencias estables, disfuncionales, auto-saboteadores de pensamientos y emociones que se han construido desde una temprana edad y se reiteran a lo largo de la vida; desempeñando un rol central en el desenvolvimiento de los trastornos clínicos y/o de personalidad en la adultez (Young, 2015). Cabe resaltar que el rango de edades de la muestra clínica es entre 18 y 60 años. El cuestionario cuenta con 90 ítems que evalúan 18 esquemas desadaptativos y se agrupan en 5 dimensiones, el cual se califica en una escala Likert de 6 puntos.

Finalmente, se adjunta las descripciones de cada enunciado, para lo cual se deberá marcar "SI" o "NO" según los criterios en mención. Se solicita considerar los siguientes criterios para lograr las evidencias de validez de contenido (Sireci y Faulkner-Bond, 2014):

1) Representación del dominio: Grado en que una prueba representa adecuadamente y mide el dominio definido en los ítems de la prueba.

2) Relevancia en el dominio: Grado en que cada ítem de la prueba es relevante para la medición del dominio, con el fin de descartar contenido trivial de la prueba.

3) Claridad en la redacción: Los ítems cuentan con una sintaxis y semántica que permiten entenderlos fácilmente.

De antemano agradezco su colaboración,

Andrea Alessandra Matute Cruces

Sireci, S. y Faulkner-Bond, M. (2014). Validity evidence based on test content. Psicothema, 26(1), 100-7. https://doi.org/10.7334/psicothema2013.256

Young, J., Klosko, J. y Weishaar, M. (2015). Terapia de esquemas. Guía práctica. Serie Psicoterapias Cognitivas. Biblioteca de psicología. Desclée de Brouwer: Bilbao. 


\section{Cuestionario de esquemas de Young (YSQ-S3)}

\begin{tabular}{l} 
CONSIGNA EN ESPAÑOL \\
\hline A continuación, encontrará una lista de frases \\
que una persona puede utilizar para \\
describirse a sí misma. Por favor, lea cada \\
frase y decida el grado de exactitud con que \\
te describe durante el último año. Cuando \\
no esté seguro, base su respuesta en lo que \\
emocionalmente sienta no en lo que piense \\
que es verdad. \\
Algunas frases hacen referencia a las \\
relaciones con sus padres o con sus parejas. \\
Si alguna de las personas ha fallecido, por \\
favor responda a esos ítems basándose en sus \\
relaciones cuando estaban vivas. Si en la \\
actualidad no tiene pareja pero tuvo parejas \\
en su pasado, por favor responda al ítem \\
basándose en la relación de pareja más \\
reciente y significativa. \\
Escoja la calificación más elevada desde 1 a \\
6 que le describe y escriba el número en el \\
espacio que se encuentra antes de la frase. \\
\hline ESCALA DE CALIFICACIÓN \\
1. Totalmente falso \\
2. La mayoría de veces falso \\
5. Más verdadero que falso
\end{tabular}


Dimensión I "Desconexión y rechazo": Describe a personas que son incapaces de constituir vinculaciones afectivas estables y sólidas con otras, puesto que tienen la creencia de que sus necesidades básicas de seguridad, protección, amor y pertenencia no serán satisfechas.

\begin{tabular}{|c|c|c|c|c|c|}
\hline $\begin{array}{l}\text { Esquema Abandono/ } \\
\text { Inestabilidad }\end{array}$ & Ítem & $\begin{array}{l}\text { Represen- } \\
\text { tación del } \\
\text { dominio }\end{array}$ & $\begin{array}{l}\text { Relevan- } \\
\text { cia en el } \\
\text { dominio }\end{array}$ & $\begin{array}{l}\text { Claridad } \\
\text { en la } \\
\text { redacción }\end{array}$ & Observaciones \\
\hline \multirow{5}{*}{$\begin{array}{l}\text { La percepción de que las } \\
\text { personas significativas no } \\
\text { serán capaces de seguir } \\
\text { proporcionándole el apoyo } \\
\text { emocional, conexión o } \\
\text { protección práctica porque } \\
\text { son emocionalmente } \\
\text { inestables e imprevisibles. }\end{array}$} & $\begin{array}{l}\text { 2. Me siento aferrado a las personas a las que estoy muy unido porque } \\
\text { tengo miedo de que me abandonen. }\end{array}$ & SI & SI NO & NO & \\
\hline & 20. Necesito tanto a los demás que me preocupa perderlo. & SI $\quad \mathrm{NO}$ & SI NO & NO & \\
\hline & $\begin{array}{l}\text { 38. Me preocupa que las personas a las que me siento unido me dejen } \\
\text { o me abandonen. }\end{array}$ & SI NO & SI NO & NO & \\
\hline & $\begin{array}{l}\text { 56. Cuando siento que alguien que me importa va a alejarse de mí o } \\
\text { se aparta de mí, me desespero. }\end{array}$ & SI & NO & SI & \\
\hline & $\begin{array}{l}\text { 74. Algunas veces estoy tan preocupado por la posibilidad de que las } \\
\text { personas me dejen que les aparto de mí. }\end{array}$ & SI & NO & NO & \\
\hline
\end{tabular}

\begin{tabular}{|c|c|c|c|c|c|c|}
\hline $\begin{array}{c}\text { Esquema } \\
\text { Desconfianza/Abuso }\end{array}$ & Ítem & $\begin{array}{l}\text { Represen- } \\
\text { tación del } \\
\text { dominio }\end{array}$ & $\begin{array}{l}\text { Relevan- } \\
\text { cia en el } \\
\text { dominio }\end{array}$ & & & Observaciones \\
\hline \multirow{5}{*}{$\begin{array}{l}\text { La expectativa de que los } \\
\text { demás perjudicarán, } \\
\text { abusarán, humillarán, } \\
\text { engañarán, manipularán o } \\
\text { se beneficiarán de uno. } \\
\text { Percepción de que el daño } \\
\text { es intencionado y que uno, } \\
\text { en comparación con otros, } \\
\text { siempre acaba engañado. }\end{array}$} & \multirow{4}{*}{$\begin{array}{l}\text { 3. Presiento que la gente se aprovechará. } \\
\text { 21. Siento que no puedo bajar la guardia cuando estoy con otras } \\
\text { personas, si no ellos me harán daño intencionadamente.. } \\
\text { 39. Es solo una cuestión de tiempo en que alguien me traicione. } \\
\text { 57. Soy bastante desconfiado respecto a los motivos de los demás. }\end{array}$} & SI $\quad$ NO & $\begin{array}{|ll|}\text { SI } & \text { NO } \\
\end{array}$ & SI & NO & \\
\hline & & SI $\quad$ NO & $\begin{array}{ll}\text { SI } & \text { NO }\end{array}$ & SI & NO & \\
\hline & & $\begin{array}{ll}\text { SI } & \text { NO }\end{array}$ & $\begin{array}{|ll|}\text { SI } & \text { NO } \\
\end{array}$ & SI & $\mathrm{NO}$ & \\
\hline & & $\mathrm{NO}$ & $\begin{array}{|ll|}\text { SI } & \text { NO } \\
\end{array}$ & SI & $\mathrm{NO}$ & \\
\hline & $\begin{array}{l}\text { 75. Normalmente estoy al acecho de las intenciones ocultas de los } \\
\text { demás. }\end{array}$ & SI NO & SI NO & SI & NO & \\
\hline
\end{tabular}


Dimensión I "Desconexión y rechazo": Describe a personas que son incapaces de constituir vinculaciones afectivas estables y sólidas con otras, puesto que tienen la creencia de que sus necesidades básicas de seguridad, protección, amor y pertenencia no serán satisfechas.

\begin{tabular}{|c|c|c|c|c|c|}
\hline $\begin{array}{l}\text { Esquema Privación } \\
\text { emocional }\end{array}$ & Ítem & $\begin{array}{l}\text { Represen- } \\
\text { tación del } \\
\text { dominio }\end{array}$ & $\begin{array}{l}\text { Relevan- } \\
\text { cia en el } \\
\text { dominio }\end{array}$ & $\begin{array}{l}\text { Claridad } \\
\text { en la } \\
\text { redacción }\end{array}$ & Observaciones \\
\hline \multirow{5}{*}{$\begin{array}{l}\text { La expectativa de que el } \\
\text { propio deseo de un grado } \\
\text { normal de apoyo emocional } \\
\text { no será adecuadamente } \\
\text { satisfecho por los demás. } \\
\text { Puede haber privación: de } \\
\text { cuidados, empatía o de } \\
\text { protección. }\end{array}$} & $\begin{array}{l}\text { 1. La mayor parte de mi vida, no he tenido a nadie que me cuide, con } \\
\text { quien compartir, o que se preocupe verdaderamente de las cosas que } \\
\text { me ocurren. }\end{array}$ & NO & SI NO & NO & \\
\hline & $\begin{array}{l}\text { 19. En general, las personas no han estado a mi lado para darme } \\
\text { cariño, apoyo y afecto. }\end{array}$ & SI $\quad \mathrm{NO}$ & $\mathrm{SI} \quad \mathrm{NO}$ & $\mathrm{NO}$ & \\
\hline & & $\mathrm{NO}$ & $\begin{array}{ll}\text { SI } & \text { NO } \\
\end{array}$ & $\mathrm{NO}$ & \\
\hline & \multirow{2}{*}{$\begin{array}{l}\text { 55. La mayor parte de mi vida, no he tenido a nadie que realmente } \\
\text { me escuchase, me comprendiese o que conectase con mis verdaderas } \\
\text { necesidades y sentimientos. } \\
\text { 73. Raramente he tenido a una persona fuerte o sabia para que me } \\
\text { diese un buen consejo o que me guiase cuando no estaba seguro de } \\
\text { lo que hacer. }\end{array}$} & SI $\quad$ NO & SI NO & SI NO & \\
\hline & & NO & SI NO & SI NO & \\
\hline \multicolumn{2}{|l|}{$\begin{array}{c}\text { Esquema } \\
\text { Imperfección/Vergüenza }\end{array}$} & $\begin{array}{l}\text { Represen- } \\
\text { tación del } \\
\text { dominio }\end{array}$ & $\begin{array}{l}\text { Relevan- } \\
\text { cia en el } \\
\text { dominio }\end{array}$ & $\begin{array}{l}\text { Claridad } \\
\text { en la } \\
\text { redacción }\end{array}$ & Observaciones \\
\hline \multirow{5}{*}{$\begin{array}{l}\text { El sentimiento de que uno } \\
\text { es imperfecto, defectuoso, } \\
\text { malo, no deseado, inferior o } \\
\text { inválido en aspectos } \\
\text { importantes o, si se expone } \\
\text { ante los demás, no será } \\
\text { querido. }\end{array}$} & \multirow{5}{*}{$\begin{array}{l}\text { 5. Ningún hombre/mujer que yo desee podría amarme cuando viese } \\
\text { mis defectos. } \\
\text { 23. Nadie que yo desee, querría estar cerca de mí si me conociese. } \\
\text { 41. No merezco el amor, la atención y el respeto de los demás. } \\
\text { 59. Siento que no soy simpático. } \\
\text { 77. En mi hay demasiadas cosas básicas que son inaceptables, como } \\
\text { para poder abrirme a los demás. }\end{array}$} & $\mathrm{NO}$ & SI NO & SI NO & \\
\hline & & NO & $\begin{array}{ll}\text { SI } & \text { NO } \\
\end{array}$ & & \\
\hline & & NO & SI $\quad \mathrm{NO}$ & $\mathrm{NO}$ & \\
\hline & & SI $\quad$ NO & SI $\quad \mathrm{NO}$ & $\mathrm{NO}$ & \\
\hline & & SI & SI NO & SI & \\
\hline
\end{tabular}


Dimensión I "Desconexión y rechazo": Describe a personas que son incapaces de constituir vinculaciones afectivas estables y sólidas con otras, puesto que tienen la creencia de que sus necesidades básicas de seguridad, protección, amor y pertenencia no serán satisfechas.

\begin{tabular}{|c|c|c|c|c|c|}
\hline $\begin{array}{c}\text { Esquema Aislamiento } \\
\text { Social }\end{array}$ & Ítem & $\begin{array}{l}\text { Represen- } \\
\text { tación del } \\
\text { dominio }\end{array}$ & $\begin{array}{l}\text { Relevan- } \\
\text { cia en el } \\
\text { dominio }\end{array}$ & $\begin{array}{l}\text { Claridad } \\
\text { en la } \\
\text { redacción }\end{array}$ & Observaciones \\
\hline \multirow{5}{*}{$\begin{array}{l}\text { El sentimiento de estar } \\
\text { aislado del resto del } \\
\text { mundo, de ser diferente de } \\
\text { las demás personas y/o de } \\
\text { no ser parte de ningún } \\
\text { grupo o comunidad. }\end{array}$} & 4. No me aceptan en ningún lugar. & $\mathrm{NO}$ & SI NO & NO & \\
\hline & 22. Soy básicamente diferente de las otras personas. & $\mathrm{NO}$ & SI $\quad$ NO & & \\
\hline & 40. No me siento unido a nadie, soy un solitario. & $\mathrm{NO}$ & SI NO & NO & \\
\hline & 58. Me siento alejado o aislado del resto de personas. & $\mathrm{NO}$ & SI NO & NO & \\
\hline & 76. Siempre me siento poco integrado a mis grupos. & NO & SI NO & NO & \\
\hline
\end{tabular}

Dimensión II "Deterioro en autonomía y desempeño": Describe a personas donde aparece vulnerada su capacidad de autonomía tanto en la separación de figuras significativas como para funcionar de manera independiente sin la necesidad del otro.

\begin{tabular}{|c|c|c|c|c|c|}
\hline $\begin{array}{l}\text { Esquema Dependencia/ } \\
\text { Incompetencia }\end{array}$ & Ítem & $\begin{array}{c}\text { Represen- } \\
\text { tación del } \\
\text { dominio }\end{array}$ & $\begin{array}{l}\text { Relevan- } \\
\text { cia en el } \\
\text { dominio }\end{array}$ & $\begin{array}{l}\text { Claridad } \\
\text { en la } \\
\text { redacción }\end{array}$ & Observaciones \\
\hline \multirow{5}{*}{$\begin{array}{l}\text { La creencia de que uno es } \\
\text { incapaz de manejar las } \\
\text { propias responsabilidades } \\
\text { cotidianos de una manera } \\
\text { competente, sin ayuda } \\
\text { considerable de los demás. }\end{array}$} & $\begin{array}{l}\text { 7. No soy capaz de arreglármelas por sí mismo en las cosas de cada } \\
\text { día. }\end{array}$ & NO & SI NO & NO & \\
\hline & $\begin{array}{l}\text { 25. Me veo a mí mismo como una persona dependiente, a lo que se } \\
\text { refiere al funcionamiento de cada día. }\end{array}$ & NO & SI NO & NO & \\
\hline & 43. No tengo sentido común. & NO & SI NO & NO & \\
\hline & 61. No se puede confiar en mi juicio en las situaciones cotidianas. & NO & SI NO & $\mathrm{NO}$ & \\
\hline & $\begin{array}{l}\text { 79. No confío en mi habilidad para resolver los problemas que van } \\
\text { surgiendo en el día a día. }\end{array}$ & SI NO & SI NO & NO & \\
\hline
\end{tabular}


Dimensión II "Deterioro en autonomía y desempeño": Describe a personas donde aparece vulnerada su capacidad de autonomía tanto en la separación de figuras significativas como para funcionar de manera independiente sin la necesidad del otro.

\begin{tabular}{|c|c|c|c|c|c|c|c|c|}
\hline $\begin{array}{c}\text { Esquema Vulnerabilidad } \\
\text { al peligro o a la } \\
\text { enfermedad }\end{array}$ & Ítem & \multicolumn{2}{|c|}{$\begin{array}{l}\text { Represen- } \\
\text { tación del } \\
\text { dominio }\end{array}$} & \multicolumn{2}{|c|}{$\begin{array}{l}\text { Relevan- } \\
\text { cia en el } \\
\text { dominio } \\
\end{array}$} & \multicolumn{2}{|c|}{$\begin{array}{l}\text { Claridad } \\
\text { en la } \\
\text { redacción }\end{array}$} & Observaciones \\
\hline \multirow{5}{*}{$\begin{array}{l}\text { Miedo exagerado a que una } \\
\text { catástrofe inminente le } \\
\text { sorprenderá en cualquier } \\
\text { momento y a que uno sea } \\
\text { incapaz de impedirla. } \\
\text { Miedo a catástrofes: } \\
\text { médicas, emocionales, } \\
\text { externas. }\end{array}$} & \multirow{3}{*}{$\begin{array}{l}\text { 8. No puedo escapar a la sensación de que algo malo va ocurrir. } \\
\text { 26. Siento que en cualquier momento podría ocurrir un desastre } \\
\text { (natural, criminal, financiero o médico). } \\
\text { 44. Me preocupa que me puedan atacar. }\end{array}$} & SI & $\mathrm{NO}$ & SI & $\mathrm{NO}$ & & $\mathrm{NO}$ & \\
\hline & & SI & NO & SI & NO & $\mathrm{S}$ & NO & \\
\hline & & SI & $\mathrm{NO}$ & SI & $\mathrm{NO}$ & $\mathrm{S}$ & $\mathrm{NO}$ & \\
\hline & \multirow{2}{*}{$\begin{array}{l}\text { 62. Me preocupa perder todo mi dinero y acabar en la miseria. } \\
\text { 80. Me preocupa estar empezando a sufrir una enfermedad grave, } \\
\text { aunque ningún médico me ha diagnosticado nada importante. }\end{array}$} & SI & $\mathrm{NO}$ & SI & $\mathrm{NO}$ & $\mathrm{S}$ & $\mathrm{NO}$ & \\
\hline & & SI & NO & SI & NO & & NO & \\
\hline $\begin{array}{c}\text { Esquema Apego } \\
\text { confuso/Yo inmaduro }\end{array}$ & Ítem & \multicolumn{2}{|c|}{$\begin{array}{l}\text { Represen- } \\
\text { tación del } \\
\text { dominio }\end{array}$} & \multicolumn{2}{|c|}{$\begin{array}{l}\text { Relevan- } \\
\text { cia en el } \\
\text { dominio }\end{array}$} & \multicolumn{2}{|c|}{$\begin{array}{c}\text { Claridad } \\
\text { en la } \\
\text { redacción }\end{array}$} & Observaciones \\
\hline \multirow{5}{*}{$\begin{array}{l}\text { La excesiva implicación y } \\
\text { proximidad emocional con } \\
\text { una o más personas } \\
\text { significativas. Creencia de } \\
\text { que, como mínimo, uno de } \\
\text { los individuos a los que se } \\
\text { siente unido no podrá } \\
\text { sobrevivir ni ser feliz sin el } \\
\text { constante apoyo del otro. }\end{array}$} & \multirow{2}{*}{$\begin{array}{l}\text { 9. No he sido capaz de independizarme de mis padres, en la medida } \\
\text { en las que las otras personas de mi edad parecen haberlo hecho. } \\
\text { 27. Mi padre y/o mi madre se involucran demasiado en mi vida y mis } \\
\text { problemas, y yo en la suya. }\end{array}$} & SI & NO & SI & NO & $\mathrm{S}$ & NO & \\
\hline & & SI & NO & SI & NO & $\mathrm{S}$ & NO & \\
\hline & \multirow{3}{*}{$\begin{array}{l}\text { 45. Es muy difícil para mis padres (o para alguno de ellos) y para mí } \\
\text { ocultarnos intimidades, sin sentirnos traicionados o culpables. } \\
\text { 63. A menudo siento como si mis padres (o uno de ellos) estuviese } \\
\text { viviendo a través de mí; no tengo una vida propia. } \\
\text { 81. A menudo siento que no tengo una identidad independiente de la } \\
\text { de mis padres o pareja. }\end{array}$} & SI & NO & SI & NO & $\mathrm{S}$ & NO & \\
\hline & & SI & NO & SI & NO & $\mathrm{S}$ & NO & \\
\hline & & & NO & SI & NO & $\mathrm{S}$ & NO & \\
\hline
\end{tabular}


Dimensión II "Deterioro en autonomía y desempeño": Describe a personas donde aparece vulnerada su capacidad de autonomía tanto en la separación de figuras significativas como para funcionar de manera independiente sin la necesidad del otro.

\begin{tabular}{|c|c|c|c|c|c|}
\hline Esquema Fracaso & Ítem & $\begin{array}{c}\text { Represen- } \\
\text { tación del } \\
\text { dominio }\end{array}$ & $\begin{array}{l}\text { Relevan- } \\
\text { cia en el } \\
\text { dominio }\end{array}$ & $\begin{array}{l}\text { Claridad } \\
\text { en la } \\
\text { redacción }\end{array}$ & Observaciones \\
\hline $\begin{array}{l}\text { La creencia de haber } \\
\text { fracaso, de fracasar en el }\end{array}$ & $\begin{array}{l}\text { 6. Casi nada de lo que hago en el trabajo (o en la escuela) está tan } \\
\text { bien hecho como lo que otras personas pueden hacer. }\end{array}$ & SI NO & SI NO & SI NO & \\
\hline futuro o de ser, & 24. Soy incompetente cuando se trata de rendir en cualquier tarea. & SI $\quad$ NO & SI NO & $\mathrm{NO}$ & \\
\hline $\begin{array}{lr}\text { básicamente, } & \text { un } \\
\text { compañero } & \text { inadecuado }\end{array}$ & $\begin{array}{l}\text { 42. La mayoría de las personas están más capacitadas que yo en } \\
\text { temas de trabajo y de rendimiento }\end{array}$ & NO & SI NO & NO & \\
\hline $\begin{array}{l}\text { para los propios amigos en } \\
\text { áreas de logro (académico, }\end{array}$ & $\begin{array}{l}\text { 60. No tengo tantas aptitudes en el trabajo como la mayoría de las } \\
\text { personas. }\end{array}$ & NO & SI NO & NO & \\
\hline $\begin{array}{l}\text { profesional, deportivo, } \\
\text { etc.). }\end{array}$ & $\begin{array}{l}\text { 78. No tengo tanta inteligencia como la mayoría de las personas en } \\
\text { lo que se refiere al trabajo (o los estudios). }\end{array}$ & SI NO & SI NO & NO & \\
\hline
\end{tabular}

Dimensión III "Límites deficitarios": Describe a personas que no han desarrollado límites internos adecuados en relación a tener consideración por los demás y/o pensar en la consecuencias de sus actos en el resto, tener adecuada regulación de sus emociones e impulsos, tolerancia a la frustración y postergación de beneficios futuros.

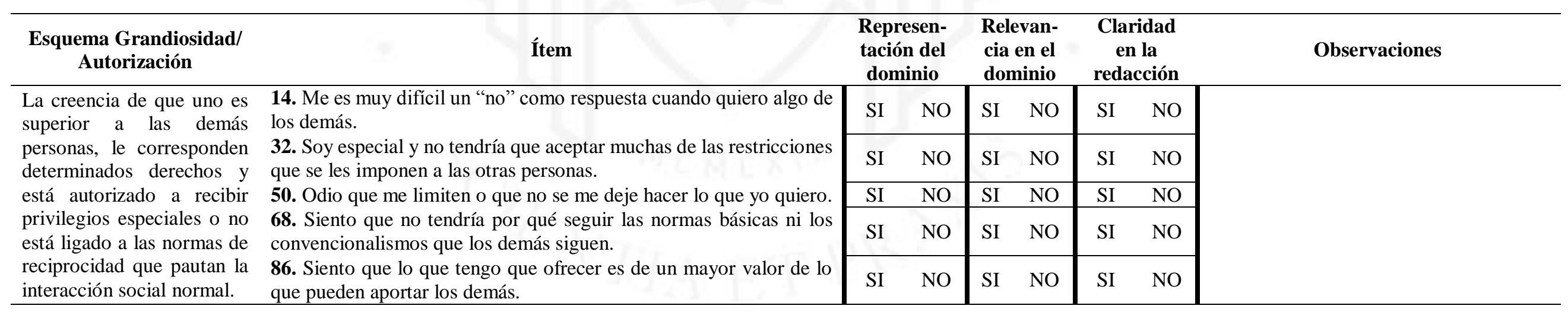


Dimensión III "Límites deficitarios": Describe a personas que no han desarrollado límites internos adecuados en relación a tener consideración por los demás y/o pensar en la consecuencias de sus actos en el resto, tener adecuada regulación de sus emociones e impulsos, tolerancia a la frustración y postergación de beneficios futuros.

\begin{tabular}{|c|c|c|c|c|c|}
\hline $\begin{array}{c}\text { Esquema Autocontrol } \\
\text { insuficiente/ } \\
\text { Autodisciplina }\end{array}$ & Ítem & $\begin{array}{c}\text { Represen- } \\
\text { tación del } \\
\text { dominio }\end{array}$ & $\begin{array}{l}\text { Relevan- } \\
\text { cia en el } \\
\text { dominio } \\
\end{array}$ & $\begin{array}{c}\text { Claridad } \\
\text { en la } \\
\text { redacción }\end{array}$ & Observaciones \\
\hline $\begin{array}{l}\text { Dificultades } \\
\text { rechazo } \quad \text { a } \quad \text { ejercer }\end{array}$ & $\begin{array}{l}\text { 15. Parece que no pueda disciplinarme para acabar tareas rutinarias } \\
\text { o aburridas. }\end{array}$ & SI NO & SI NO & SI NO & \\
\hline $\begin{array}{l}\text { autocontrol suficiente y a la } \\
\text { tolerancia a la frustración }\end{array}$ & $\begin{array}{l}\text { 33. Si no puedo alcanzar un objetivo, me siento fácilmente frustrado } \\
\text { y renuncio a él. }\end{array}$ & SI NO & NO & SI NO & \\
\hline $\begin{array}{l}\text { para alcanzar los propios } \\
\text { objetivos personales o para }\end{array}$ & $\begin{array}{l}\text { 51. La paso mal cuando tengo que sacrificar gratificaciones } \\
\text { inmediatas para conseguir un objetivo a largo plazo. }\end{array}$ & SI NO & NO & NO & \\
\hline $\begin{array}{l}\text { restringir el exceso de } \\
\text { expresión de las propias }\end{array}$ & $\begin{array}{l}\text { 69. No consigo obligarme a hacer aquellas cosas que no me } \\
\text { divierten, incluso cuando sé que son para mi propio beneficio. }\end{array}$ & SI NO & NO & $\mathrm{NO}$ & \\
\hline emociones e impulsos. & 87. Raramente he sido capaz de mantenerme firme en mis propósitos & NO & NO & $\mathrm{NO}$ & \\
\hline
\end{tabular}

Dimensión IV "Dirigido por las necesidades de los demás": Describe a personas que se orientan en un énfasis excesivo a satisfacer las necesidades de los demás frente a las propias.

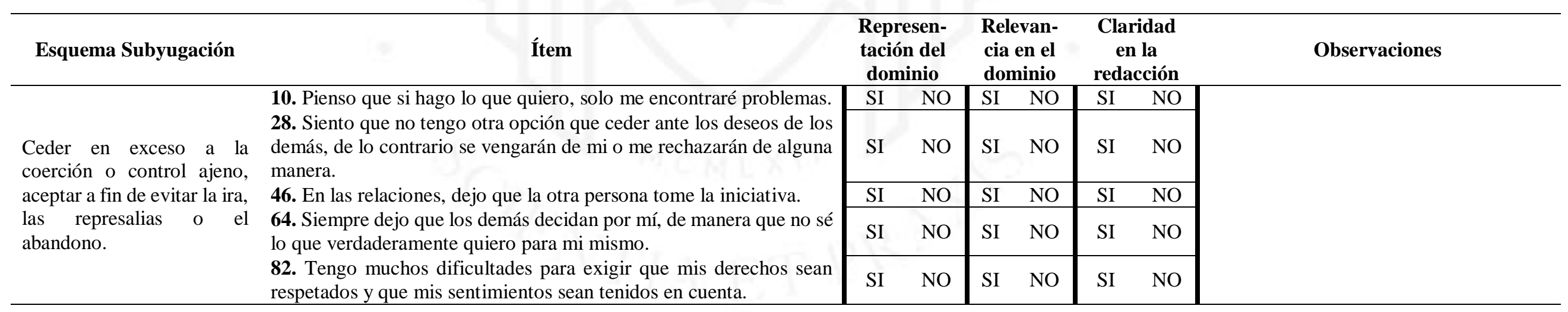


Dimensión IV "Dirigido por las necesidades de los demás": Describe a personas que se orientan en un énfasis excesivo a satisfacer las necesidades de los demás frente a las propias.

\begin{tabular}{|c|c|c|c|c|c|}
\hline Esquema Autosacrificio & Ítem & $\begin{array}{l}\text { Represen- } \\
\text { tación del } \\
\text { dominio }\end{array}$ & $\begin{array}{l}\text { Relevan- } \\
\text { cia en el } \\
\text { dominio }\end{array}$ & $\begin{array}{l}\text { Claridad } \\
\text { en la } \\
\text { redacción }\end{array}$ & Observaciones \\
\hline \multirow{5}{*}{$\begin{array}{l}\text { El exceso de atención por } \\
\text { satisfacer voluntariamente } \\
\text { las necesidades de los } \\
\text { demás en situaciones } \\
\text { cotidianas a expensas de la } \\
\text { propia gratificación. } \\
\text { Sensibilidad aguda hacia el } \\
\text { dolor de los demás. }\end{array}$} & $\begin{array}{l}\text { 11. Soy el que normalmente acabo cuidando de las personas cercanas } \\
\text { a mí }\end{array}$ & SI $\quad \mathrm{NO}$ & SI NO & NO & \\
\hline & $\begin{array}{l}\text { 29. Soy una buena persona porque pienso más en los demás que en } \\
\text { mi mismo. }\end{array}$ & SI $\quad \mathrm{NO}$ & SI NO & NO & \\
\hline & $\begin{array}{l}\text { 47. Estoy tan ocupado haciendo cosas por las personas que me } \\
\text { importan, que me queda poco tiempo para mí mismo. }\end{array}$ & SI $\quad$ NO & SI NO & NO & \\
\hline & 65. Siempre he sido el que escucha los problemas de los demás. & NO & NO & NO & \\
\hline & $\begin{array}{l}\text { 83. Las personas que me ven como alguien que hace demasiadas } \\
\text { cosas para los demás y no las suficientes para mí mismo. }\end{array}$ & NO & SI NO & NO & \\
\hline
\end{tabular}

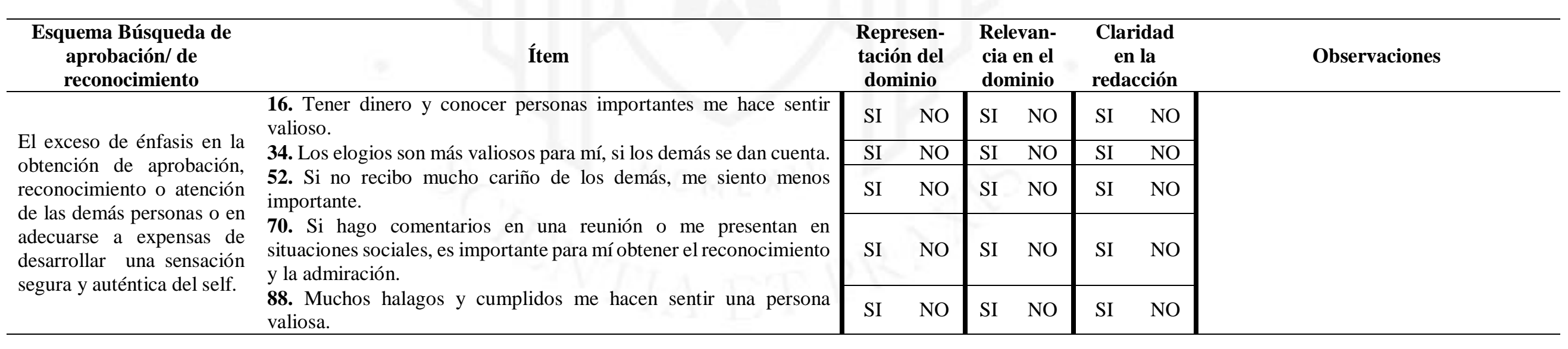


Dimensión V "Sobrevigilancia e inhibición": Describe a personas que suprimen sentimientos y su desenvolvimiento espontáneo por la complacencia de reglas internas rígidas acerca de las adecuadas maneras de comportarse que guían su accionar. Podría centrarse su atención en "deberías" de la vida.

\begin{tabular}{|c|c|c|c|c|c|}
\hline $\begin{array}{l}\text { Esquema Negatividad/ } \\
\text { Pesimismo }\end{array}$ & Ítem & $\begin{array}{c}\text { Represen- } \\
\text { tación del } \\
\text { dominio }\end{array}$ & $\begin{array}{l}\text { Relevan- } \\
\text { cia en el } \\
\text { dominio }\end{array}$ & $\begin{array}{l}\text { Claridad } \\
\text { en la } \\
\text { redacción }\end{array}$ & Observaciones \\
\hline \multirow{5}{*}{$\begin{array}{l}\text { Percepción generalizada y } \\
\text { constante en los aspectos } \\
\text { negativos (dolor, muerte, } \\
\text { pérdida, conflicto, etc.) y } \\
\text { simultáneamente } \\
\text { minimizar o pasar por alto } \\
\text { aspectos positivos u } \\
\text { optimistas. }\end{array}$} & $\begin{array}{l}\text { 17. Incluso cuando las cosas parecen ir bien, siento que es una cosa } \\
\text { temporal. }\end{array}$ & NO & SI NO & NO & \\
\hline & $\begin{array}{l}\text { 35. Si algo bueno ocurre, me preocupo porque es probable que algo } \\
\text { malo le siga. }\end{array}$ & $\mathrm{NO}$ & SI NO & $\mathrm{NO}$ & \\
\hline & \multirow{2}{*}{$\begin{array}{l}\text { 53. No puedes tener tanto cuidado, casi siempre algo irá mal. } \\
\text { 71. No importa lo duro que trabaje, me preocupa que me pueda } \\
\text { arruinar y perderlo casi todo. }\end{array}$} & NO & NO & NO & \\
\hline & & NO & SI NO & SI $\quad \mathrm{NO}$ & \\
\hline & $\begin{array}{l}\text { 89. Me preocupa que una decisión equivocada me pueda llevar al } \\
\text { desastre. }\end{array}$ & NO & SI NO & SI NO & \\
\hline $\begin{array}{l}\text { Esquema Inhibición } \\
\text { emocional }\end{array}$ & Ítem & $\begin{array}{l}\text { Represen- } \\
\text { tación del } \\
\text { dominio }\end{array}$ & $\begin{array}{l}\text { Relevan- } \\
\text { cia en el } \\
\text { dominio }\end{array}$ & $\begin{array}{c}\text { Claridad } \\
\text { en la } \\
\text { redacción }\end{array}$ & Observaciones \\
\hline \multirow{5}{*}{$\begin{array}{l}\text { Excesiva inhibición de la } \\
\text { acción, sentimiento o } \\
\text { comunicación espontánea, } \\
\text { normalmente, para evitar } \\
\text { sentimientos de vergüenza, } \\
\text { pérdida de control de } \\
\text { impulsos o desaprobación. }\end{array}$} & \multirow{2}{*}{$\begin{array}{l}\text { 12. Soy demasiado tímido para expresar sentimientos positivos hacia } \\
\text { los demás (p. ej., afecto, preocupación...) } \\
\text { 30. Me resulta embarazoso tener que expresar mis sentimientos a los } \\
\text { demás. }\end{array}$} & NO & SI NO & NO & \\
\hline & & NO & SI NO & NO & \\
\hline & \multirow{2}{*}{$\begin{array}{l}\text { 48. Me es difícil ser cálido y espontáneo. } \\
\text { 66. Me controlo tanto que las personas piensan que no tengo } \\
\text { emociones o que soy insensible. }\end{array}$} & NO & SI $\quad$ NO & $\mathrm{NO}$ & \\
\hline & & SI NO & SI NO & SI NO & \\
\hline & 84. La gente me ve como alguien emocionalmente rígido. & $\mathrm{NO}$ & SI NO & SI $\quad$ NO & \\
\hline
\end{tabular}


Dimensión V "Sobrevigilancia e inhibición": Describe a personas que suprimen sentimientos y su desenvolvimiento espontáneo por la complacencia de reglas internas rígidas acerca de las adecuadas maneras de comportarse que guían su accionar. Podría centrarse su atención en "deberías" de la vida.

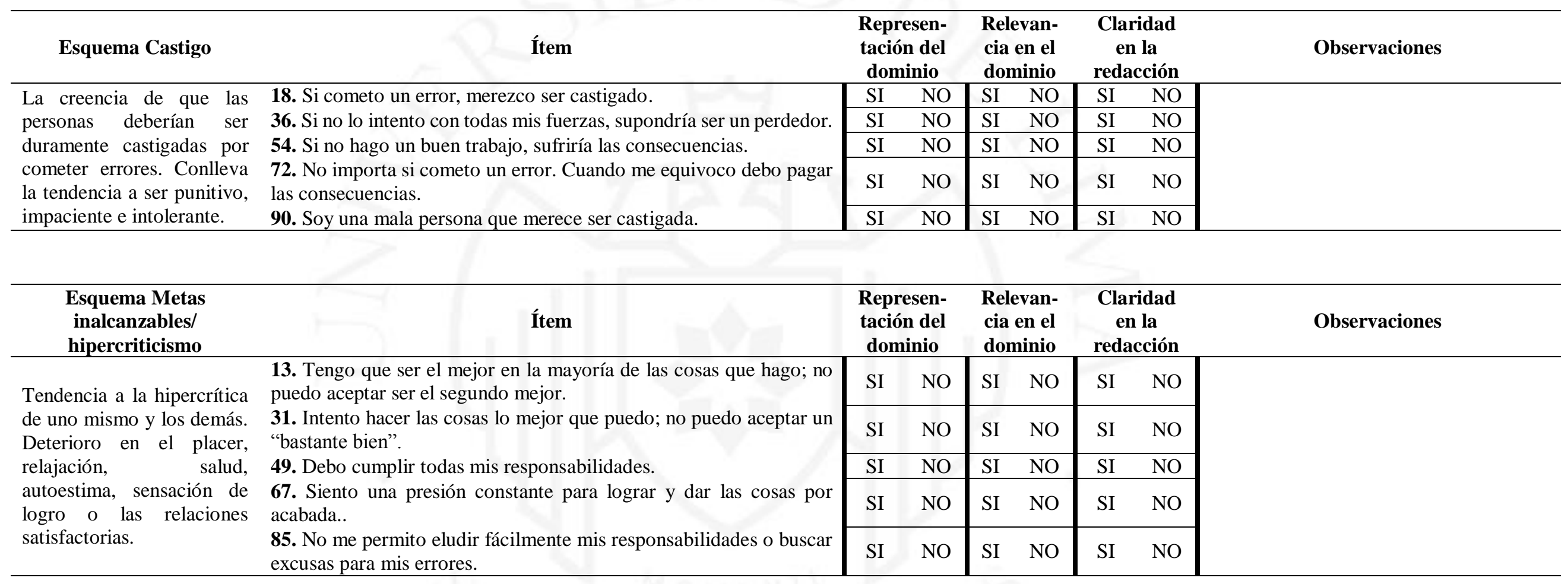

Nombre del evaluador(a):

Profesión: 


\section{Apéndice 10: Libro de códigos}

Sexo

Edad

1 Masculino

2 Femenino

En Años

Grado de instrucción

1 Secundaria completa

2 Tecnica

3 Universitaria

4 Posgrado

Tratamiento Psiquiátrico (TPQ)

$1 \quad \mathrm{Si}$

$0 \quad$ No

Tratamiento Psicológico (TPS)

$1 \quad \mathrm{Si}$

$0 \quad$ No

Tiempo de tratamientos

En Meses

Base

$1 \quad$ Muestra Clínica

$0 \quad$ No clínico

Diagnóstico (Dx)

1 T. relacionados con el alcohol

2 T. relacionados con alucinógenos

3 T. relacionados con el cannabis

4 T. relacionados con cocaína

5 T. relacionados con otras sustancias

6 Esquizofrenia y otros trastornos psicóticos

7 T. depresivos

8 T. de ansiedad

9 T. bipolares

10 T. sexuales y de la identidad sexual

11 T. de la conducta alimentaria

12 T. paranoide

13 T. esquizoide

14 T. antisocial

15 T. límite

16 T. histriónico

17 T. narcisista

18 T. evitación

19 T. por dependencia

20 T. anancásico

21 T.no especificado 